\title{
Multiphase processes in the EC-Earth Earth System model and their relevance to the atmospheric oxalate, sulfate, and iron cycles
}

Stelios Myriokefalitakis ${ }^{1}$, Elisa Bergas-Massó2,3, María Gonçalves-Ageitos ${ }^{2,3}$, Carlos Pérez GarcíaPando $^{2,4}$, Twan van Noije ${ }^{5}$, Philippe Le Sager ${ }^{5}$, Akinori Ito ${ }^{6}$, Eleni Athanasopoulou ${ }^{1}$, Athanasios Nenes ${ }^{7,8}$,

5 Maria Kanakidou $^{9,10,7}$, Maarten C. Krol ${ }^{11,12}$, and Evangelos Gerasopoulos ${ }^{1}$

${ }^{1}$ Institute for Environmental Research and Sustainable Development (IERSD), National Observatory of Athens, Penteli, Greece

${ }^{2}$ Barcelona Supercomputing Center (BSC), Barcelona, Spain

${ }^{3}$ Universitat Politècnica de Catalunya (UPC), Barcelona, Spain

$10 \quad{ }^{4}$ ICREA, Catalan Institution for Research and Advanced Studies, Barcelona, Spain

${ }^{5}$ Royal Netherlands Meteorological Institute (KNMI), De Bilt, the Netherlands

${ }^{6}$ Yokohama Institute for Earth Sciences, JAMSTEC, Yokohama, Japan

${ }^{7}$ Institute for Chemical Engineering Sciences, Foundation for Research and Technology, Patras, Greece

${ }^{8}$ School of Architecture, Civil and Environmental Engineering, École Polytechnique Fédérale de Lausanne, Lausanne,

15 Switzerland

${ }^{9}$ Environmental Chemical Processes Laboratory (ECPL), Department of Chemistry, University of Crete, Heraklion, Greece

${ }^{10}$ Institute of Environmental Physics, University of Bremen, Bremen, Germany

${ }^{11}$ Institute for Marine and Atmospheric Research (IMAU), Utrecht University, Utrecht, the Netherlands

${ }^{12}$ Wageningen University, Wageningen, the Netherlands

20 Correspondence to: Stelios Myriokefalitakis (steliosm@noa.gr)

Abstract. Understanding how multiphase processes affect the iron-containing aerosol cycle is key to predict ocean biogeochemistry changes and hence the feedback effects on climate. For this work, the EC-Earth Earth system model in its climate-chemistry configuration is used to simulate the global atmospheric oxalate (OXL), sulfate $\left(\mathrm{SO}_{4}{ }^{2-}\right)$, and iron (Fe) cycles, after incorporating a comprehensive representation of the multiphase chemistry in cloud droplets and aerosol water. The model considers a detailed gas-phase chemistry scheme, all major aerosol components, and the partitioning of gases in aerosol and atmospheric water phases. The dissolution of Fe-containing aerosols accounts kinetically for the solution's acidity, oxalic acid, and irradiation. Aerosol acidity is explicitly calculated in the model, both for accumulation and coarse modes, accounting for thermodynamic processes involving inorganic and crustal species from sea-salt and dust.

Simulations for present-day conditions (2000-2014) have been carried out with both EC-Earth and the atmospheric composition component of the model in standalone mode driven by meteorological fields from ECMWF's ERA-Interim reanalysis. The calculated global budgets are presented and the links between the 1) aqueous-phase processes, 2) aerosol dissolution, and 3) atmospheric composition, are demonstrated and quantified. The model results are supported by comparison

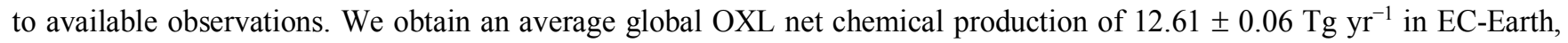
with glyoxal being by far the most important precursor of oxalic acid. In comparison to the ERA-Interim simulation, 
35 differences in atmospheric dynamics as well as the simulated weaker oxidizing capacity in EC-Earth result overall in a $\sim 30 \%$ lower OXL source. On the other hand, the more explicit representation of the aqueous-phase chemistry in EC-Earth compared to the previous versions of the model leads to an overall $\sim 20 \%$ higher sulfate production, but still well correlated with atmospheric observations.

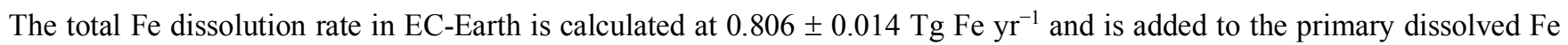

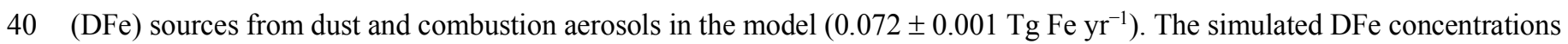
show a satisfactory comparison with available observations, indicating an atmospheric burden of $\sim 0.007 \mathrm{Tg} \mathrm{Fe}$, and overall

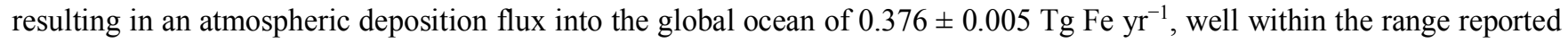
in the literature. All in all, this work is a first step towards the development of EC-Earth into an Earth System Model with fully interactive bioavailable atmospheric Fe inputs to the marine biogeochemistry component of the model. 


\section{Introduction}

Clouds, fog, and deliquescent aerosols host chemical reactions involving inorganic and organic polar atmospheric compounds (Calvert et al., 1985; Chameides and Davis, 1983; Collett et al., 1999; Donaldson and Valsaraj, 2010; Jacob, 1986; Lelieveld and Crutzen, 1991). These reactions result in the production of species that can neither be formed via gas-phase processes directly, nor explained solely by primary sources. These compounds participate in chemical transformations across the gas, aqueous, and solid phases. Such multiphase processes have a significant impact on the atmospheric cycles of important inorganic species like sulfur (e.g., Hoyle et al., 2016; Seinfeld and Pandis, 2006; Tsai et al., 2010), and act as a complementary pathway for the formation of organic particulate matter (e.g., Lin et al., 2014; Liu et al., 2012; Myriokefalitakis et al., 2011). The produced inorganic and organic aerosols serve as cloud condensation nuclei and thus affect the Earth's energy balance

55 (Stocker et al., 2013).

Multiphase processes may also impact the global carbon balance indirectly by altering the atmospheric cycles of species that act as nutrients for the marine biota (Hamilton et al., 2022; Kanakidou et al., 2018; Mahowald et al., 2017; Myriokefalitakis et al., 2020a). Nutrient availability in marine ecosystems is key for the primary production that modulates both the surface oceanic concentrations and the uptake of $\mathrm{CO}_{2}$ (e.g., Le Quéré et al., 2007, 2013; Smith, 2019). A large portion of the global ocean is

60 found, however, to be iron-limited (Krishnamurthy et al., 2009, 2010), therefore, the importance of iron (Fe) to oceanic productivity is well established (Hamilton et al., 2020; Kanakidou et al., 2020; Meskhidze et al., 2019; Tagliabue et al., 2016). Besides rivers and sea ice, along with sediment dissolution and hydrothermal vents, which are the main sources of bioavailable $\mathrm{Fe}$ in the ocean, the atmospheric deposition of nutrients is the most effective external pathway that provides $\mathrm{Fe}$ in the open ocean. Fe is a critical micronutrient for marine biota that is mainly utilized in its dissolved form (e.g., aqueous, colloidal, or nanoparticulate). Thus, the atmospheric processing of Fe-containing minerals, i.e., the conversion from insoluble to soluble that is readily available Fe for marine organisms, is a central step in the atmospheric and marine Fe cycles and directly connected to atmospheric multiphase processes.

Fe is mainly present in the atmosphere in crystalline lattices of aluminosilicates or as iron-oxides in dust aerosols $(\sim 95 \%$; Mahowald et al., 2009), and tends to be rather insoluble when emitted (up to $\sim 1 \%$ solubility; Journet et al., 2008). In fact,

70 observed high Fe solubility downwind of dust source regions can be only explained via the atmospheric processing of dust aerosols (Baker and Jickells, 2017; Oakes et al., 2012). Enhanced Fe solubility is observed for biomass burning aerosols (e.g., ranging 2-46 \%; Bowie et al., 2009; Guieu et al., 2005b; Mahowald et al., 2018; Oakes et al., 2012; Paris et al., 2010), depending strongly on the source region and/or the type of burned wood. Significantly higher Fe solubility (up to 80-90 \%) is found, however, for Fe-containing aerosols from oil combustion (Ito, 2013, 2015; Ito et al., 2021; Myriokefalitakis et al.,

75 2011), with Fe in oil fly ash being mainly in the form of ferric sulfate and nanosized iron oxide aggregates (Chen et al., 2012; Schroth et al., 2009). The uncertainty in Fe-containing combustion aerosol solubility is nevertheless also reflected in modeling studies, with some models assuming relatively high solubility at emission (e.g., Hamilton et al., 2019; Myriokefalitakis et al., 
2011) depending on the aerosol size, and others assuming an almost completely insoluble emitted Fe whose solubility is then enhanced during transport via atmospheric processing (Ito, 2015; Ito et al., 2021). Recent multimodel studies estimate an overall global dissolved $\mathrm{Fe}(\mathrm{DFe})$ production rate due to atmospheric processing of dust and combustion aerosols of $0.56 \pm$ $0.29 \mathrm{Tg} \mathrm{Fe} \mathrm{yr}^{-1}$ (Ito et al., 2019; Myriokefalitakis et al., 2018), indicating that a large uncertainty still remains in the impact of atmospheric processing on the mineral Fe solubilization processes.

During atmospheric transport, inorganic strong acids along with organic ligands may coat mineral aerosols and eventually convert part of the contained insoluble Fe forms (e.g., hematite) to bioavailable forms of Fe for marine biota in the euphotic zone (e.g., free ferrous forms, inorganic soluble Fe, and organic Fe-complexes). Mineral dissolution rates depend on the solution's acidity levels, the mineral surface concentration of organic ligands, sunlight, and ambient temperature (e.g., Hamer et al., 2003; Lanzl et al., 2012; Lasaga et al., 1994; Zhu et al., 1993). Although sulfate $\left(\mathrm{SO}_{4}{ }^{2-}\right)$ is the dominant aerosol species that controls the aerosol liquid water content and acidity, oxalate $\left(\left(\mathrm{COO}^{-}\right)_{2}\right.$; hereafter $\left.\mathrm{OXL}\right)$ acts as an organic ligand for the Fe-containing aerosol dissolution processes (e.g., Paris et al., 2011; Paris and Desboeufs, 2013) that can effectively break the Fe-O bonds at the mineral's surface via the formation of ligand-containing surface structures (Yoon et al., 2004). Despite the dominant role of acidity in the mineral Fe dissolution processes, modeling estimates (Ito, 2015; Johnson and Meskhidze, 2013; Myriokefalitakis et al., 2015) show the importance of OXL to atmospheric DFe concentrations (e.g., including the formation of Fe(II/III)-oxalato complexes). The dissolution of Fe by OXL may further contribute to the organic-bounded pool of nutrients deposited into the ocean, and thus affects the marine primary production especially in oligotrophic subtropical gyres (e.g., up to $20 \%$; Myriokefalitakis et al., 2020a).

Notwithstanding their different roles and efficiencies in Fe solubilization processes, atmospheric observations demonstrate a strong correlation between $\mathrm{SO}_{4}{ }^{2-}$ and OXL concentrations (Yu et al., 2005), especially above clouds (Sorooshian et al., 2006), indicating common chemical production pathways despite the differences in their precursors and primary sources. $\mathrm{SO}_{4}{ }^{2-}$ and OXL are the most common species formed via aqueous-phase reactions of inorganic and organic origin, respectively, with modeling studies supporting that more than $60 \%$ of the sulfates (e.g., Liao et al., 2003) and about $90 \%$ of oxalates (Lin et al., 2012; Liu et al., 2012; Myriokefalitakis et al., 2011) are produced in clouds. OXL is the dominant dicarboxylic acid (DCA) in the troposphere (e.g., Kawamura and Ikushima, 1993; Kawamura and Sakaguchi, 1999; Norton et al., 1983) and is formed primarily through cloud processing of glyoxal and other water-soluble products of alkenes and aromatics of anthropogenic, biogenic, and marine origin (Carlton et al., 2007; Warneck, 2003). OXL is mostly present in the troposphere in the particulate form (Yang and $\mathrm{Yu}, 2008$ ) with aerosol concentrations roughly four times larger than in the gas phase (Martinelango et al., 2007; Yao et al., 2002). OXL can be present in urban environments (Yang et al., 2009) as well as in remote regions (Sempére and Kawamura, 1994), and is produced during the photochemical aging of organic aerosols (Eliason et al., 2003). The observed correlation of OXL with ammonium $\left(\mathrm{NH}_{4}^{+}\right)$(Martinelango et al., 2007) indicates that $\mathrm{OXL}$ is mostly present as a salt (i.e., ammonium oxalate; $\left.\left(\mathrm{NH}_{4}\right)_{2} \mathrm{C}_{2} \mathrm{O}_{4}\right)$ in the atmosphere (Paciga et al., 2014). Ortiz-Montalvo et al. (2014) found that in the 
presence of $\mathrm{NH}_{4}{ }^{+}$under cloud-relevant conditions, the OXL produced by the aqueous-phase glyoxal oxidation is efficiently converted to ammonium oxalate, with its vapor pressure being several orders of magnitude lower than that of oxalic acid. However, in the presence of metals, such as calcium $\left(\mathrm{Ca}^{2+}\right)$ and magnesium $\left(\mathrm{Mg}^{2+}\right)$ from dust and sea salt aerosols, most of the oxalic acid is found to be present in the form of metal complexes (Furukawa and Takahashi, 2011). Nevertheless, due to their different solubility the stability of oxalate complexes can be rather diverse; while calcium- and magnesium-oxalates precipitate from the solution, other salts, such as sodium or ammonium oxalates, remain in a deliquescent form (Furukawa and Takahashi, 2011).

Laboratory and modeling studies support that OXL is directly produced in atmospheric water via glyoxylic acid (GLX; $\mathrm{HC}(\mathrm{O}) \mathrm{COOH})$ oxidation by hydroxyl $(\mathrm{OH})$ and nitrate $\left(\mathrm{NO}_{3}\right)$ radicals. The estimated net global OXL production rate in atmospheric water ranges between 13 and $30 \mathrm{Tg} \mathrm{yr}^{-1}$ (Lin et al., 2014; Liu et al., 2012; Myriokefalitakis et al., 2011). However, modeling studies where the OXL production is only based on the GLX aqueous phase oxidation tend to underestimate its observed atmospheric concentrations (e.g., Lin et al., 2014; Myriokefalitakis et al., 2011). Based on laboratory experiments, Carlton et al. (2007) proposed that predictions of oxalic acid concentrations could be significantly improved when larger multifunctional compounds are allowed to be produced under elevated glyoxal concentrations in typical cloud conditions. These larger multifunctional products can act as precursors for the glyoxylic and oxalic acids via their rapid oxidation by $\mathrm{OH}$ radicals (Carlton et al., 2007). When such reactions are included, models tend to predict a higher oxalate atmospheric load and thus match better the observations (e.g., Myriokefalitakis et al., 2011). Note that although small carbonyl compounds, such as glyoxal and methylglyoxal, can undergo oligomerization under concentrated acidic conditions (Ervens and Volkamer, 2010; Lim et al., 2010, 2013), the mechanism behind the production of larger multifunctional products in dilute solutions may be rather complex, e.g., for products with alcohol functional groups, covalently bonded oligomers, larger carboxylic acids, and other humic-like substances (HULIS) components (Altieri et al., 2006; Blando and Turpin, 2000; Cappiello et al., 2003; Carlton et al., 2007).

The involvement of Fe chemistry in the aqueous phase decreases overall (by $\sim 57.6 \%$ ) the global OXL net production rates, despite the increase in dissolved OH radical sources and thus the oxidation of OXL precursors (Lin et al., 2014). Besides the dissolved $\mathrm{H}_{2} \mathrm{O}_{2}$ photolysis that enhances drastically the $\mathrm{OH}$ production in the solution during the daytime, the presence of

135 transition metal ions (TMIs) may play a central role in aqueous-phase oxidizing capacity, especially under dark conditions (Tilgner et al., 2013; Tilgner and Herrmann, 2018). Among other metals, Fe is the most efficient for the aqueous-phase oxidizing capacity, since on one hand, it contributes to the $\mathrm{OH}$ reactivity via the Fenton reaction and the direct Fe photolysis, and on the other hand its dissolved concentrations are high due to the mineral dust contribution. The metal-oxalato complexes formed in the presence of Fe in the solution (Zuo and Deng, 1997), however, can also undergo Fenton reaction and further

140 increase the dissolved $\mathrm{OH}$ source, in particular for air masses of continental origin (Bianco et al., 2020). The photolysis of Feoxalato complex $\left[\mathrm{Fe}\left(\mathrm{C}_{2} \mathrm{O}_{4}\right)_{2}\right]^{-}$eventually transforms $\mathrm{C}_{2} \mathrm{O}_{4}{ }^{2-}$ into $\mathrm{CO}_{2}$ in the aqueous phase (Ervens et al., 2003). Overall, it is 
clear that the impact of the Fe redox chemistry on the OXL production, and vice versa, is a rather complex issue, that it is expected to also affect the ligand-promoted dissolution process of the Fe-containing minerals under ambient atmospheric conditions.

145 For this work, we incorporate a comprehensive aqueous-phase chemistry scheme into a state-of-the-art global climatechemistry model to simulate the atmospheric multiphase processes with respect to iron-containing aerosol dissolution. Section 2 provides an overview of the model, focusing mostly on the new implementations. In particular, we describe the multiphase chemistry scheme used to simulate the atmospheric $\mathrm{OXL}, \mathrm{SO}_{4}{ }^{2-}$, and $\mathrm{Fe}$ cycles, along with the respective developments for the primary soil and combustion sources applied in the model. In Sect. 3, we present the model-derived $\mathrm{OXL}_{2} \mathrm{SO}_{4}^{2-}$, and $\mathrm{Fe}-$ containing aerosol atmospheric concentrations and their evaluation with available observations, and in Sect. 4 we discuss the impact of the simulated aqueous-phase processes on the DFe deposition fluxes to the global ocean. Finally, in Sect. 5, we summarize the global implications of explicitly resolving multiphase chemistry in a climate-chemistry model for the atmospheric Fe cycle, along with the plans for future model development.

\section{Model description}

\subsection{The EC-Earth3 Earth System Model}

Our tropospheric multiphase chemistry developments have been implemented in the global Earth System Model (ESM) ECEarth3 (Döscher et al., 2021). EC-Earth3 took part in the Coupled Model Intercomparison Project phase 6 (CMIP6; Eyring et al., 2016). The atmospheric General Circulation Model (GCM) of EC-Earth3 is based on cycle 36r4 of the Integrated Forecast System (IFS) from the European Centre for Medium-Range Weather Forecasts (ECMWF), which includes the land surface model H-TESSEL (Balsamo et al., 2009). The ocean model is the Nucleus for European Modeling of the Ocean (NEMO) release 3.6 (Rousset et al., 2015), with sea ice processes represented by the Louvain-la-Neuve sea ice model (LIM) (Rousset et al., 2015; Vancoppenolle et al., 2009). The ESM presents two configurations: the carbon cycle one that represents the marine biogeochemistry processes through PISCES (Aumont et al., 2015), the dynamic terrestrial vegetation through LPJ-Guess (Smith et al., 2001, 2014), and the atmospheric cycle of $\mathrm{CO}_{2}$ through the Tracer Model version 5 release 3.0 (TM5-MP 3.0) as well as the EC-Earth3-AerChem configuration (van Noije et al., 2021) that represents the atmospheric chemistry and transport of aerosols and reactive species, also through the TM5-MP 3.0. Most of the information exchange and interpolation between modules is handled through the Ocean Atmosphere Sea Ice Soil version 3 (OASIS3) coupler (Craig et al., 2017). For this work, specifically, we rely on the EC-Earth3-AerChem branch (van Noije et al., 2021).

EC-Earth3-AerChem includes TM5-MP to simulate tropospheric aerosols and the reactive greenhouse gases methane $\left(\mathrm{CH}_{4}\right)$ and ozone $\left(\mathrm{O}_{3}\right)$ and allows the coupling of those species to relevant processes in the atmospheric module IFS (e.g., radiation and clouds). The model can be executed in an atmospheric mode only, i.e., using prescribed sea surface temperature and sea 
ice concentration, or coupled to the NEMO-LIM ocean and sea-ice model. In addition, TM5-MP can run as a standalone (offline) atmospheric Chemistry and Transport Model (CTM) driven by meteorological and surface fields (Krol et al., 2005). The present work is structured around a recently released version of TM5-MP that incorporates a rather detailed gas-phase tropospheric chemistry scheme, the MOGUNTIA (Myriokefalitakis et al., 2020b). MOGUNTIA simulates explicitly the organic polar species that partition in the atmospheric aqueous phase and allows for a sophisticated parameterization of the multiphase processes needed for this study.

All major aerosol components such as sulfate, black carbon, organic aerosols, sea salt, and mineral dust aerosols are included in TM5-MP and are distributed (depending on the aerosol type) in seven lognormal modes, i.e., four soluble modes (i.e., nucleation, Aitken, accumulation, and coarse) and three insoluble modes (i.e., Aitken, accumulation and coarse). The aerosol microphysics in the model is calculated by the modal aerosol scheme M7 (Aan de Brugh et al., 2011; Vignati et al., 2004), which represents both the evolution of the total particle number and mass of the different species in each mode. Ammonium, nitrate, and aerosol water are determined based on gas/particle partitioning. Primary emissions of anthropogenic, biogenic, and biomass burning processes are defined through a variety of datasets; the most updated being those produced for the CMIP6 project. Natural emissions of mineral dust, sea salt, marine dimethyl sulfide (DMS), and nitrogen oxides from lighting are calculated online, while other natural emissions are prescribed. Details on the various parameterizations used for the definition of the gas and aerosol emissions in the model can be found in van Noije et al. (2021).

\subsection{The EC-Earth3-Iron model}

EC-Earth3-Iron is the new version of the model developed and used for this work that builds on EC-Earth3-AerChem. The new features required to determine the global aqueous-phase OXL formation, the atmospheric acidity, and the Fe cycle in the atmosphere can be summarized as:

1. Treatment of mineral dust emission that considers soil mineralogical composition variations to account for the emission of Fe-containing minerals (and calcite), along with a detailed speciation of anthropogenic combustion and biomass burning emissions to explicitly account for Fe both in soluble and insoluble forms,

2. Acidity calculations for water contained in fine and coarse aerosols, as well as, for cloud droplets,

3. A comprehensive aqueous phase chemistry scheme in cloud droplets and aerosol water, and

4. An explicit description of the Fe-containing aerosol dissolution processes of mineral dust, anthropogenic combustion and biomass burning aerosols. 


\subsubsection{Speciated emissions}

EC-Earth3-Iron includes a characterization of the dust mineralogical composition at emission and explicitly traces the Fe and calcium-containing species. The relative amounts of eight different minerals, namely: illite, kaolinite, montmorillonite, calcite, feldspars, quartz, gypsum, and hematite, are derived from the soil mineralogy atlas of Claquin et al. (1999), including the updates proposed in Nickovic et al. (2012). The atlas provides the soil mineralogical composition in arid and semi-arid regions of the world, distinguishing between two soil size classes (i.e., the clay-size fraction, up to $2 \mu \mathrm{m}$, and the silt-size fraction from 2 to $50 \mu \mathrm{m}$ diameter). The mineral fractions emitted in the accumulation and coarse insoluble modes of TM5-MP are estimated from the soil mineralogy atlas based on the Brittle Fragmentation Theory (BFT) from Kok (2011). BFT posits that the emitted particle size distribution (PSD) is independent of wind and soil conditions and additionally allows estimating the size-resolved mineral fractions (Pérez García-Pando et al., 2016; Perlwitz et al., 2015a, 2015b). The resulting mineral mass fractions are then applied to the dust emission fluxes, as calculated online in the model, yielding the corresponding accumulation and coarse mode emission of each mineral. We note that although we derive the mineral dust fractions in each mode using BFT, we maintain the dependence of the emitted dust PSD (i.e., the ratio between the accumulation and coarse mode dust mass at emissions) upon wind and soil conditions of the original dust emission scheme (Tegen et al., 2002).

In EC-Earth3-Iron, the different Fe-containing minerals are not prognostic variables (tracers). Instead, we trace the mineral dust $\mathrm{Fe}$ according to three dissolution classes, namely fast, intermediate, and slow Fe pools (Ito and Shi, 2016). Moreover, an initial solubility of $0.1 \%$ to all Fe-containing mineral soil emissions (Ito and Shi, 2016) is considered. The emitted amounts of calcium (i.e., in calcite) and Fe (i.e., in illite, kaolinite, montmorillonite, feldspars, and hematite) are derived either from the average elemental compositions of minerals or based on experimental analyses (Journet et al., 2008; Nickovic et al., 2013). The average fractions between the years 2000 to 2014 applied to mineral dust sources are listed in Table S1.

Fe is also emitted in the model from anthropogenic combustion and biomass burning sources following Ito et al. (2018) and Hajima et al. (2019). The Fe-containing combustion emissions are estimated here from the total particulate carbon emissions (i.e., the sum of organic carbon and black carbon), based on the Fe content in the sub-micron and super-micron combustion aerosols. The scaling factors for each aerosol size (and solubility) are applied to the sectors energy, industrial, iron and steel industries, residential and commercial shipping, and waste treatment, as well as to the biomass burning emissions. The historical anthropogenic emissions are taken from the Community Emissions Data System (Hoesly et al., 2018) and the historical fire emissions from the BB4CMIP6 data set (van Marle et al., 2017). Fe-containing aerosol combustion emissions are considered to be insoluble (Ito, 2015), except for ship oil combustion that is assumed to be mostly soluble ( $\sim 79 \%$ on average for the years 2000-2014). The year-to-year variation in anthropogenic combustion Fe-emission fractions follows Ito et al. (2018), except for biomass burning where no variation is considered. The average Fe fractions between the years 2000 to 2014 applied to the total particulate carbon emissions are also listed in Table S1. 
EC-Earth3-Iron also includes OXL primary emissions from natural and anthropogenic wood-burning processes, that mainly account for its rapid formation in the sub-grid plumes not represented in the model. Indeed, OXL is well correlated with elemental carbon and levoglucosan (Cao et al., 2017; Cong et al., 2015), which are observed at significant levels during biomass burning episodes in the Amazon (Kundu et al., 2010), suggesting that oxalic acid could be either directly emitted or formed rapidly via combustion processes. During biomass burning episodes enhanced emissions of ionic species have been generally measured, indicating an average OXL mass concentration measured in plumes of $\sim 0.04-0.07 \% \mathrm{w} / \mathrm{w}$ (Yamasoe et al., 2000). Furthermore, domestic wood combustion is a potential OXL source (Schmidl et al., 2008) since measurements indicate an OXL contribution to the total particulate concentrations of $\sim 0.09-0.28 \% \mathrm{w} / \mathrm{w}$. Gasoline engines may also contribute to total dicarboxylic acid mass emitted to the atmosphere (Kawamura and Kaplan, 1987), although their direct contribution to ambient OXL concentrations is generally found to be low (Huang and $\mathrm{Yu}, 2007$ ) and, therefore, neglected here. All in all, primary OXL sources are quite uncertain and, given the current estimates, may only have a limited impact on the calculation of its atmospheric concentrations (e.g., Myriokefalitakis et al., 2011).

\subsubsection{Thermodynamic equilibrium and atmospheric acidity calculations}

The gas/particle equilibrium calculations of $\mathrm{NH}_{3} / \mathrm{NH}_{4}{ }^{+}$and $\mathrm{HNO}_{3} / \mathrm{NO}_{3}{ }^{-}$have been substantially revised in EC-Earth3-Iron. In EC-Earth3-AerChem, EQSAM (Metzger et al., 2002) is used to determine the partitioning of $\mathrm{NH}_{3} / \mathrm{NH}_{4}{ }^{+}$and $\mathrm{HNO}_{3} / \mathrm{NO}_{3}{ }^{-}$. In

245 EC-Earth3-Iron, the ISORROPIA II thermodynamic equilibrium model (Fountoukis and Nenes, 2007), replaces EQSAM to determine the equilibrium between the inorganic gas and the aerosol phases. ISORROPIA-II calculates the gas/liquid/solid equilibrium partitioning of the $\mathrm{K}^{+}-\mathrm{Ca}^{2+}-\mathrm{Mg}^{2+}-\mathrm{NH}_{4}{ }^{+}-\mathrm{Na}^{+}-\mathrm{SO}_{4}{ }^{2-}-\mathrm{NO}_{3}{ }^{-}-\mathrm{Cl}^{-}-\mathrm{H}_{2} \mathrm{O}$ aerosol system, and is used in the forward mode, assuming that all aerosols are in a metastable (liquid) state. The inclusion of sea salt and dust aerosols in the aerosol thermodynamic calculations has been shown, nevertheless, to substantially affect the ion balance and thus the partitioning of $\mathrm{HNO}_{3} / \mathrm{NO}_{3}{ }^{-}$and $\mathrm{NH}_{3} / \mathrm{NH}_{4}{ }^{+}$species, especially in areas with abundant mineral dust and/or sea spray aerosols (Athanasopoulou et al., 2008, 2016; Karydis et al., 2016). In EC-Earth3-Iron nitrate aerosols are calculated for both the accumulation and coarse modes, in contrast to the bulk aerosol approximation used in the EC-Earth3-AerChem. For this, kinetic limitations by mass transfer and transport between the gas and the particulate phases in accumulation and coarse modes (Pringle et al., 2010) are considered, with ISORROPIA-II then re-distributing the respective masses between the gas and the aerosol phases. We note that $\mathrm{Ca}^{2+}$ from calcite is simulated prognostically in the model based on mineralogy maps (Sect. 2.2.1), in contrast to other crustal elements in soils that are calculated by assuming constant mass ratios to dust concentrations of $1.2 \%, 1.5 \%$, and $0.9 \%$ for $\mathrm{Na}^{+}, \mathrm{K}^{+}$, and $\mathrm{Mg}^{2+}$, respectively (Karydis et al., 2016; Sposito, 1989). For sea spray aerosols, mean mass fractions of 55\% $\mathrm{Cl}^{-}, 30.6 \% \mathrm{Na}^{+}, 7.7 \% \mathrm{SO}_{4}^{2-}, 3.7 \% \mathrm{Mg}^{2+}, 1.2 \% \mathrm{Ca}^{2+}$, and $1.1 \% \mathrm{~K}^{+}$(Seinfeld and Pandis, 2006) are also applied.

The acidity levels of deliquescent aerosols are calculated in the model based on thermodynamic processes for accumulation 260 and coarse particles. Aerosol acidity impacts the scavenging efficiency and the dry deposition of inorganic reactive nitrogen species due to changes in the partitioning of total nitrate and ammonium between the gas and aerosol phases as well as between 
the various aerosol sizes (Pye et al., 2020). Acidity levels also play a fundamental role in the aqueous-phase chemistry by controlling the dissociation reactions and thus, the reactivity of the chemical mechanism. Indeed, aqueous-phase species, such as organic and inorganics acids, are oxidized with higher rates when they are dissociated. Nevertheless, in the case of the forward and reverse reactions, they typically occur fast and thus the concentrations of the reactants and the products are generally assumed to be in equilibrium in the global model due to its relatively long timestep and large model grid. Note, however, that recent modeling studies showed that the metastable assumption applied here could lead to an increase of aerosols' acidity (i.e., regionally up to $2 \mathrm{pH}$-units in the presence of crustal elements over dust sources, and roughly $0.5 \mathrm{pH}$ units globally; Karydis et al., 2020) compared to the stable aerosol state assumption (i.e., the aerosols both in solid and liquid phases).

Under ambient atmospheric conditions, the water vapor uptake on aerosols depends on both the inorganic and organic components, along with the meteorological conditions (e.g., the temperature and the relative humidity conditions). ISORROPIA II does not, however, include water associated with organic aerosols, possibly leading to an underestimation of the aerosol hygroscopicity especially within the boundary layer where the contribution of water-soluble organics to total aerosol mass can be substantial. For this, we account here for a contribution of aerosol water from organic particles in the acidity calculations, using a hygroscopicity parameter $\kappa_{\text {org }}=0.15$ (Bougiatioti et al., 2016). In more detail, the particulate water due to the organics $\left(\mathrm{W}_{\text {org }}\right)$ that is added to the aerosol water associated with the inorganic aerosol as calculated from ISORROPIA-II ( $\mathrm{W}_{\text {inorg }}$ ), is determined in the model as:

$W_{\text {org }}=m_{s} \cdot \frac{\rho_{w}}{\rho_{s}} \cdot \frac{\kappa_{\text {org }}}{\left(\frac{1}{R H}-1\right)}$

where $\mathrm{m}_{\mathrm{s}}$ is the soluble organic mass concentration $\left(\mu \mathrm{g} \mathrm{m}^{-3}\right)$ as simulated by the TM5-MP chemistry scheme, $\rho_{\mathrm{w}}$ is the water density $\left(1 \mathrm{~kg} \mathrm{~m}^{-3}\right), \rho_{\mathrm{s}}$ is the organic aerosol density $\left(1.4 \mathrm{~kg} \mathrm{~m}^{-3}\right)$, and $\mathrm{RH}(0-1)$ is the relative humidity.

Cloud acidity is also an important factor for simulating the multiphase processes in the atmosphere. The in-cloud proton concentration is initially determined by the electroneutrality of strong acids and bases (i.e., $\mathrm{H}_{2} \mathrm{SO}_{4}, \mathrm{SO}_{4}{ }^{2-}$, methanesulfonate $\left(\mathrm{MS}^{-}\right), \mathrm{HNO}_{3}, \mathrm{NO}_{3}{ }^{-}$, and $\mathrm{NH}_{4}{ }^{+}$), and then the subsequent dissociations of $\mathrm{CO}_{2}, \mathrm{SO}_{2}$, and $\mathrm{NH}_{3}$ (Jeuken et al., 2001) are solved iteratively in the model. For the cloud acidity calculations, the liquid water content, and the respective cloud cover fraction 285 (i.e., 0-1) are obtained from meteorology. Note, however, that the effect of mineral dust, and especially calcium, on cloud proton concentrations is neglected. This assumption may result in some overestimation of cloud acidity, although the overall impact should be small particularly in dusty areas with a low presence of clouds. Another limitation in the determination of cloud acidity is the omission of light gaseous organic acids (such as formic and acetic acids), possibly leading to some underestimation in cloud acidity where their concentration is important. 


\subsubsection{The aqueous phase chemistry scheme}

The aqueous-phase chemistry scheme used in this work is based to a large extent on the Chemical Aqueous Phase Radical Mechanism (CAPRAM) (e.g., Deguillaume et al., 2004; Ervens et al., 2003; Herrmann et al., 2000, 2015). However, CAPRAM includes more than 70 aqueous-phase species, 34 equilibria for compounds that are present both in the gas and the aqueous phases, along with numerous photolytic and aqueous-phase reactions, also covering a large series of acid-base and metalcomplex equilibria. Note that various updates may further extend the mechanism by including among others, the oxidation of aromatic hydrocarbons (Hoffmann et al., 2018), the multiphase oxidation of DMS (Hoffmann et al., 2016), and the tropospheric multiphase halogen chemistry (Bräuer et al., 2013). For this, some reactions are considered here in a more simplified way based on various assumptions published in literature. Indeed, the level of chemical complexity of such a detailed mechanism is beyond the computational resources available for three-dimensional global climate-chemistry simulations, and thus simplifications, that preserve however the essential features of the aqueous mechanism, are needed.

Aqueous-phase chemical transformations are considered at the interface and in the bulk, initiated mainly by free radicals and oxidants produced both via photochemical reactions and in dark conditions (Bianco et al., 2020). The sources of OH radicals in the aqueous phase, however, strongly differ from those in the gas phase, primarily because of the presence of ionic species and TMIs in the solution. $\mathrm{OH}$ radicals are the main oxidant in the aqueous phase, either produced directly in the aqueous medium or diffused from the gas phase (i.e., via a gas-to-liquid transfer). However, aqueous phase oxidation can also be induced by non-radical species, such as ozone $\left(\mathrm{O}_{3}\right)$ and hydrogen peroxide $\left(\mathrm{H}_{2} \mathrm{O}_{2}\right)$. A characteristic example is the formation of $\mathrm{SO}_{4}{ }^{2-}$ in cloud droplets, via the oxidation of dissolved sulfur dioxide $\left(\mathrm{SO}_{2}\right)$ by $\mathrm{O}_{3}$ and $\mathrm{H}_{2} \mathrm{O}_{2}$, with $\mathrm{H}_{2} \mathrm{O}_{2}$ being nevertheless the most effective oxidant (Seinfeld and Pandis, 2006), especially when the solution becomes acidic. Upon the absorption of $\mathrm{SO}_{2}$ in cloud droplets, the establishment of the equilibrium between the dissolved sulfur species in oxidation state 4, i.e., $\mathrm{SO}_{2} . \mathrm{H}_{2} \mathrm{O}, \mathrm{HSO}_{3}{ }^{-}\left(\mathrm{pKa}_{1}=1.9\right)$, and $\mathrm{SO}_{3}{ }^{2-}\left(\mathrm{pKa}_{2}=7.2\right)$ (hereafter also as $\left.\mathrm{S}(\mathrm{IV})\right)$ is calculated in the model. Then, depending on the availability of oxidants and the solution's acidity, the different $\mathrm{S}(\mathrm{IV})$ species can participate in the formation of S(VI) (i.e., dissolved sulfur in oxidation state 6).

In EC-Earth3-Iron, the aqueous-phase sulfur scheme is applied both in cloud droplets and aerosol water, replacing the S(VI) production through the dissolved S(IV) oxidation in cloud droplets previously included in the EC-Earth-AerChem (van Noije

315 et al., 2014, 2021). In more detail, besides the two classic reactions of bisulfite and sulfite with hydrogen peroxide and ozone included in EC-Earth3-AerChem, additional reactions of S(IV) oxidation via methyl hydroperoxide $\left(\mathrm{CH}_{3} \mathrm{O}_{2} \mathrm{H}\right)$, peroxyacetic acid, and with the hydroperoxyl radical $\left(\mathrm{HO}_{2}\right)$ /superoxide radical anion $\left(\mathrm{O}_{2}{ }^{-}\right)$are considered. Nevertheless, in acidic solutions, the oxidation by peroxides, and especially $\mathrm{H}_{2} \mathrm{O}_{2}$, is significantly more important than other oxidants (Herrmann, 2003; Jacob, 1986). $\mathrm{H}_{2} \mathrm{O}_{2}$ is produced in the gas phase and can be rapidly dissolved in the liquid phase due to its high solubility. The dissolved $\mathrm{H}_{2} \mathrm{O}_{2}$ (as well as the organic peroxides, such as $\mathrm{CH}_{3} \mathrm{OOH}$ ) can react rapidly with the $\mathrm{HSO}_{3}^{-}$. However, the $\mathrm{pH}-$ independent reaction of $\mathrm{HSO}_{3}{ }^{-}$with $\mathrm{CH}_{3} \mathrm{OOH}$ (or other organic peroxides) is expected to be less important than $\mathrm{H}_{2} \mathrm{O}_{2}$ under 
typical cloud conditions due to the much lower solubility of $\mathrm{CH}_{3} \mathrm{OOH}$. Note that the dissociation of $\mathrm{H}_{2} \mathrm{O}_{2}$ is here neglected since it is not expected to significantly influence the total $\mathrm{H}_{2} \mathrm{O}_{2}$ concentrations under typical tropospheric conditions (Herrmann, 2003; Jacob, 1986). In contrast, at a higher pH, the S(IV) oxidation by ozone tends to dominate the S(IV) oxidation (Seinfeld and Pandis, 2006). $\mathrm{O}_{3}$ oxidizes rapidly all three S(IV) forms in the aqueous phase, becoming significant at $\mathrm{pH}$ higher than 4 (Seinfeld and Pandis, 2006), even in the absence of light. S(IV) oxidation by $\mathrm{O}_{3}$ is also predicted to dominate $\mathrm{S}(\mathrm{VI})$ formation during winter in arctic regions due to the lack of photochemical production of $\mathrm{OH}$ and $\mathrm{H}_{2} \mathrm{O}_{2}$ at high latitudes, as well as to the high anthropogenic $\mathrm{SO}_{2}$ emissions in the Northern Hemisphere (Alexander et al., 2009). Laboratory studies indicate that S(IV) compounds may be also oxidized in the aqueous phase via other pathways. For example, the aqueous S(VI) production can be enhanced by TMIs (Harris et al., 2013), such as the Mn(II) catalyzed oxidation of S(IV) by dissolved $\mathrm{O}_{2}$. In a global modeling study, Alexander et al. (2009) attributed 9-17\% of the total S(VI) production to the latter mechanism. However, such reactions would require several oxysulfur radicals as intermediates (e.g., Deguillaume et al., 2004; Herrmann et al., 2005), like a free radical chain mechanism initiated by reactions of $\mathrm{HSO}_{3}{ }^{-}, \mathrm{SO}_{3}{ }^{2-}$ with radicals and radical anions, or TMIs catalyzed oxidation of several S(IV)-compounds, which is not considered in our model. Thus, in the case of the sulfate radical anion $\left(\mathrm{SO}_{4}^{-}\right)$production via the $\mathrm{Fe}(\mathrm{III})$-sulfato-complex $\left[\mathrm{Fe}\left(\mathrm{SO}_{4}\right)\right]^{+}$photolysis (Table $\left.\mathrm{S} 2\right)$, the sulfate radical anion is simply added to the $\mathrm{S}(\mathrm{VI})$ pool.

Gas-phase organics can be also oxidized in the interstitial cloud space, form water-soluble compounds like aldehydes, and rapidly partition into the droplets. In the presence of oxidants such as $\mathrm{OH}$ and $\mathrm{NO}_{3}$ radicals in the solution, the dissolved organics undergo chemical conversions and form low volatile organics that remain, at least partly, in the particulate phase upon droplet evaporation (Blando and Turpin, 2000). The dissolved $\mathrm{OH}$ radicals react with organic compounds in the aqueous phase by hydrogen abstraction or electron transfer, forming alkyl radicals $(\mathrm{R})$ which, in the presence of dissolved oxygen, further form peroxyl radicals $\left(\mathrm{RO}_{2}\right)$. The $\mathrm{OH}$ oxidation of organic compounds in the aqueous phase can lead either to fragmentation or, to the formation of oxidized organic species, resulting overall in $\mathrm{CO}_{2}$. However, the recombination of organic radicals can also be a favorable pathway when the water evaporates, and the aqueous solution becomes more concentrated. Box-model simulations have shown that the cloud processing of polar products from isoprene oxidation can be an important contributor to secondary organic aerosol (SOA) production (Lim et al., 2005). Indeed, laboratory measurements show that the aqueous-phase photooxidation of C2 and C3 carbonyl compounds (Perri et al., 2009, 2010), such as glyoxal (Carlton et al., 2007, 2009), methylglyoxal (Altieri et al., 2008), glycolaldehyde, pyruvic acid (Carlton et al., 2006), and acetic acid (Tan et al., 2012) leads to the production of low volatility DCAs, which are commonly found in atmospheric aerosols and clouds (Sorooshian et al., 2006).

In EC-Earth3-Iron, gas-phase species can be reversibly transferred to the aqueous phase and oxidized by radicals and radical anions. The partitioning of 15 organic species that exist in both phases are considered in the aqueous-phase mechanism, namely methyl-peroxy radical $\left(\mathrm{CH}_{3} \mathrm{O}_{2}\right)$, methyl hydroperoxide $\left(\mathrm{CH}_{3} \mathrm{O}_{2} \mathrm{H}\right)$, formaldehyde $(\mathrm{HCHO})$, methanol $\left(\mathrm{CH}_{3} \mathrm{OH}\right)$, formic acid 
( $\mathrm{HCOOH})$, acetaldehyde $\left(\mathrm{CH}_{3} \mathrm{CHO}\right)$, glycolaldehyde (GLYAL; $\left.\mathrm{HOCH}_{2} \mathrm{CHO}\right)$, glyoxal (GLY; $\mathrm{CH}(\mathrm{O}) \mathrm{CH}(\mathrm{O})$ ), ethanol $\left(\mathrm{CH}_{3} \mathrm{CH}_{2} \mathrm{OH}\right)$, acetic acid $\left(\mathrm{CH}_{3} \mathrm{COOH}\right)$, methylglyoxal (MGLY; $\left.\mathrm{CH}_{3} \mathrm{C}(\mathrm{O}) \mathrm{CHO}\right)$, hydroxyacetone ( $\left.\mathrm{HYAC} ; \mathrm{CH}_{3} \mathrm{C}(\mathrm{O}) \mathrm{CH}_{2} \mathrm{OH}\right)$, pyruvic acid (PRV; $\left.\mathrm{CH}_{3} \mathrm{C}(\mathrm{O}) \mathrm{COOH}\right), \mathrm{GLX}$, and oxalic acid $\left(\mathrm{H}_{2} \mathrm{C}_{2} \mathrm{O}_{4}\right)$. The aqueous phase oxidation is taking place by the $\mathrm{OH}$ and $\mathrm{NO}_{3}$ radicals, as well as the $\mathrm{CO}_{3}{ }^{-}$radical anion. $\mathrm{OH}$ is either produced by photolytic reactions of dissolved compounds or via a direct transfer from the gas phase into the solution, as well as by Fenton reaction (Deguillaume et al., 2010). $\mathrm{NO}_{3}$ radicals are transferred from the gas phase, while the $\mathrm{CO}_{3}{ }^{-}$radical anion is produced mainly via the oxidation of hydrated $\mathrm{CO}_{2}$. In general, the aqueous phase oxidation largely proceeds via $\mathrm{OH}$ radicals, followed by $\mathrm{NO}_{3}$ radicals under dark conditions, while the $\mathrm{CO}_{3}{ }^{-}$radical has an overall small impact on the oxidizing capacity of the solution.

Upon their transfer to the solution, aldehydes are considered to be in equilibrium with the corresponding diols. The hydrated aldehydes are oxidized via $\mathrm{H}$-atom abstraction with radicals $\left(\mathrm{OH}, \mathrm{NO}_{3}\right)$ or radical anions $\left(\mathrm{CO}_{3}{ }^{-}\right)$, followed by the elimination of $\mathrm{HO}_{2}$ in reaction with $\mathrm{O}_{2}$, leading overall to the formation of organic acids. Alcohols, such as $\mathrm{CH}_{3} \mathrm{OH}$ and $\mathrm{C}_{2} \mathrm{H}_{5} \mathrm{OH}$, are also oxidized via an $\mathrm{H}$-atom abstraction; the resulting $\alpha$-hydroxy-alkyl radicals, however, are not explicitly resolved, but the direct formation of aldehydes (e.g., formaldehyde and acetaldehyde) is considered via the respective peroxyl radical reactions with molecular oxygen to yield $\mathrm{HO}_{2}$. Moreover, the glycolic acid $\left(\mathrm{HOCH}_{2} \mathrm{COOH}\right)$ production via glycolaldehyde oxidation is not also explicitly described in the aqueous-phase scheme, and only the direct production of GLX is considered (Lin et al., 2012; Myriokefalitakis et al., 2011). This assumption is expected to have a negligible impact on the overall chemical mechanism since the glycolic acid is rapidly oxidized into glyoxylic acid with its net in-cloud production being rather small (Liu et al., 2012).

After cloud evaporation, $\mathrm{OXL}$ and $\mathrm{SO}_{4}{ }^{2-}$ are considered to reside entirely in the particulate phase of the model. This approximation may, nevertheless, result in an overestimate of OXL $\left(\mathrm{pKa}_{1}=1.23 ;\left(\mathrm{COO}^{-}\right)_{2}, \mathrm{pKa}_{2}=4.19\right)$ concentrations, since low levels of gas-phase oxalic acid have been also observed in the atmosphere under favorable conditions (e.g., Baboukas et al., 2000; Martinelango et al., 2007). Note that other products, such as pyruvate, glyoxylate as well as the oligomers from GLY and MGLY, are also considered to reside in the particulate phase upon cloud evaporation (Lim et al., 2005; Lin et al., 2012; Liu et al., 2012) and are thus added directedly to the SOA pool of the model. However, in contrast to OXL and the lowvolatility oligomers, the pyruvic and glyoxylic acids are allowed to be partially transferred back to the gas phase of the model when the cloud droplets evaporate.

380 For the present work, the aqueous reaction rate coefficients are taken (where available) from the available literature of the CAPRAM schemes and supplemented with reaction rates from laboratory and modeling studies (i.e., Carlton et al., 2007; Deguillaume et al., 2009; Lim et al., 2005; Sedlak and Hoigné, 1993). For the sulfur chemistry, the aqueous reaction rates are taken from Seinfeld and Pandis (2006). In the case of missing experimental data for temperature dependencies, the rate constants for $\mathrm{T}=298 \mathrm{~K}$ are only applied in chemistry calculations. $\mathrm{O}_{3}, \mathrm{H}_{2} \mathrm{O}_{2}, \mathrm{NO}_{3}, \mathrm{HONO} / \mathrm{NO}_{2}{ }^{-}, \mathrm{HNO}_{3} / \mathrm{NO}_{3}{ }^{-}$, and $\mathrm{CH}_{3} \mathrm{O}_{2} \mathrm{H}_{\text {, }}$ 385 along with $\mathrm{Fe}^{3+},\left[\mathrm{Fe}\left(\mathrm{SO}_{4}\right)\right]^{+}$and $\left[\mathrm{Fe}(\mathrm{OXL})_{2}\right]^{-}$are photolyzed in the aqueous phase. Aqueous photolysis frequencies are taken 
from the gas-phase chemistry (where available), and increased in the case of cloud droplets due to refraction effects by a factor of 1.5 (Barth et al., 2003). For Fe-species (e.g., $\left.\mathrm{Fe}^{3+},\left[\mathrm{Fe}\left(\mathrm{SO}_{4}\right)\right]^{+},\left[\mathrm{Fe}(\mathrm{OXL})_{2}\right]^{-}\right)$, their maximum (i.e., noontime at $51^{\circ} \mathrm{N}$ ) photolysis frequencies, as proposed by Ervens et al. (2003), are scaled based on the gas-phase $\mathrm{H}_{2} \mathrm{O}_{2}$ photolysis rates. A list of all aqueous and photochemical reactions included in the chemical scheme of this study is presented in Table S2, with the respective equilibrium reactions shown in Table S3.

\subsubsection{The iron solubilization scheme}

A three-stage kinetic approach (Shi et al., 2011) is applied to describe the solubilization of the Fe-containing dust mineral pools (Ito and Shi, 2016); i.e., representing: 1) a rapid dissolution of ferrihydrite on the surface of minerals (i.e., fast pool), 2) an intermediate stage dissolution of nano-sized Fe oxides from the surface of minerals (i.e., intermediate pool), and 3) the Fe release from heterogeneous inclusion of nano-Fe grains in the internal mixture of various Fe-containing minerals, such as aluminosilicates, hematite, and goethite (i.e., slow pool). A separate Fe pool for combustion aerosols (Ito, 2015) is also considered in the model.

The dissolved $\mathrm{Fe}$ in the model is produced via dissolution processes in aerosol water and cloud droplets depending on the acidity levels of the solution (i.e., proton-promoted dissolution scheme), the OXL concentration (i.e., ligand-promoted dissolution scheme), and irradiation (photo-reductive dissolution scheme), following Ito (2015) and Ito and Shi (2016). The Fe release from different types of minerals depends, thus, on the solution acidity $(\mathrm{pH})$ and the temperature $(\mathrm{T})$, as well as on the degree of solution saturation. In more detail, the dissolution rates for each of the three dissolution processes considered can be empirically described (e.g., Ito, 2015; Ito and Shi, 2016; Lasaga et al., 1994) as:

$R F e_{i}=K_{i}(p H, T) \cdot \alpha\left(H^{+}\right)^{m_{i}} \cdot f_{i} \cdot g_{i}$

405 where $K_{i}$ (moles $\mathrm{Fe} \mathrm{g} \mathrm{gi}^{-1} \mathrm{~s}^{-1}$ ) is the Fe release rate due to the dissolution process $i, \alpha\left(H^{+}\right)$is the $\mathrm{H}^{+}$activity of the solution, $m_{i}$ is the empirical reaction order for protons derived from experimental data, and the functions $f_{\mathrm{i}}$ and $\mathrm{g}_{\mathrm{i}}$ represent the suppression of the different dissolution rates due to the solution saturation state (Eq. 4 and Eq. 5). The net Fe dissolution rate results from the sum of the three rates. The activation energy that accounts for the temperature dependence is derived as a function of acidity based on soil measurements (Bibi et al., 2014; Ito and Shi, 2016), i.e.:

$E_{p H}=-1.5610^{3} \cdot p H+1.0810^{4}$

The functions $f_{\mathrm{i}}$ and $\mathrm{g}_{\mathrm{i}}$ represent the suppression of the different dissolution rates due to the solution saturation state, i.e.:

$$
\begin{aligned}
& f_{i}=1-\left(a_{F e^{3+}} \cdot a_{H^{+}}^{-n_{i}}\right) / K_{e q_{i}} \\
& g_{i}=0.17 \cdot \ln \left(\frac{a_{O X L}}{a_{F e^{3+}}}\right)+0.63
\end{aligned}
$$


where, $\alpha_{H^{+}}, \alpha_{\mathrm{Fe}+3}$, and $\alpha_{O X L}$ stand for the solution's activities of 1) protons, 2) ferric cations, and 3) OXL, respectively, as

415 calculated each time step in the model, and $\mathrm{K}_{\text {eqi }}\left(\mathrm{mol}^{2} \mathrm{~kg}^{-2}\right)$ is the equilibrium constant. All parameters used for the calculation of dissolution rates for this work are presented in Table S4.

\subsection{The chemistry solver}

All concentrations of gas, aqueous, and aerosol species evolve dynamically in the model. The ordinary differential equations that govern the production and destruction terms due to chemical reaction and interphase mass transfer in the model are:

$\begin{aligned} 420 \frac{d \mathrm{G}}{d t} & =R_{\mathrm{G}}-L W C k_{m t} \mathrm{G}+\frac{K_{m t}}{H R T} \mathrm{~A} \\ \frac{d \mathrm{~A}}{d t} & =R_{\mathrm{A}}+L W C k_{m t} \mathrm{G}-\frac{K_{m t}}{H R T} \mathrm{~A}\end{aligned}$

where,

$\mathrm{G}=$ Gas-phase concentrations (molecules $\mathrm{cm}^{-3}$ of air)

$\mathrm{A}=$ Aqueous-phase concentrations (molecules $\mathrm{cm}^{-3}$ of air)

$\mathrm{R}_{\mathrm{G}}=$ Gas-phase reaction terms (molecules $\mathrm{cm}^{-3}$ of air $\mathrm{s}^{-1}$ )

$\mathrm{R}_{\mathrm{A}}=$ Aqueous-phase reaction terms (molecules $\mathrm{cm}^{-3}$ of air $\mathrm{s}^{-1}$ )

$\mathrm{LWC}=$ Liquid water content $\left(\mathrm{cm}^{3}\right.$ of water $\mathrm{cm}^{-3}$ of air $)$

$\mathrm{k}_{\mathrm{mt}}=$ Mass transfer coefficient $\left(\mathrm{s}^{-1}\right)$

$\mathrm{H}=$ Henry's Law coefficient (moles $\mathrm{L}^{-1} \mathrm{~atm}^{-1}$ )

$430 \mathrm{R}=$ Ideal gas constant $\left(\mathrm{L}\right.$ atm mol$\left.{ }^{-1} \mathrm{~K}^{-1}\right)$

$\mathrm{T}=$ Temperature $(\mathrm{K})$

The mass transfer between the gas- and aqueous phases (Lelieveld and Crutzen, 1991; Schwartz, 1986) is applied only for those species that exist in both phases and is represented in the mechanism by two separate reactions, i.e., one reaction for transfer from the gas to the aqueous phase and one for the transfer from the aqueous to the gas phase. All Henry's law solubility constants (H) used in this work are taken from Sander (2015) and are presented in Table S5.

The mass transfer coefficient $\left(\mathrm{k}_{\mathrm{mt}}\right)$ for a species is calculated as:

$k_{m t}=\left(\frac{r^{2}}{3 D_{g}}+\frac{4 r}{3 v \alpha}\right)^{-1}$ 
where $r$ is the effective droplet or aqueous aerosol radius (m), $D_{g}$ is the gas-phase diffusion coefficient $\left(\mathrm{m}^{2} \mathrm{~s}^{-1}\right), v$ the mean molecular speed $\left(\mathrm{m} \mathrm{s}^{-1}\right)$, and $\alpha$ the mass accommodation coefficient (dimensionless). $\mathrm{D}_{\mathrm{g}}$ and $\alpha$ used for this study are also presented in Table S5. The mean molecular speed of a gaseous species is calculated as:

$v=\sqrt{\left(\frac{8 R_{g} T}{\pi M_{w}}\right)}$

where, $M_{W}$ is the respective molecular weight $\left(\mathrm{kg} \mathrm{mol}^{-1}\right)$ and $R_{g}$ is the ideal gas constant $\left(\mathrm{J} \mathrm{mol}^{-1} K^{-1}\right)$ (Herrmann et al., 2000). The cloud droplet effective radius may vary between $\sim 3.6-16.5 \mu \mathrm{m}$ for remote clouds, $1-15 \mu \mathrm{m}$ for continental clouds, and $\sim 1-25 \mu \mathrm{m}$ for polluted clouds (Herrmann, 2003). For this work, the effective radius of cloud droplets (ranging between 4-30

$\mu \mathrm{m}$ in the model) is calculated online based on the cloud liquid water content and the cloud droplet number concentration (van Noije et al., 2021). The effective radii (i.e., the ratio of the third to the second wet aerosol moments) for the accumulation and coarse deliquescence particles, are based on the respective M7 calculations. According to Eq. (8), the gas transfer to small droplets is faster, owing to the larger surface-to-volume ratio of smaller droplets. However, sensitivity model simulations using different droplet radii showed that varying droplet sizes result only in small changes in the chemical production of aqueousphase species (Lelieveld and Crutzen, 1991; Liu et al., 2012; Myriokefalitakis et al., 2011).

KPP version 2.2.3 (Damian et al., 2002; Sandu and Sander, 2006) was used to generate the Fortran 90 code for the numerical integration of the aqueous-phase chemical mechanism. For this, a separate model driver was developed to arrange the respective couplings to the TM5-MP I/O requirements (e.g., species that partition in the aqueous-phase, the reaction and dissolution rates, and the photolysis coefficients). The Rosenbrock solver is used in this work as the numerical integrator, since it is found to be rather robust and capable of integrating very stiff sets of equations (Sander et al., 2019). However, as for the case of the gas-phase mechanism's coupling (Myriokefalitakis et al., 2020b), minor changes were needed to be applied in the original KPP code. For instance, the aqueous and photolysis reactions are not calculated inside KPP, but directly provided through calculations in the aqueous chemistry driver. In contrast, for the Fe dissolution scheme, the suppressions of the mineral dissolution rates due to the solution saturation are calculated online by KPP (see Eq. 4 and Eq. 5).

\subsection{Simulations}

We performed a range of present-day simulations, including experiments using EC-Earth3-Iron atmosphere-only runs (hereafter referred to as EC-Earth), and TM5-MP standalone driven by ERA-Interim (Dee et al., 2011) reanalysis fields (hereafter referred to as ERA-Interim), covering the period 2000-2014. For the EC-Earth simulation, TM5-MP is coupled to the IFS atmospheric dynamics. We used prescribed sea surface temperature and sea-ice concentration fields from a set of input

465 files through the AMIP interface (Taylor et al., 2000). Thus, for the atmosphere and chemistry modules, our setup follows the EC-Earth3-AerChem standard configuration in CMIP6 experiments. The IFS horizontal resolution is T255 (i.e., a spacing of roughly $80 \mathrm{~km}$ ), 91 layers are used in the vertical direction up to $0.01 \mathrm{hPa}$, and a time step of $45 \mathrm{~min}$ is applied. Respectively, 
TM5-MP (both for the online and offline configurations) has a horizontal resolution of $3^{\circ}$ in longitude by $2^{\circ}$ in latitude and 34 layers in the vertical direction up to $0.1 \mathrm{hPa}(\sim 60 \mathrm{~km})$.

The ERA-Interim setup allows constraining the model with the assimilated observed atmospheric circulation data and is therefore used for budget analysis and comparison with other estimates from the literature. ERA-Interim is further used to explore uncertainties regarding the aqueous-phase chemistry scheme. Specifically, an additional simulation is performed to identify the potential importance of glyoxal-derived oligomers and high molecular weight species in the aqueous phase (Carlton et al., 2007) on the OXL production rates and the respective ambient concentrations. In this sensitivity simulation, (hereafter referred to as ERA-Interim(sens)), the OXL formation via high molecular weight species formation from glyoxal oxidation is neglected. Comparisons between the corresponding 15-year climatologies from the EC-Earth and ERA-Interim simulations are used to identify uncertainties in the aqueous-phase production terms of OXL, the iron-dissolution rates, and finally the atmospheric concentrations and deposition rates of Fe-containing aerosols due to the applied meteorology (i.e., online vs. offline). Note that the same emission datasets are used both in the ERA-Interim driven and the EC-Earth3-Iron experiments, thus only natural primary sources depending on meteorology may differ (see Sect. 2.1). A summary of the simulations is listed in Table 1.

\subsection{Observations}

A general evaluation of the modeled Aerosol Optical Depth (AOD) at $550 \mathrm{~nm}$ allows for characterizing EC-Earth3-Iron's ability to reproduce the aerosol fields. The Aerosol Robotic Network (AERONET) version 3 (Giles et al., 2019) level 2.0 direct sun retrievals at a monthly basis are used to calculate annual mean AOD values for the 2000-2014 period. The model's coarse horizontal resolution hinders, however, the representation of high-altitude locations, thus, following Huneeus et al. (2011), we exclude sites above $1000 \mathrm{~m}$ asl., leaving 738 locations with information available during the simulated period. In addition, we perform a specific evaluation of mineral dust, which constitutes a key modulator of the outcome of our new developments as a source of $\mathrm{Fe}$ and $\mathrm{Ca}$. To that end, we apply two additional filters to the AERONET data mentioned above, also following Huneeus et al. (2011), to identify dust-dominated sites. First, we exclude those sites where the monthly mean Angstrom exponent is above 0.4 more than 2 months in the selected period. To further discriminate dust from sea salt, a minimum threshold of 0.2 for AOD at $550 \mathrm{~nm}$ is considered (i.e., if more than half of the retrieved AOD is above that threshold, the site is considered as dust-dominated). This filtering allows identifying a subset of stations potentially dominated by dust aerosols, however, it cannot ensure that there is no influence of other aerosol types in the monthly retrievals. Therefore, the evaluation of AOD at $550 \mathrm{~nm}$ at those sites is taken as a proxy for the dust optical depth, acknowledging that other aerosols may also be present.

Pure dust measurements of surface concentration and deposition complement our evaluation of the model. The modeled annual mean surface dust concentration for 2000-2014 is compared to climatological observations from the Rosenstiel School of 
Marine and Atmospheric Science (RSMAS) of the University of Miami (Arimoto et al., 1995; Prospero, 1996, 1999; Prospero et al., 1989) and the African Aerosol Multidisciplinary Analysis (AMMA) international program (Marticorena et al., 2010) observations. The 23 available sites cover locations close to sources (e.g., the AMMA stations over the Sahelian dust transect), in transport regions (e.g., stations from RSMAS on the Atlantic), and remote regions (e.g., RSMAS sites close to Antarctica). The modeled dust deposition fluxes are compared to the compilation of observations for the modern climate in Albani et al. (2014) including measurements at 110 locations, the mass fraction for particles with diameter lower than $10 \mu \mathrm{m}$ is used to keep the observed mass fluxes within the range of the modeled sizes.

Model simulations are also evaluated against in-situ (surface and cruise) observations. The simulated OXL and $\mathrm{SO}_{4}{ }^{2-}$ concentrations are compared against measurements for representative sites, such as the Eastern Mediterranean (Finokalia, Greece; Koulouri et al., 2008), central Europe (Puy de Dome, France; Legrand et al., 2007), and the North Atlantic Ocean (Azores Portugal; Legrand et al., 2007). Simulated monthly mean surface concentrations of OXL are also compared against a range of observations ( $\mathrm{n}=143$ ) from remote sites around the world as compiled in Myriokefalitakis et al. (2011). Moreover, $\mathrm{SO}_{4}{ }^{2-}$ monthly mean surface concentrations over Europe and the USA are also compared against observations $(\mathrm{n}=3828)$ obtained from the European Monitoring and Evaluation Programme (EMEP; http://www.emep.int) and the Interagency Monitoring of Protected Visual Environments (IMPROVE; http://vista.cira. colostate.edu/improve/), respectively, as compiled in Daskalakis et al. (2016). The simulated Fe-containing aerosol concentrations are evaluated against cruise measurements covering a period from late 1999 up to early 2015, as compiled by Myriokefalitakis et al. (2018) and Ito et al. (2019a), and include daily observations for fine, coarse, and the total suspended particles.

Statistical parameters are here used to demonstrate the model performance. These are the correlation coefficient (R) that reflects the strength of the linear relationship between model results and observations (i.e., the ability of the model to simulate the observed variability), the normalized mean bias (nMB), and the normalized root mean square error (nRMSE) as a measure of the mean deviation of the model from the observations due to random and systematic errors. The equations used for the statistical analysis of model results are provided in the Supplement (Eq. S1-S3) and the locations (and regions) of the various observations used for evaluating the model for this work are presented in Fig. 1. Overall, a summary of statistics used for the evaluation of model simulations with the observations is presented in the Appendix (see Tables A1 and A2).

\section{Results}

\section{3.1 Budget calculations}

The chemical production and destruction terms of OXL and its precursors, along with the Fe-containing aerosols' dissolution rates from combustion $(\mathrm{FeC})$ and mineral dust $(\mathrm{FeD})$, their emissions, and their removal terms from the atmosphere are presented for EC-Earth and ERA-Interim model configurations in this section. Additionally, we discuss differences compared 
to sensitivity simulations. Due to the common formation pathways of $\mathrm{SO}_{4}{ }^{2-}$ and $\mathrm{OXL}$ in the atmosphere, the $\mathrm{SO}_{4}{ }^{2-}$ budget calculations are also presented and discussed. All calculations are presented as a mean ( \pm standard error) for the years $2000-$ 2014.

\subsubsection{Oxalate}

The annual net chemistry production of OXL (Table 2a) in EC-Earth is $12.61 \pm 0.06 \mathrm{Tg} \mathrm{yr}^{-1}$, which is lower than in ERAInterim $\left(18.12 \pm 0.07 \mathrm{Tg} \mathrm{yr}^{-1}\right)$. The difference is explained by a higher oxidizing capacity in ERA-Interim than in EC-Earth. ERA-Interim calculates higher $\mathrm{OH}$ concentrations in the tropical and subtropical troposphere (Fig. S1b). In contrast, zonal mean $\mathrm{OH}$ levels in EC-Earth are slightly higher in the extratropics, causing a more efficient oxidation of the OXL precursors, such as GLY (Fig. S1d), GLYAL (Fig. S1f), MGLY(Fig. S1h), and $\mathrm{CH}_{3} \mathrm{COOH}$ (Fig. S1j) at higher latitudes, especially in the SH. Note that, van Noije et al. (2014) also showed that in large parts of the troposphere, the simulated oxidizing capacity in the previous version of EC-Earth (EC-Earth v2.4) was lower compared to a respective ERA-Interim configuration, due to the simulated lower temperatures (cold biases) and specific humidities. However, since SSTs and sea-ice concentrations are prescribed in our EC-Earth atmosphere-only simulations, the long-term means of tropospheric temperatures and water vapor are not expected to differ significantly to ERA-Interim close to the surface levels, as also indicated by the low differences in the $\mathrm{OH}$ levels of the two simulations at low altitudes (Fig. S1b).

The production term of $\mathrm{OH}$ in EC-Earth is $\sim 5 \%$ lower than in ERA-Interim, due to a lower amount of water vapor available to react with $\mathrm{O}\left({ }^{1} \mathrm{D}\right)$. In addition, a $\sim 6 \%$ lower $\mathrm{OH}$ production through the $\mathrm{H}_{2} \mathrm{O}_{2}$ photolysis is simulated in EC-Earth. Note, that $\mathrm{H}_{2} \mathrm{O}_{2}$ is an important driver of the aqueous-phase oxidizing capacity in the model, with about 78-79\% of the OH radicals in the liquid phase being produced by photolysis of the dissolved $\mathrm{H}_{2} \mathrm{O}_{2}$. In more detail, the lower atmospheric abundance of the gas-phase $\mathrm{H}_{2} \mathrm{O}_{2}$ in EC-Earth $(\sim 11 \%)$ leads to smaller $\mathrm{H}_{2} \mathrm{O}_{2}$ uptake in the aqueous phase $(\sim 13 \%)$, and thus to a slower oxidation of OXL precursors due to the respective lower dissolved $\mathrm{OH}$ radical production $(\sim 19 \%)$. Overall, the total $\mathrm{OH}$ production is $\sim 7 \%$ lower in EC-Earth, which corresponds to a $\sim 18 \%$ lower aqueous-phase $\mathrm{OH}$ production, resulting in a $\sim 30 \%$ lower OXL net chemistry production compared to ERA-Interim.

The total OXL production is $15.5 \mathrm{Tg} \mathrm{yr}^{-1}$ in Lin et al. (2014) and $14.5 \mathrm{Tg} \mathrm{yr}^{-1}$ in Liu et al. (2012), both lower compared to our

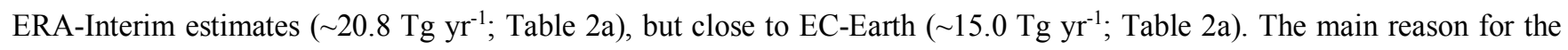
lower chemistry production of other published estimates compared to our results is the contribution of the aqueous-phase glyoxal oxidation scheme proposed by Carlton et al. (2007) that is applied in our simulations. The oxidation of the glyoxalderived high molecular weight products formed mainly in the cloud droplets is calculated to contribute significantly to the global OXL production in our model (Table 2a). This result is in line with Carlton et al. (2007), who indicated that the GLXpathway may not be the primary pathway for oxalic acid formation, but instead the rapid oxidation of GLY-multifunctional products via the $\mathrm{OH}$ radicals (i.e., $3.110^{10} \mathrm{~L} \mathrm{~mol}^{-1} \mathrm{~s}^{-1}$; Table S2). For ERA-Interim(sens) however, where no such reactions 
are considered, the total OXL chemical production is calculated on average $11.5 \mathrm{Tg} \mathrm{yr}^{-1}$ (Table 2); i.e., closer to the estimates of Lin et al. (2014) and Liu et al. (2012). On the other hand, our ERA-Interim net chemistry production calculations are close to the estimates of Myriokefalitakis et al. (2011) (i.e., $\sim 21.2 \mathrm{Tg} \mathrm{yr}^{-1}$ ) when no potential effects of the ionic strength (e.g., Herrmann, 2003) on OXL precursors are considered, although no Fe chemistry was considered that latter study. Indeed, the enhanced aqueous-phase oxidation capacity due to the Fenton reaction increases both the production and the destruction terms of OXL in our model, leading to $\sim 7 \%$ lower net OXL production and, respectively, a lower ( $>8 \%)$ atmospheric abundance. Nonetheless, our calculations indicate that Fe chemistry impacts on OXL net production drastically, increasing by at least $\sim 50 \%$ the destruction of the dissolved oxalic acid. The potential primary sources $\left(0.373 \pm 0.005 \mathrm{Tg} \mathrm{yr}^{-1}\right)$ accounted for in the model (Table 2a) do not, however, significantly contribute to the simulated OXL atmospheric levels, and only a small fraction of OXL is calculated to be formed in aerosol water $(\sim 6 \%)$ for all simulations in this work.

Focusing further on the atmospheric sinks of OXL, roughly $\sim 13 \%$ in ERA-Interim and $\sim 16 \%$ in EC-Earth of the produced oxalic acid is oxidized into $\mathrm{CO}_{2}$ in the aqueous phase, mainly via the photolysis of the $\left[\mathrm{Fe}(\mathrm{OXL})_{2}\right]^{-}$complex $(\sim 55 \%)$ and via $\mathrm{OH}$ radicals $(\sim 45 \%)$. The fraction of the total produced OXL that is destroyed in the aqueous-phase is higher than in Liu et al. (2012) by $\sim 7 \%$, where no Fe chemistry was considered, but lower compared to Lin et al. (2014) and Myriokefalitakis et al. (2011), where roughly $30 \%$ of the produced OXL is oxidized into $\mathrm{CO}_{2}$ in the aqueous phase. Finally, a total average deposition rate of $\sim 18.5 \mathrm{Tg} \mathrm{yr}^{-1}$ is calculated in ERA-Interim, primarily due to wet scavenging ( $\left.\sim 99 \%\right)$, resulting in a global atmospheric lifetime of $\sim 5.7$ days, close to Liu et al. (2012) and Lin et al. (2014), but higher compared to Myriokefalitakis et al. (2011) ( $\sim 3$ days) probably because the more intense OXL production at higher altitudes in our model.

The major pathways of global OXL production, both in ERA-Interim and EC-Earth, are the oxidation of glyoxal ( 74 \%), followed by glycolaldehyde $(\sim 11 \%)$, methylglyoxal ( $\sim \%)$, and acetic acid $(\sim 7 \%)$. Glyoxylic acid is, nevertheless, an important intermediate species because it is directly converted to OXL in the aqueous phase upon oxidation. Other important findings concerning the chemical budgets are summarized below:

1. Glyoxal: About $70 \mathrm{Tg} \mathrm{yr}^{-1} \mathrm{GLY}$ is produced in the gas-phase in ERA-Interim, similar to Lin et al. (2014). EC-Earth calculates that is $\sim 3 \%$ lower. The global gas-phase production of the present work is higher than other global model estimates, e.g., $\sim 56 \mathrm{Tg} \mathrm{yr}^{-1}$ (Myriokefalitakis et al., 2008), 40 $\mathrm{Tg} \mathrm{yr}^{-1}$ (Fu et al., 2009, 2008), and $21 \mathrm{Tg} \mathrm{yr}^{-1}$ (Liu et al., 2012). This difference can be explained by the more comprehensive isoprene chemistry of the gas-phase scheme used here (Myriokefalitakis et al., 2020b). Indeed, isoprene secondary oxidation products (e.g., epoxides) are significant precursors of GLY in the atmosphere (Knote et al., 2014) and the contribution of isoprene epoxides (IEPOX) from the gas-phase isoprene oxidation is here considered as a pathway of GLY formation. Note that the oxidation of other biogenic hydrocarbons, like terpenes and other reactive organics, may also result in GLY formation, since their chemistry is lumped on the first generation peroxy radicals of isoprene in the model (Myriokefalitakis et al., 2020b). Besides the biogenic hydrocarbon oxidation, the model considers GLY formation due to the oxidation of 
other organic species (e.g., Warneck, 2003), such as acetylene $\left(\sim 4.8 \mathrm{Tg} \mathrm{yr}^{-1}\right)$ and aromatics $\left(\sim 18.8 \mathrm{Tg} \mathrm{yr}^{-1}\right)$. In the gas phase, other hydrocarbons, like ethene, further contribute to the atmospheric production of GLY via their oxidation products, mainly glycolaldehyde $\left(\sim 5.4 \mathrm{Tg} \mathrm{yr}^{-1}\right)$. However, as in many modeling studies, additional primary and/or secondary glyoxal sources might be still missing in our model. Indeed, the elevated glyoxal concentrations over oceans that have been observed from space (e.g., Wittrock et al., 2006) would require at least $\sim 20 \mathrm{Tg} \mathrm{yr}^{-1} \mathrm{of}_{\text {extra }}$ marine sources to reconcile model simulations with satellite retrievals (Myriokefalitakis et al., 2008). Great uncertainties, however, still exist on these oceanic sources (Alvarado et al., 2020; Sinreich et al., 2010) and therefore the only glyoxal primary sources accounted for in the model are from biofuel combustion and biomass burning processes (e.g., Christian et al., 2003; Fu et al., 2008; Hays et al., 2002), resulting overall in $\sim 7 \mathrm{Tg} \mathrm{yr}^{-1}$ on average in the model (Myriokefalitakis et al., 2020b). Glyoxal is rapidly destroyed in the atmosphere via photolysis ( $70 \%$ ), followed by its oxidation in the gas phase $(\sim 15 \%)$ and the aqueous phase $(\sim 15 \%)$. Roughly $5.4 \mathrm{Tg} \mathrm{yr}^{-1}$ of glyoxal are produced in the aqueous phase via the dissolved GLYAL oxidation in ERA-Interim, close to the Liu et al. (2012) calculations, but somehow higher compared to EC-Earth. Overall, the net cloud uptake of glyoxal in ERA-Interim is $\sim 6.3 \mathrm{Tg} \mathrm{yr}^{-1}$, which is higher than the estimates from Liu et al. (2012) $\left(\sim 1.6 \mathrm{Tg} \mathrm{yr}^{-1}\right)$. As expected, this increase is due to the applied glyoxal oxidation scheme in the aqueous phase of our base simulations. Finally, $\sim 4.2 \mathrm{Tg} \mathrm{yr}^{-1}$ of glyoxal are removed from the atmosphere via wet scavenging ( $\sim 73 \%)$ and dry deposition $(\sim 27 \%)$.

2. Glycolaldehyde: GLYAL is also a significant species for OXL atmospheric abundance since its oxidation directly produces GLY both in the gas and the aqueous phase. In ERA-Interim, the gas-phase production is $\sim 92.5 \mathrm{Tg}^{-1} \mathrm{on}^{-1}$ global scale, with the primary sources accounting for $\sim 5.4 \mathrm{Tg} \mathrm{yr}^{-1}$ (Myriokefalitakis et al., 2020b) on average. In ECEarth, the gas-phase production is $\sim 1 \%$ lower. GLYAL is destroyed via gas-phase photolysis ( $\sim 55 \%)$ and by $\mathrm{OH}$ radicals in the gas phase $(\sim 35 \%)$ and the aqueous phase $(\sim 10 \%)$. Ethene oxidation products contribute $\sim 39 \%$ to GLYAL production, but isoprene chemistry dominates its chemical production in the model. The only source of GLYAL in the aqueous phase is nevertheless the transfer from the gas phase. The dissolved GLYAL is oxidized to produce GLY ( $\sim 60 \%$ ) and GLX ( $\sim 4 \%$ ), overall resulting in a net aqueous uptake of $\sim 8 \mathrm{Tg} \mathrm{yr}^{-1}$ in ERA-Interim, close to the estimates of Liu et al. (2012), but almost $40 \%$ higher than in Lin et al. (2014). This higher uptake of GLYAL in the aqueous phase is due to the respective higher ( 14\%) gas-phase production in our model. Note that in ERA-Interim, the net aqueous uptake of GLYAL is calculated $\sim 24 \%$ lower compared to ERA-Interim.

3. Methylglyoxal: The global annual mean gas-phase production of MGLY in ERA-Interim is $\sim 237{\mathrm{Tg} \mathrm{yr}^{-1}} \mathrm{on}$ average, with the primary sources accounting for $\sim 4.6 \mathrm{Tg} \mathrm{yr}^{-1}$. The gas-phase production is higher than the $160-169{\mathrm{Tg} \mathrm{yr}^{-1}}^{-1}$ reported by other modeling studies (Fu et al., 2008; Lin et al., 2014; Liu et al., 2012) owing to the contribution of oxidation products considered in the gas-phase isoprene chemistry scheme (Myriokefalitakis et al., 2020b). Roughly $56 \%$ of MGLY is produced via the gas-phase oxidation of HYAC with OH radicals, which is lower than the estimated 
$\sim 75 \%$ in Fu et al. (2008). The remaining MGLY production is due to isoprene oxidation products, i.e., $\sim 10 \%$ from IEPOX oxidation, and $\sim 7 \%$ from methyl vinyl ketone (MVK) and methacrolein (MACR) oxidation. In the aqueous phase, MGLY is produced via the dissolved HYAC oxidation $\left(\sim 13.0 \mathrm{Tg} \mathrm{yr}^{-1}\right)$ and then further oxidized by OH radicals ( 11.6 $\mathrm{Tg} \mathrm{yr}^{-1}$ ) into pyruvic acid (PRV), methylglyoxal oligomers (MGLYOLI), and to a lesser extent into GLX. Note that the calculated contribution of dissolved HYAC to the aqueous-phase production of MGLY is higher compared to the nearly negligible rates in Liu et al. (2012) because of the higher gas-phase production of HYAC in our model. MGLY is chemically destroyed in the model mainly by gas-phase photolysis ( $\sim 60 \%)$, the $\mathrm{OH}$ radicals in the gas phase $(\sim 35 \%)$, and via oxidation in the aqueous phase $(\sim 5 \%)$.

4. Pyruvic and acetic acids: The chemical production of PRV is $\sim 14.7 \mathrm{Tg} \mathrm{yr}^{-1}$ in ERA-Interim and $\sim 16.7 \mathrm{Tg} \mathrm{yr}^{-1}$ in ECEarth. PRV is mainly produced by terpene oxidation via $\mathrm{O}_{3}(\sim 51 \%)$ in the gas phase followed by methyl vinyl ketone (MVK) oxidation $(\sim 5 \%)$. In the aqueous phase, PRV is solely produced from MGLY oxidation $\left(\sim 6.5 \mathrm{Tg} \mathrm{yr}^{-1}\right)$ and subsequently oxidized to $\mathrm{CH}_{3} \mathrm{COOH}$. $\mathrm{PRV}$ is mainly removed via photolysis in the gas phase and via oxidation by $\mathrm{OH}$ radicals in the aqueous phase $(\sim 30 \%)$. However, more than half of the produced PRV in the aqueous phase directly contributes to the SOA mass of the model upon cloud evaporation. The gas-phase production of acetic acid is $\sim 44.3 \mathrm{Tg} \mathrm{yr}^{-1}$, with the primary sources accounting for approximately $24 \mathrm{Tg} \mathrm{yr}^{-1}$. In the aqueous phase, roughly 3 $\mathrm{Tg}^{-1}$ of $\mathrm{CH}_{3} \mathrm{COOH}$ is produced via $\mathrm{PRV}$ oxidation. Note that the net uptake of $\mathrm{CH}_{3} \mathrm{COOH}\left(\sim 0.7 \mathrm{Tg}^{-1}\right)$ is calculated in the model similar to the Lin et al. (2014) estimates, but smaller than the $6.7 \mathrm{Tg} \mathrm{yr}^{-1}$ calculated by Liu et al. (2012).

5. Glyoxylic acid: The GLX production rate is $7.1 \mathrm{Tg} \mathrm{yr}^{-1}$ in EC-Earth and it is $\sim 30 \%$ lower in ERA-Interim. About 55 $\%$ of the produced GLX is directly oxidized to oxalic acid in the aqueous phase and $\sim 25 \%$ is added directly to the SOA pool. Upon cloud evaporation, part of the produced GLX is also transferred in the gas phase, where it is either oxidized by OH radicals ( $\sim 60 \%$ ), photolyzed ( $\sim 33 \%$ ) or deposited $(\sim 7 \%)$. Due to the destruction of GLX in the gas phase, its total production is lower ( $\sim 60 \%$ ) compared to the production estimates in Lin et al. (2014) and Liu et al. (2012). For the EC-Earth and ERA-Interim, most of the produced GLX in the aqueous phase is derived from the oxidation of GLYAL ( $48 \%$ ), followed by the oxidation of $\mathrm{CH}_{3} \mathrm{COOH}(30 \%)$, GLY and its oligomeric products ( $15 \%$ ), and MGLY. The relative contributions in our calculations differ from the estimates in Lin et al. (2014), where GLX is primarily produced by GLY oxidation ( $77 \%)$ followed by GLYAL ( $14 \%)$, MGLY ( $\sim 1 \%)$, and acetic acid $(\sim 8 \%)$. These differences are also caused by the direct contribution of the GLY oxidation products to the OXL formation. On the other hand, in the ERA-Interim(sens) simulation the calculated fractions agree well with other published estimates, where GLY overall dominates ( $60 \%)$ the GLX production in the aqueous phase.

Figure 2a presents the annual mean (average 2000-2014) net chemistry production rates of OXL in EC-Earth, and the respective 
and in the southern hemisphere, where both biogenic emissions (mainly isoprene) and the liquid cloud water are substantially enhanced (Fig. S2a). The Amazon region appears as the largest source of OXL, along with central Africa and Southeast Asia. At higher latitudes $\left(>45^{\circ} \mathrm{N}\right)$ the lower cloud liquid water content and vegetation cover lead to a lower OXL production over Asia and North America. However, over highly populated regions in the northern hemisphere, such as in Europe, the US, and China, enhanced OXL production rates are calculated due to its anthropogenic precursors. Furthermore, a significant source of OXL is calculated downwind land areas, such as the South Pacific, and the tropical Atlantic Ocean, due to the long-range transport of OXL precursors.

The illustrated differences in OXL production between ERA-interim and EC-Earth (Fig. S2c) are caused due to the adopted atmospheric dynamics (i.e., online calculated versus offline), as both simulations use identical prescribed anthropogenic and biogenic emissions. For instance, EC-Earth calculates higher cloud water concentrations at $\sim 800-600 \mathrm{hPa}$ around the tropics $\left(30^{\circ} \mathrm{S}-30^{\circ} \mathrm{N}\right)$ compared to ERA-Interim. In contrast, lower concentrations are derived aloft, with ERA-Interim presenting enhanced cloud water concentrations at $\sim 400 \mathrm{hPa}$ (Fig. S2b). Moreover, due to the lower $\mathrm{OH}$ concentrations in the tropical and subtropical troposphere (Fig. S1b), EC-Earth gives lower OXL production rates, especially over intense biogenic emission areas. Overall, the difference in the oxidizing capacity of the atmosphere between the two configurations significantly impacts the aqueous phase OXL production efficiency in the model.

\subsubsection{Sulfate}

Sulfate $\left(\mathrm{SO}_{4}{ }^{2-}\right)$ is the main inorganic aerosol species produced in the aqueous phase, and similar to OXL its production in the model mainly occurs in cloud droplets. In addition, these two species largely reside in the aerosol accumulation mode of the model (roughly $99 \%$ for $\mathrm{SO}_{4}^{-2}$ and $\sim 97 \%$ for OXL). $\mathrm{SO}_{4}{ }^{2-}$ is a key species for determining atmospheric acidity, and therefore we also present here the sulfate budget in conjunction with that of OXL. Sulfate is produced both in cloud droplets and in aerosol water, with the production in aerosol water having however a negligible contribution on a global scale. In contrast to $\mathrm{OXL}$, for which no gas-phase production is considered, the gas-phase oxidation of $\mathrm{SO}_{2}$ via $\mathrm{OH}$ radicals contributes to the total $\mathrm{SO}_{4}{ }^{2-}$ concentrations with about $12.0 \mathrm{Tg} \mathrm{S} \mathrm{yr}^{-1}$ (Table 2b). Our global estimate of the gaseous sulfuric acid $\left(\mathrm{H}_{2} \mathrm{SO}_{4}\right)$ production is higher than in EC-Earth v2.4 ( 7.8 $\mathrm{Tg} \mathrm{S} \mathrm{yr}^{-1}$ averaged for the years 2000-2009; van Noije et al., 2014), but slightly lower than in the EC-Earth3-AerChem AMIP simulations (van Noije et al., 2021) used for the CMIP6 experiments (available in https://esg-dn1.nsc.liu.se/search/cmip6-liu/; last access 11/06/2021) where $\sim 12.9 \mathrm{Tg} \mathrm{S} \mathrm{yr}^{-1}$ of $\mathrm{H}_{2} \mathrm{SO}_{4}$ are produced (averaged for the years 2000-2014). These differences can be directly attributed to the $\mathrm{OH}$ radical production rates in the gas phase between the new and the previous versions of the atmospheric model, as have been discussed in Myriokefalitakis et al. ( 2020b). Despite the generally lower gas-phase OH radical levels (Fig. S1b), the slightly higher ( 8 \%) global $\mathrm{H}_{2} \mathrm{SO}_{4}$ gas-phase production rate in EC-Earth than in ERA-Interim (Table 2b), can be attributed to the higher ( 6\%) DMS emissions in ECEarth (Fig. S4b), that contribute to the atmospheric $\mathrm{SO}_{2}$ levels over the ocean. 
The aqueous-phase $\mathrm{SO}_{4}{ }^{2-}$-chemistry production from the oxidation of dissolved $\mathrm{SO}_{2}$ is $39.8 \mathrm{Tg} \mathrm{S} \mathrm{yr}^{-1}$ in EC-Earth (Table $2 \mathrm{~b}$ ), which is higher than in EC-Earth v2.4 (29.3 Tg S yr${ }^{-1}$; van Noije et al., 2014) and EC-Earth3-AerChem (32.5 Tg S yr $\left.{ }^{-1}\right)$. The higher $\mathrm{SO}_{4}{ }^{2-}$ chemical production is mainly due to the higher $\mathrm{SO}_{2}$ aqueous-phase oxidation rates by $\mathrm{H}_{2} \mathrm{O}_{2}$. In more detail, our calculations show that $\sim 84 \%$ of the global $\mathrm{SO}_{4}{ }^{2-}$ production in EC-Earth is due to the dissolved $\mathrm{SO}_{2}$ oxidation via $\mathrm{H}_{2} \mathrm{O}_{2} ; \sim 33.3$ Tg S yr ${ }^{-1}$ is produced due to $\mathrm{H}_{2} \mathrm{O}_{2}$, higher compared to $23.9 \mathrm{Tg} \mathrm{S} \mathrm{yr}^{-1}$ in van Noije et al. (2014). The dissolved $\mathrm{SO}_{2}$ oxidation via $\mathrm{O}_{3}\left(6.4 \mathrm{Tg} \mathrm{S} \mathrm{yr}^{-1}\right)$ is also higher than in EC-Earth v2.4 (5.4 $\left.\mathrm{Tg} \mathrm{S} \mathrm{yr}^{-1}\right)$. The contribution of $\mathrm{CH}_{3} \mathrm{O}_{2} \mathrm{H}_{\text {to }}$ the $\mathrm{SO}_{4}{ }^{2-}$ aqueousphase production is however small $\left(\sim 0.05 \mathrm{Tg} \mathrm{S} \mathrm{yr}^{-1}\right)$ in the model, with the $\mathrm{HO}_{2}$ contribution being practically negligible on the global scale $\left(\sim 0.02 \mathrm{Tg} \mathrm{S} \mathrm{yr}^{-1}\right)$ for all simulations performed in this study. A total annual mean deposition rate of $\sim 53 \mathrm{Tg} \mathrm{S}$ $\mathrm{yr}^{-1}$ is simulated in EC-Earth, with wet scavenging dominating the total deposition rate ( $\left.\sim 93 \%\right)$. Note also that $2.5 \%$ of the sulfur in the $\mathrm{SO}_{2}$ emissions $\left(\sim 1.6 \mathrm{Tg} \mathrm{S} \mathrm{yr}^{-1}\right)$ is assumed to be in the form of $\mathrm{SO}_{4}{ }^{2-}$ for all simulations, which accounts for its formation in the sub-grid plumes (Aan de Brugh et al., 2011; Huijnen et al., 2010). Overall, a global $\mathrm{SO}_{4}^{2-}$ lifetime over deposition of $\sim 4.8$ days is calculated in EC-Earth, which is lower than in ERA-Interim ( $\sim 6.6$ days), but similar to the EC-Earth v2.4 estimate ( $\sim 4.9$ days).

700 Figure $2 \mathrm{~b}$ also shows the annual mean $\mathrm{SO}_{4}^{2-}$ net chemistry production rates in EC-Earth. High $\mathrm{SO}_{4}^{2-}$ production rates are calculated downwind of major anthropogenic $\mathrm{SO}_{2}$ emission hotspots, such as Central Europe, Eastern US, India, Russia, and Eastern Asia. Furthermore, relatively high production rates due to biomass burning and volcanic eruptions are calculated in South America, Southern Africa, and Indonesia. Significant $\mathrm{SO}_{4}{ }^{2-}$ production is calculated over almost all oceanic regions due to the $\mathrm{SO}_{2}$ production via the gas-phase oxidation of marine DMS emissions (Fig. S4a). Compared to the ERA-Interim simulation, however, the $\mathrm{SO}_{4}^{2-}$ production rates in EC-Earth are on average slightly higher over land in the tropics and extratropics. This increase can be attributed to combined effects that result in differences in chemical production and deposition rates (Table 2b). Some differences over oceans are nevertheless expected due to the differences in DMS concentrations since DMS emissions are online calculated in the model based on sea surface temperature and wind velocity (Fig. S4b).

\subsubsection{Iron}

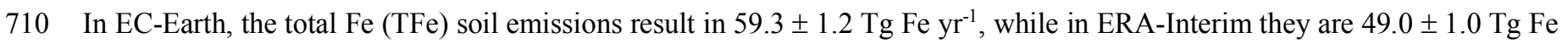
$\mathrm{yr}^{-1}$. This difference results from the differences in wind speed between EC-Earth and ERA-Interim. EC-Earth produces higher dust emissions over large parts of the Middle East and Asia compared to ERA-Interim (Fig. S4f), which explains the differences in TFe emissions (TFeC emissions do not differ). However, most of the dissolved Fe from mineral dust in the model originates

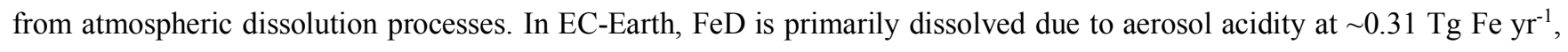

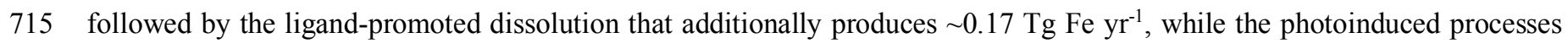

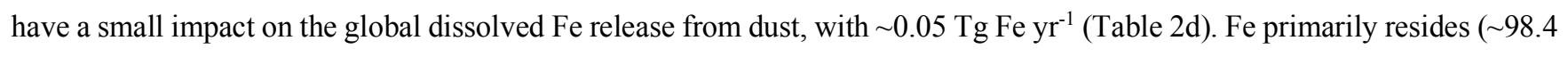
$\%$ ) in the slow pool of Fe-containing dust aerosols in the model, in particular in the coarse mode, with about $1.0 \%$ being emitted as nano-sized iron oxides (intermediate pool), and $\sim 0.5 \%$ as ferrihydrite (fast pool). Thus, most of the dissolved $\mathrm{Fe}$ 
release originates from the heterogeneous inclusion of nano-Fe grains in the internal mixture of various Fe-containing minerals such as aluminosilicates, hematite, and goethite ( $66 \%)$, followed by nano-sized iron oxides $(\sim 24 \%)$ and to a lesser extent by ferrihydrite $(\sim 10 \%)$. Note, however, that the Fe release from aluminosilicates, hematite, and goethite particles is a slower process compared to the other soil classes considered in the model, as dictated by the three-stage approach applied for this study (Table S4).

Fe emissions from combustion processes, such as biomass burning, coal, and ship oil combustion, are estimated at $2.52 \pm 0.10$

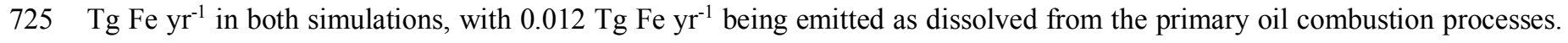
Roughly $0.274 \pm 0.01 \mathrm{Tg} \mathrm{Fe} \mathrm{yr}^{-1}$ are released through Fe dissolution from combustion aerosols in EC-Earth, in good agreement

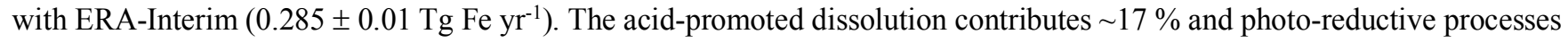
$\sim 16 \%$ to the Fe release from combustion particles, thus most Fe release comes from the ligand-promoted dissolution. This result is in line with laboratory studies (e.g., Chen and Grassian, 2013), where the contribution of oxalate-promoted dissolution is several times larger than the proton-promoted pathway under highly acidic dark conditions. According to our calculations, the relative contribution of atmospheric processing to the combustion aerosol Fe solubilization $(\sim 11 \%)$ is significantly higher compared to that of crystalline dust minerals ( $\sim 1 \%$ ), in agreement with laboratory (e.g., Chen et al., 2012; Fu et al., 2012) and modeling (e.g., Ito, 2015; Ito and Shi, 2016) studies. All in all, the total DFe atmospheric source in EC-Earth, accounting for both primary emissions and atmospheric processing, is $0.88 \pm 0.04 \mathrm{Tg}_{-} \mathrm{Fe}_{\mathrm{r}^{-1}}$ for the present day, well in the range of estimates presented in the model intercomparison study $\left(0.7 \pm 0.3 \mathrm{Tg}-\mathrm{Fe}_{\mathrm{yr}}{ }^{-1}\right)$ in Myriokefalitakis et al. (2018).

The annual mean dissolution rates of $\mathrm{FeC}$ and $\mathrm{FeD}$ in EC-Earth are presented in Fig. 3. For combustion aerosols, the maximum dissolution rates occur downwind of biomass burning sources and highly populated regions, such as South America and Central Africa, the Middle East, India, and China. High dissolution rates are more likely to coincide with high OXL concentrations (Ito, 2015). Indeed, the model calculates important dissolution rates near regions where the OXL production rates are enhanced (Fig. 2a), such as over the Amazon basin and Central Africa, as well as downwind of these regions as the combustion aerosols are transported to the open ocean, in agreement with observations (e.g., Sholkovitz et al., 2012). For the mineral dust aerosols, most of the FeD dissolution fluxes occur downwind of the major dust source regions (e.g., the Sahara and the Gobi Desert), where the atmospheric transport of anthropogenic pollutants, such as SOx and NOx, enhances atmospheric acidity; e.g., the Fe release from the dust minerals due to proton-promoted dissolution processes is enhanced over the Middle East. Significant dissolution rates are also simulated over the Atlantic Ocean at the outflow of the Sahara, as well as at the outflow of Asian desert regions to the Pacific Ocean. High rates due to the contribution of the organic ligand-promoted dissolution processes are calculated downwind of central Africa and the equatorial Atlantic Ocean, where the oxidation of biogenic hydrocarbons in the presence of cloudiness leads to enhanced OXL aqueous-phase formation rates. On the contrary, the efficiency of ligandpromoted dissolution is substantially suppressed near dust source regions due to the low OXL availability (Fig. 2a). 
750 Figure 3 also presents the absolute differences between the ERA-Interim and EC-Earth annual mean Fe dissolution rates. ERAInterim has significantly lower dissolution rates in the tropics (e.g., Central Africa) and around the equator, both for FeC (Fig. 3c) and FeD (Fig. 3d). This decrease is attributed both to the differences in atmospheric dynamics between the two model configurations, as well as to the suppression of the organic-dissolution processes with lower OXL production. Indeed, Fig. 2c shows that in ERA-Interim, OXL production rates increase in the tropics, impacting Fe-dissolution rates. In contrast, $\mathrm{FeC}$ dissolution rates increase in ERA-Interim over the Arabian Peninsula, India, and Eastern Asia, due to fluctuations in OXL production and aerosol acidity. EC-Earth also shows lower FeD dissolution rates over the Northern Pacific in the outflow of Asia. These differences are due to a higher to aerosol acidity (i.e., up to $\sim 1 \mathrm{pH}$ unit; Fig. S3d,f) in ERA-Interim due to changes in the buffering capacity of dust promoted by the higher calcite emissions in EC-Earth (Fig. S4f). This is the case especially for coarse dust aerosols where the majority of the Fe resides. EC-Earth also shows differences (positive or negative) with ERAInterim in the Fe dissolution rates over oceanic regions (Fig. 3e,d), likely due to differences in $\mathrm{SO}_{4}{ }^{2-}$ production over oceans from marine DMS emissions (Fig. S4b), and to the impact of sea salt emissions (Fig. S4d) upon the buffering capacity of the solution

\subsection{Evaluation of new model features against observations}

All developments described in this work have been implemented over the EC-Earth3-AerChem model version, which has 765 proved to simulate the atmospheric aerosol cycles comparably well to other global models and to behave outstandingly in the simulation of optical properties (Gliß et al., 2021). Thus, we do not expect substantial changes in EC-Earth3-Iron ability to represent the aerosol cycle, nor their optical properties, compared to EC-Earth3-AerChem. However, owing to the significant differences in the gas-phase and aqueous chemistry between versions, we provide an overall assessment of the Aerosol Optical Depth (AOD). In addition, as one of the novelties of this work is to consider explicitly how dust composition affects the atmospheric iron burden and alters acidity (e.g., through calcite), and therefore a comparison of dust fields with in-situ observations is also provided. Finally, simulations of specific species key to our developments, such as oxalate, sulfate, and total and soluble iron are also evaluated.

\subsubsection{AOD, dust concentration and deposition}

The annual mean AOD at $550 \mathrm{~nm}$ modeled in EC-Earth for 2000-2014 compares favorably with AERONETv3 direct-sun level

7752.0 data (Fig. 4a). Overall, the model presents an nMB of $-9.1 \%$ and an nRMSE of $45.7 \%$, considering information from 738 AERONET sites. The regional analysis suggests a slightly better behavior in northern hemisphere regions (e.g., North America, Europe, East Asia) dominated by anthropogenic aerosols (normalized errors and biases, below $45 \%$ and $\pm 10 \%$, respectively). The largest deviations from observed AOD occur in the Southern Hemisphere (e.g., South Africa, Australia, and Oceania) or remote regions. Over dust-dominated regions (e.g., North Africa, West Asia, and the Middle East) the model also behaves well 780 (with normalized errors and biases below $45 \%$ and $\pm 10 \%$, respectively). Selecting specifically dust-dominated sites for the 
comparison (Fig. 4b) and following the criteria explained in Sect. 2.5, EC-Earth slightly overestimates the retrieved AOD at $550 \mathrm{~nm}$ over North Africa $(\mathrm{nMB}=21.5 \%)$ and shows underestimations over sources in West Asia and the Middle East, as well as in transport regions such as Central America. In general, EC-Earth's ability to reproduce the annual mean AOD at $550 \mathrm{~nm}$ holds for dusty sites, with a normalized mean bias of $2.7 \%$, and a normalized root mean square error of $37.2 \%$ over 38 sites.

785 The comparison of model outputs with climatologies of dust surface concentration from the RSMA and the AMMA campaign (Fig. 4c) yields slightly poorer results, with an $\mathrm{nMB}$ of $19.3 \%$ and an $\mathrm{nRMSE}$ of $81.2 \%$, as an average of the 23 sites available. EC-Earth best reproduces dust surface concentrations over source regions, such as North Africa (nMB=21.9\%, nRMSE $=37.7 \%$ ), shows underestimations in transport areas (e.g., Central America: $\mathrm{nMB}=-37.5 \%, \mathrm{nRMSE}=38.7 \%$ ) and poorly represents the surface concentration in remote regions (e.g., South Pacific and Southern Ocean, with nMB up to $-98.5 \%$ and nRMSE up to $112.7 \%$ ). This issue is also reflected in the evaluation of the dust deposition field (Fig. 4d), with positive and negative biases over source regions but a clear underestimation of the deposited mass on transport and remote regions (e.g., the Southern Ocean). These discrepancies point towards an overestimation of dust deposition. For instance, EC-Earth3-Iron may share the difficulties of many global dust models in representing the long-range transport of dust, in particular coarse dust downwind of dust sources (e.g., Adebiyi and Kok, 2020). As minerals in dust constitute the primary source of TFe to the atmosphere, the overestimation close to the source regions and the underestimation in remote regions will also influence the representation of dust-related $\mathrm{DFe}$ in the model.

\subsubsection{Oxalate}

The averaged OXL surface concentrations in EC-Earth for the boreal winter (December, January, and February; DJF) and summer (June, July, and August; JJA) are presented in Fig. 5. OXL surface concentrations are distributed roughly between $60^{\circ}$

$800 \mathrm{~S}$ and $60^{\circ} \mathrm{N}$, mainly in regions where intensive VOC emissions from anthropogenic and biogenic sources coexist with cloud water. The highest OXL concentrations are calculated over tropical Africa, the Amazon Basin, eastern Asia, the eastern United States, and Europe, clearly showing the strong impact of OXL precursors (e.g., glyoxal) and the availability of cloud water, along with increased biogenic emissions at these latitudes. In the northern hemisphere, OXL concentrations are generally calculated higher in summer and lower in winter, indicating a strong impact of temperature and photochemistry on the production rate of oxalic acid in the aqueous phase. During DJF, the model calculates lower OXL concentrations over midand high-latitude regions, such as East Asia, Central Europe, and Northern US. Over these highly populated regions, the aerosol water content is enhanced, following the increased $\mathrm{SO}_{4}{ }^{-2}$ production due to anthropogenic activities, and the aqueous-phase OXL production in deliquesce particles also contributes to OXL atmospheric concentrations. Furthermore, high OXL concentrations are calculated in the tropics for both seasons, due to the photochemical activity and the intense sources of biogenic VOCs in these regions. 
https://doi.org/10.5194/gmd-2021-357

Preprint. Discussion started: 10 November 2021

(c) Author(s) 2021. CC BY 4.0 License.

\section{(c) (i)}

Figure 5 further presents the differences between EC-Earth and ERA-Interim. In general, OH levels in ERA-Interim are higher, which causes a more efficient oxidation of OXL precursors for both seasons. Moreover, ERA-Interim shows higher concentrations around the intertropical convergence zone (ITCZ) due to differences in meteorology between the two simulations, as discussed above. During boreal winter, some differences are observed over the subtropics of the Northern

815 Hemisphere. Although OXL concentrations are very low over these latitudes, the relatively strong increase in liquid water that serves as a medium for OXL production, both for clouds (Fig. S2b) in higher altitudes ( $400 \mathrm{hPa}$ ), and at the surface for deliquescent particles (Fig. S2d,e) in the ERA-Interim simulation. In the vertical, OXL concentrations are distributed in the model from the surface to $\sim 400 \mathrm{hPa}$ with a maximum at around $900 \mathrm{hPa}$. The zonal mean differences, however, indicate strong increases in the southern hemisphere $\left(30^{\circ} \mathrm{S}-0^{\circ}\right)$ during boreal winter (Fig. 5e). Compared to EC-Earth, ERA-Interim calculates higher OXL concentrations in the upper troposphere for both seasons (Fig. 5e,f), mostly due to more efficient transport of OXL precursors by deep convection into the tropical and extratropical upper troposphere. In the lower and middle troposphere, higher concentrations are calculated in ERA-Interim depending on the location and the season. The concentrations in EC-Earth are also lower than in ERA-Interim in the NH extratropics during boreal summer due to a lower chemical production (Fig. 5f). Figure 6 presents the comparison of the different model simulations performed for this work with OXL surface observations. OXL concentrations show a strong seasonal dependence, with maxima during the warm season due to the intense photochemical activity combined with the higher precursor's abundance. Over the Mediterranean, and specifically the eastern part which is characterized by the long-range transport of air pollution and from surrounding urban centers (Kanakidou et al., 2011), the model underestimates the observed concentrations during winter at the Finokalia station in all simulations (Fig. 6a), either due to missing OXL primary and secondary sources, or to a too strong removal. During summer, ERA-Interim satisfactorily simulates the observed OXL levels, also representing the observed trend, which indicates that the model reproduces the mixing and aging of the air masses in the region under favorable meteorological conditions and intense solar radiation. EC-Earth calculates lower OXL concentrations than ERA-Interim, due to the lower oxidizing capacity, underestimating thus the observed concentrations for all seasons. On the other hand, ERA-Interim(sens) tends to underestimate the observations for all seasons more than the other simulations, further indicating the important role of the secondary sources to OXL atmospheric concentrations in the region. At the Puy de Dome site (Fig. 6c), which is located at 1450m asl, ERAInterim underestimates the observed OXL concentrations, although simulates them more realistically compared to EC-Earth, especially during summer (Fig. 2c). The seasonal variation in the area can be explained by the stronger upward transport of air masses during summer (Legrand et al., 2007), increasing thus the OXL production in the region. However, the model fails to represent the observed OXL levels, possibly due to missing sources. The importance of other production pathways, not related to the aqueous-phase GLX oxidation, is demonstrated in the comparison of the observed OXL levels with the ERAInterim(sens) simulation. Again, ERA-Interim(sens) deviates more from measured values than the other simulations. Nevertheless, this indicates that other species may further contribute to OXL production, such as the decay of longer diacids (e.g., azelaic, and malonic acids) (Legrand et al., 2007) that are currently not included in the model. Another reason may be 
the impact of the enhanced cloud LWC in the region, implying a more intense cloud processing compared to other surface sites, and thus, faster oxidation of oxalic acid into $\mathrm{CO}_{2}$ (Ervens et al., 2004) in the model. Finally, at the Azores (Fig. 6e), a site that is characterized by a marine environment, the model tends to underestimate the observed OXL concentrations most of the time, with ERA-Interim presenting again a better skill than other simulations. EC-Earth underestimates the observed concentrations more than ERA-Interim, especially during summertime, and ERA-Interim(sens) simulates the lowest OXL concentrations. The observed OXL levels in the region, however, can be explained either by to the transport of pollutants from the continents or the photochemical production in the region. Thus, the illustrated differences against the observations between EC-Earth and ERA-Interim can be attributed to differences in the oxidizing capacity and in simulated transport of EC-Earth, such as the vertical mixing in the troposphere (e.g., van Noije et al., 2014), that has a further impact on OXL precursors like glyoxal. Furthermore, since the long-range transport is found relatively constant in summer and winter in the region (Legrand et al., 2007), other species of marine origin, such as the unsaturated fatty acids (e.g., linoleic and oleic acids) may also contribute as precursors to the OXL production, especially during summer, but are not included in the model too. We acknowledge that other formation pathways of OXL, primary or secondary, may exist in the atmosphere (e.g., Baboukas et al., 2000). For example, higher DCAs (such as malonic, succinic, glutaric, and adipic acids) may act as precursors for smaller dicarboxylic acids like OXL, both in the gas- (e.g., Kawamura and Ikushima, 1993) and the aqueous phase (e.g., Ervens et al., 2004; Lim et al., 2005; Sorooshian et al., 2006) and could further contribute to atmospheric OXL concentrations.

860 In Fig. 6g, OXL observations reported in the literature are compared with monthly mean simulations. Due to the relatively low resolution of the global model (i.e., $3^{\circ} \times 2^{\circ}$ in longitude by latitude), the spatial variability of urban emissions cannot be not expected to be resolved. Therefore, urban stations are omitted and the comparison is limited to locations representative of background concentrations. All simulations tend to underestimate OXL observations, with lower biases in ERA-Interim (i.e., $\mathrm{nMB}=\sim-46 \%, \mathrm{nRSME}=\sim 117 \%$ ). As expected, for almost all sites the ERA-Interim simulation calculates the highest OXL

865 concentrations and the ERA-Interim(sens) the lowest (i.e., nMB $=\sim-74 \%$, nRSME $=\sim 125 \%$ ). The latter indicates that additional production pathways need to be considered in modeling studies to capture the observed OXL concentrations. ECEarth underestimates the observed concentrations more than ERA-Interim (i.e., nMB $=\sim-64 \%$, nRSME $=\sim 110 \%$ ) but less than ERA-Interim(sens), highlighting the importance of the atmospheric oxidating capacity and atmospheric dynamics in the OXL production. Overall, our analysis indicates that the model either misses OXL sources (primary and secondary) or 870 overestimates OXL sinks especially during winter. Thus, under relatively lower temperatures and irradiation, the model may neither represent well the fast secondary OXL production in wood-burning plumes nor the secondary production through species produced by the oxidation of emitted from vehicles and other anthropogenic activities, such as ethane and aromatic hydrocarbons. 


\subsubsection{Sulfate}

875 The averaged $\mathrm{SO}_{4}{ }^{2-}$ surface concentrations as calculated in EC-Earth for the boreal winter and summer are presented in Fig. 7. During both seasons, high $\mathrm{SO}_{4}{ }^{2-}$-concentrations are simulated near or downwind major anthropogenic emission hotspots, where the vast majority of the surface $\mathrm{SO}_{2}$ emissions from anthropogenic origin occur (e.g., Tsai et al., 2010). Enhanced $\mathrm{SO}_{4}{ }^{2-}$ surface concentrations are also calculated downwind of biomass burning and volcanic eruptions, showing overall the impact of $\mathrm{SO}_{2}$ primary sources and the abundance of cloud water over these latitudes. Over the remote oceans, however, DMS oxidation may significantly contribute to the $\mathrm{SO}_{4}{ }^{2-}$ surface concentrations, as also the sulfur emissions over major shipping routes. The differences of between EC-Earth and EC-Earth-AerChem in the averaged $\mathrm{SO}_{4}{ }^{2}$-surface and zonal mean concentrations are also presented, both for boreal winter (Fig. 7c,e) and summer (Fig. 7d,f). Considering that the EC-Earth version developed for this work is based on the EC-Earth-AerChem model version, the illustrated differences are solely due to the applied chemistry schemes in the model. During boreal winter, the largest differences appear over Eastern Asia, the Middle East, India, and

885 Central Europe. In EC-Earth-AerChem, the gas-phase $\mathrm{SO}_{2}$ oxidation by $\mathrm{OH}$ radicals is roughly $8 \%$ larger than in EC-Earth (see Sect. 3.1.2), leading overall to a lower conversion of $\mathrm{SO}_{2}$ to sulfate in the aqueous phase. Moreover, in our simulations $\mathrm{SO}_{4}{ }^{2-}$ is also produced in deliquesced particles, which partly contribute to $\mathrm{SO}_{4}{ }^{2-}$ atmospheric concentrations, especially over highly populated regions during the boreal winter when sulfur emissions due to anthropogenic activities are enhanced. On the contrary, during boreal summer some differences are illustrated (Fig. 7d) mostly over the Middle East where the EC-Earth-

890 AerChem simulation results in lower $\mathrm{SO}_{4}{ }^{2-}$ concentrations, and over Eastern Asia, where some higher concentrations in ECEarth-AerChem occur. These negative/positive differences can be attributed to differences in oxidizing capacity between the two models, both in the gas and the aqueous phase. Finally, the zonal mean differences indicate higher concentrations in ECEarth in the lower troposphere of the northern hemisphere during boreal winter (Fig.7e), as for the $\mathrm{SO}_{4}{ }^{2-}$ surface concentrations. Again, for boreal summer, no important differences are presented (Fig.7f).

895 Figure 6 further presents the model comparison with $\mathrm{SO}_{4}{ }^{2-}$ surface observations. Sulfate concentrations maximize during intense photochemical activity and high $\mathrm{SO}_{2}$ atmospheric levels, generally suggesting a faster formation rate compared to oxalic acid (Ervens et al., 2004; Legrand et al., 2007). At the Finokalia station in the Mediterranean (Fig. 6b), the model overestimates the observed $\mathrm{SO}_{4}{ }^{2-}$ concentrations during boreal winter and summer in ERA-Interim, probably due to too high $\mathrm{SO}_{2}$ background concentrations owing to the long-range transport from surrounding regions. During winter, EC-Earth better

900 reproduces the observations, probably due to the lower oxidizing capacity compared to ERA-Interim, but in late spring and early summer, the active photochemistry in the region leads to an overestimation of the observed concentrations. The ECEarth-AerChem simulation leads to generally lower concentrations compared to our EC-Earth simulation, tending to somehow underestimate the observed concentrations, except for autumn. At Puy de Dome (Fig. 6d), ERA-Interim, which has a higher cloud liquid water content aloft and a more intense oxidizing capacity compared to EC-Earth, overestimates the observed $\mathrm{SO}_{4}{ }^{2-}$ 905 concentrations in almost in all seasons. In contrast, EC-Earth better simulates the $\mathrm{SO}_{4}{ }^{2-}$ concentrations, although it seems to 
underestimate the observations during summer. At that site, the EC-Earth-AerChem calculations agree well with EC-Earth, although again concentrations are slightly lower. At the Azores (Fig. 6f), ERA-Interim also simulates the observed concentrations well, following the observed annual cycle. In contrast, both EC-Earth and EC-Earth-AerChem underestimate the $\mathrm{SO}_{4}{ }^{2-}$ observations, especially during spring and summer. Note that the $\mathrm{SO}_{4}{ }^{2-}$ production in this marine site is attributed to the $\mathrm{SO}_{2}$ atmospheric levels both from air masses advected from industrialized regions and the local production due to the oxidation of marine DMS emissions. Thus, the differences between ERA-Interim and the other EC-Earth simulations presented in this study may indicate slower aging of the polluted air masses transported in the region. Finally, a comparison of the model's monthly mean predictions with a compilation of $\mathrm{SO}_{4}{ }^{2-}$ observations $(\mathrm{n}=3828)$ around the globe (Daskalakis et al., 2016 ) is presented in Fig. 6h. EC-Earth tends to overestimate the available $\mathrm{SO}_{4}{ }^{2}$-observations, presenting positive biases (i.e., $915 \mathrm{nMB}=\sim 15.9 \%$, nRSME $=\sim 5 \%$ ), that are slightly lower than in ERA-Interim (i.e., nMB $=\sim 23 \%$, nRSME $=\sim 57 \%$ ). In contrast, EC-Earth-AerChem tends to slightly underestimate the observed concentrations (i.e., nMB $=\sim-4.7 \%$, nRSME $=\sim 57$ $\%$ ), showing a slightly lower correlation coefficient $(\mathrm{R}=0.70)$ than $\mathrm{EC}$-Earth (i.e., $\mathrm{R}=\sim 0.76)$ and ERA-Interim (i.e., $\mathrm{R}=$ $\sim 0.75)$.

\subsubsection{Dissolved iron}

Figures 8 and 9 present the averaged dissolved $\mathrm{FeC}(\mathrm{DFeC})$ and $\mathrm{FeD}(\mathrm{DFeD})$ surface concentrations, respectively, for DJF and JJA. EC-Earth calculates an annual global DFeC atmospheric burden of $\sim 0.002 \mathrm{Tg}$, while ERA-Interim calculates slightly higher concentrations $(\sim 0.003 \mathrm{Tg})$ due to the more intense ligand promoted dissolution rates (Table $2 \mathrm{c}$ ). Elevated $\mathrm{DFeC}$ concentrations during boreal winter (Fig. 8a) are calculated over central Africa, eastern Asia, and India, where significant DFe concentrations ( 0.01-0.1 $\mu \mathrm{g} \mathrm{Fe} \mathrm{m}^{-3}$ ) are associated with biomass burning and anthropogenic combustion emissions. During boreal summer (Fig. 8b), the maximum DFeC concentrations are calculated in the Northern latitudes, in particular over the Mediterranean Basin, the Middle East, the Western US, and China. The increase in the surface dissolved Fe concentrations over these regions, ranging from $\sim 0.01-0.1 \mu \mathrm{g} \mathrm{Fe} \mathrm{m}^{-3}$, clearly highlights the anthropogenic contribution due to the enhanced solubilization of Fe when the combustion aerosols are mixed with acidic and organic pollutants during atmospheric transport (Fig. 3b). Due to the intense biomass burning in the Southern Hemisphere (i.e., South America, Central Africa, and Indonesia), the enhanced OXL production rates over such regions (Fig. 2a) lead to higher dissolved Fe concentrations. Figures 8a and 8b demonstrate, overall, that the geographic pattern of the $\mathrm{DFeC}$ concentrations may change from boreal winter to summer, following the biomass burning activity and the atmospheric processing of Fe-containing combustion aerosols of anthropogenic origin.

Mineral dust emissions mostly occur in the mid-latitudes of the Northern Hemisphere (Figs. 9a, b), relatively close to where the vast majority of the population exists and the anthropogenic emissions of acidic compounds dominate. For both seasons, high DFe concentrations from dust occur over the midlatitudes of the Northern Hemisphere, where the major dust sources are located. However, the equatorial maximum during boreal winter tends to shift to the North during boreal summer following 
the migration of the ITCZ (Fig. 9b). DFe from mineral dust aerosols maximize over the major dust source regions, with surface concentrations of roughly 0.1-1 $\mu \mathrm{g} \mathrm{Fe}^{-3}$ (Fig. 9a, b), overall dominating the Fe burden. The outflow from these regions transports DFe over the global oceans, where secondary maxima of $\sim 0.01-0.1 \mu \mathrm{g} \mathrm{Fe} \mathrm{m}^{-3}$ are calculated, mainly over the Northern Hemisphere in the tropical Atlantic Ocean. The dissolved Fe associated with Saharan dust is, nevertheless, attributed to the long-range transport and the atmospheric processing that converts the insoluble Fe minerals to soluble forms.

The differences between the EC-Earth and ERA-Interim are illustrated in the averaged DFeC (Fig. 8c,d) and DFeD (Fig. 9c,d) surface concentrations. The differences in DFeC between the EC-Earth and ERA-Interim are well correlated with those of OXL concentrations (Fig. 5 c,d), indicating the strong impact of ligand-promoted dissolution on the DFeC atmospheric load (Table 2c). Note, however, that the most important relative differences between the two simulations are calculated over regions with low dissolved $\mathrm{FeC}$ concentrations, and consequently the total burden does not change significantly (Table $2 \mathrm{c}$ ). The differences in the DFe concentrations associated with mineral dust aerosols follow the general anomaly pattern of the two model configurations due to differences in transport, leading overall to higher ( $15 \%$ globally) dust emissions in EC-Earth (Fig. S4f).

Figure 10 presents a comparison of the different model simulations with cruise observations of dissolved Fe concentrations. The spatial distributions of the DFe observations for the accumulation, the coarse, and the total suspended aerosols are shown in Fig. 10a-c, respectively. The DFe concentration (mean \pm standard deviation) in the accumulation mode amounts to $3.7 \pm$ $6.4 \mathrm{ng} \mathrm{m}^{-3}$ in the observations, while in EC-Earth and ERA-Interim is $5.8 \pm 5.2 \mathrm{ng} \mathrm{m}^{-3}$ and $5.7 \pm 6.5 \mathrm{ng} \mathrm{m}^{-3}$, respectively. The observed concentration of DFe in the coarse mode is $5.0 \pm 10.9 \mathrm{ng} \mathrm{m}^{-3}$, while in EC-Earth and ERA-Interim the calculated values are around $6.2 \pm 7.3 \mathrm{ng} \mathrm{m}^{-3}$ and $5.7 \pm 10.6 \mathrm{ng} \mathrm{m}^{-3}$. Finally, the concentration of DFe in total suspended particles (tsp) is $7.8 \pm 19.0 \mathrm{ng} \mathrm{m}^{-3}$ in the observations, as well as $12.5 \pm 19.1 \mathrm{ng} \mathrm{m}^{-3}$ and $11.8 \pm 20.4 \mathrm{ng} \mathrm{m}^{-3}$ in EC-Earth and ERA-Interim, respectively. The correlation coefficients between the DFe cruise observations and the model results in EC-Earth and ERAInterim are calculated as $\sim 0.51(\mathrm{nMB}=\sim 58 \%$, nRMSE $=\sim 170 \%)$ and $0.59(\mathrm{nMB}=\sim 56 \%$, nRMSE $=\sim 169 \%)$ for the accumulation aerosols, while for the coarse mode the values are calculated around 0.49 (nMB $=\sim 23 \%$, nRMSE $=\sim 194 \%$ ) and $\sim 0.67(\mathrm{nMB}=\sim 13 \%$, nRMSE $=\sim 174 \%$ ) for EC-Earth and ERA-Interim (Fig. S5).

The spatial distributions of the absolute differences between the simulated DFe concentrations in EC-Earth and the observations are also presented in Fig. 10 d-e. The model shows a general overestimation of the observed DFe concentrations around the tropics (up to $\sim 10 \mathrm{ng} \mathrm{m}^{-3}$ ), but an underestimation at the mid-to-higher latitudes (up to $\sim 5 \mathrm{ng} \mathrm{m}^{-3}$ ). It is, however, unclear why the model is unable to capture the observed concentrations over such regions. Reasons could be the misrepresentation of dust coarse emissions, missing anthropogenic primary Fe emissions, weak secondary sources of the dissolved Fe (especially in the southern latitudes), or even systematic errors in the transport of coarse particles. Over the Pacific, EC-Earth better predicts the average DFe concentrations. For completeness, Fig. S5 also presents a comparison of the simulated and observed TFe concentrations, showing that the model better captures the TFe concentrations in the accumulation 
mode (Fig. S6g) than in coarse mode (Fig. S6h). Considering, however, that the TFe is mostly dominated by primary sources, the calculated differences to the observed concentrations (Fig. S6e-f) downwind continental sources should mainly depict errors in the emission parameterizations, or a misrepresentation in the mineralogical composition of the larger Fe-containing soil particles.

The overestimation around the tropics and the northern latitudes is further illustrated by a comparison of the model predictions with observations as a function of latitude (binned at $2^{\circ}$ ) (Fig. 10g-i). Although the dissolved Fe in the accumulation mode (Fig.10g) is well simulated over the Southern Ocean, the model strongly overestimates the observed concentrations in the tropics especially around the Equator, as well as in the northern extratropics. In contrast, for the coarse and the total suspended aerosols, an underestimation of the DFe aerosol observations in the southern latitudes (i.e., around $30^{\circ}-60^{\circ} \mathrm{S}$ ) is clearly visible for both simulations (Fig. 10h and Fig. 10i), along with an overestimation around the tropics, as for accumulation DFe aerosols. All in all, the differences between the two model configurations are relatively small.

\section{Discussion}

The ocean is a critical component of the Earth's climate system and Fe plays a key role in the efficiency of the biological carbon pump. For this reason, accurate estimates of the bioavailable Fe inputs to the ocean are a prerequisite for climate simulations. Our work attempts at properly simulating the effects of atmospheric multiphase processes on the chemical sources and sinks of the Fe-containing aerosols in an Earth System Model. Indeed, the atmospheric processing of Fe-containing aerosols is rather important for the geographical pattern of DFe deposition fluxes into the ocean, especially in remote regions away from land sources. In agreement with other studies (e.g., Ito et al., 2019; Mahowald et al., 2005; Myriokefalitakis et al., 2018; Scanza et al., 2018), we find that mineral dust is the principal source of atmospheric Fe in EC-Earth (95 $\pm 1 \%$ ), with most of the remaining sources attributable to biomass burning. Focusing on the bioavailable fraction for marine biota, OXL aqueous-phase production is shown to be an important driver of aerosol DFe release, contributing $\sim 44 \%$ to the aerosol Fe dissolution, along with the atmospheric acidity that accounts for $\sim 45 \%$ of total DFe secondary sources in the model. We aim therefore here to realistically represent the atmospheric OXL concentrations to properly simulate the ligand-promoted mineral Fe dissolution.

Present-day simulations indicate that $61.82 \pm 1.29 \mathrm{Tg} \mathrm{yr}^{-1}$ of Fe in EC-Earth is deposited to the Earth's surface, which is 995 towards the low end (40 - $\left.140 \mathrm{Tg} \mathrm{yr}^{-1}\right)$ of the model intercomparison study by Myriokefalitakis et al. (2018). However, the large variability in global models can be partly attributed to the different size ranges considered in the models. Indeed, since most of the Fe mass is associated with coarse dust aerosols ( $\sim 91 \%$ in this work), models that additionally account for supercoarse mineral dust emission sources (i.e., $>10 \mu \mathrm{m}$ in diameter), eventually calculate a higher TFe source and thus increased TFe global deposition rates. In our EC-Earth simulations, roughly $0.88 \pm 0.01 \mathrm{Tg} \mathrm{yr}^{-1}$ of DFe are calculated to be deposited globally (Table 2), in the range of estimates presented in Myriokefalitakis et al. (2018) (0.8 $\left.\pm 0.2 \mathrm{Tg} \mathrm{yr}^{-1}\right)$. Although we do not 
consider a super-coarse mode of dust in our simulations, the DFe deposition rates over the remote ocean are not expected to be severely impacted (Myriokefalitakis et al., 2018), but reaching a firm conclusion in this respect will need further work. Focusing on the marine environment, about $40 \%\left(0.376 \pm 0.005 \mathrm{Tg} \mathrm{yr}^{-1}\right)$ of the simulated DFe is deposited into the global ocean, indicating that a large fraction of Fe atmospheric inputs to the global ocean results from the dissolution of atmospheric aerosols. Our calculations are close to the high-end of other global estimates $\left(0.173-0.419 \mathrm{Tg} \mathrm{yr}^{-1}\right)$ as presented in the model intercomparison study of Myriokefalitakis et al. (2018), and slightly higher than the respective DFe deposition fluxes in Ito et al. (2021) $\left(\sim 0.271 \mathrm{Tg} \mathrm{yr}^{-1}\right)$. The Fe-containing dust aerosols dominate $(\sim 70 \%)$ the total deposition fluxes over the ocean in the model, although combustion sources are calculated to have a significant impact over remote oceanic regions, such as the Pacific and the Southern Oceans. The average Fe solubility at the deposition of combustion aerosols is $\sim 19 \%$ (Fig. 11a), much higher compared to the solubility of mineral dust aerosols ( $2 \%$; Fig. 11b), clearly indicating the importance of atmospheric processing on the potential bioavailable inputs to the global ocean. Indeed, our simulations show high Fe solubilities far from continental regions, such as the tropical Pacific and Atlantic Oceans (Fig. 11c), due to aerosol aging and lower Fe concentrations. Overall, the maximum DFe deposition fluxes occur in EC-Earth downwind of the main desert source regions, with high deposition rates being also simulated in the outflow of tropical biomass burning regions (such as South America,

1015 Africa, and Indonesia), as well as over highly populated regions due to the Fe released from anthropogenic combustion processes in the presence of polluted air masses (such as in India and China).

\section{Summary and conclusions}

This work documents the implementation of a detailed multiphase chemistry scheme in the EC-Earth3 Earth system model, aiming to provide consistent estimates of the atmospheric concentrations of the Fe-containing aerosols, along with the species that modulate its atmospheric processing, i.e., $\mathrm{OXL}$ and $\mathrm{SO}_{4}{ }^{2-}$. For this, a comprehensive description of the atmospheric $\mathrm{Fe}$ cycle is included in the model, accounting for 1) an explicit soil mineralogy, 2) the contribution of combustion emissions, and 3) an atmospheric dissolution scheme that accounts for atmospheric acidity, ambient levels of OXL, and photoinduced processes. The multiphase chemistry scheme simulates the aqueous-phase processes of the troposphere for inorganic and organic compounds, along with Fenton reaction. The KPP software is used in the model to integrate the aqueous-phase and the dissolution equations, which adds flexibility to the code. Overall, simulations of tropospheric chemistry and aerosols for present-day conditions (2000-2014) have been realized, and budget calculations for OXL, $\mathrm{SO}_{4}^{2-}$, and the DFe-containing aerosols have been presented.

Model simulations have been performed both as a coupled system with IFS as well as driven by offline meteorological fields from the ERA-Interim reanalysis. Budget analysis has shown that glyoxal is the main precursor of OXL in the atmosphere $1030(\sim 74 \%)$, and that the potential primary sources in the model $\left(0.373 \pm 0.005 \mathrm{Tg} \mathrm{yr}^{-1}\right)$ have a negligible impact on OXL concentrations. Moreover, laboratory-derived aqueous-phase production of OXL due to glyoxal oxidation pathways is also 
accounted in our simulations. We have shown that when these pathways are omitted in the simulations, the calculated global OXL atmospheric concentrations can be substantially lowered ( 43\%). For the ERA-Interim set-up, the OXL net chemical production is calculated as $12.61 \pm 0.06 \mathrm{Tg} \mathrm{yr}^{-1}$, resulting in an atmospheric burden of $\sim 0.33 \mathrm{Tg}$. For the online-coupled system, however, the OXL net chemical production is $\sim 30 \%$ lower, mainly attributed to a lower atmospheric OH abundance in ECEarth due to biases that can be generally found in climate-chemistry models, such as in temperature and humidity especially in the higher altitudes. Overall, the simulated oxidizing capacity along with the contribution of secondary sources other than the GLX oxidation are shown to have a significant impact on the OXL atmospheric abundance. However, we acknowledge that other formation pathways of OXL, primary or secondary, may exist in the gas- and the aqueous phases of the atmosphere that could further contribute to OXL levels.

The dissolution of dust and combustion aerosols dominates on the dissolved Fe fraction in the model, calculated in EC-Earth at $0.806 \pm 0.014 \mathrm{Tg} \mathrm{Fe} \mathrm{yr}^{-1}$, in good agreement with the ERA-Interim simulation and well in the range of other model estimates. Furthermore, a broad evaluation of the EC-Earth proves the models' ability to represent AOD, particularly over regions that are dominated by anthropogenic aerosol, but also over selected dusty sites, in line with previous EC-Earth evaluations. 1045 However, dust is underestimated over remote areas. The model generally underestimates the in-situ OXL measurements, especially during winter, indicating that additional sources (primary and/or secondary) are needed to realistically simulate the atmospheric OXL concentrations. Model comparisons with cruise measurements demonstrate a strong link between atmospheric DFe concentrations and atmospheric composition. The model seems to better capture the observations in the accumulation mode than in the coarse mode. This is attributed to differences either in the atmospheric processing between the accumulation and coarse particles (i.e., aerosol water content and acidity levels), the misrepresentation in the aerosol sizes (e.g., surface area/volume ratios), or in systematic errors in the mineralogical composition of the emitted Fe-containing soil particles. For this, several developments are planned, aiming to improve the representation of the dust aerosols' size distribution, the description of the mineralogical composition, and the Fe-content in combustion sources, which are expected to reduce the existing uncertainties in the model for a more accurate simulation of the atmospheric $\mathrm{Fe}$ cycle.

1055 Emphasizing on the biogeochemistry-related implications of this study, EC-Earth calculates a global annual present-day DFe

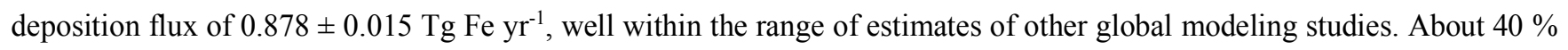
of the DFe deposition fluxes are calculated to occur over the global ocean with a strong spatial and temporal variability. The highest annual mean DFe inputs to the global ocean are associated with aerosols of soil origin, especially downwind of the major dust source regions. In addition, Fe-containing combustion aerosols are calculated to have a significant contribution downwind of biomass burning source regions and highly populated areas in the Northern Hemisphere. It is further demonstrated that over the open ocean the Fe solubility in deposition for aerosols of combustion origin is about an order of magnitude higher than that of mineral dust origin, indicating that the relative contributions of the primary sources can 
significantly affect bioavailable aerosol fraction and may thus play an important role in oceanic areas where the phytoplankton growth is limited by Fe supply, such as the Southern Ocean.

1065 It is widely recognized that a combined approach considering both $\mathrm{Fe}$ atmospheric processing and deposition over oceans should ideally be used in Earth System Models for the assessment of the impact of nutrient-containing aerosol deposition on marine productivity. A deeper understanding of the atmospheric Fe cycle is thus needed for a better description of the biogeochemistry implications in the presence of a changing climate. Such type of knowledge, however, should be obtained by extensive model evaluation with observations, especially over the remote regions of the world like the Southern Ocean, where 1070 currently the largest discrepancies between models and measurements exist. Therefore, a comprehensive calculation of the Fe physicochemical transformations is necessary to predict the strength of DFe inputs to the ocean, despite the complexity of the related atmospheric multiphase processes. The present study complements, thus, the marine biogeochemistry component of EC-Earth by a fully coupled calculation scheme for atmospheric dissolved Fe fluxes into the global ocean. This EC-Earth model version is expected to eventually allow for a better representation of the marine biogeochemistry perturbations in past 1075 and future climates and air-quality. 
https://doi.org/10.5194/gmd-2021-357

Preprint. Discussion started: 10 November 2021

(c) Author(s) 2021. CC BY 4.0 License.

\section{Appendix A}

Table A1. Summary of statistics for all points and per region (as depicted in Fig. 1) for the evaluation of a) the modeled annual mean AOD at $550 \mathrm{~nm}$ against AERONET version 3 level 2.0 retrievals for all available stations covering the 2000-2014 period, b) same but for selected dust-dominated AERONET sites (characterized as described in Sect. 2.5), c) the modeled annual mean dust surface concentration for 2000-2014 compared to climatological mean values from RSMA sites and AMMA campaign, and d) the modeled annual dust deposition flux averaged for the period 2000-2014 against observations compiled in Albani et al. (2014) from several sources. The number of stations ( $n$ ), the Pearsons' correlation coefficients $(R)$ between the simulated and measured monthly mean concentrations, the normalized mean bias (nMB), and the normalized root mean square errors (nRMSE) are indicated for the EC-

\begin{tabular}{|c|c|c|c|c|}
\hline & n & $\mathbf{R}$ & nMB (\%) & nRSME (\%) \\
\hline \multicolumn{5}{|l|}{ a) $\mathrm{AOD}(550 \mathrm{~nm})$} \\
\hline N. America & 208 & & -8.8 & 40.9 \\
\hline C. America & 41 & & -2.8 & 33.1 \\
\hline S. America & 41 & & -13.3 & 54.2 \\
\hline Europe & 159 & & -9.9 & 26.9 \\
\hline N. Africa & 27 & & 21.6 & 44.6 \\
\hline S. Africa & 15 & & -35.0 & 61.8 \\
\hline W. Asia & 49 & & -21.5 & 36.6 \\
\hline E. Asia & 162 & & -8.9 & 38.4 \\
\hline Australian Ocean & 26 & & -21.7 & 110.8 \\
\hline Remote oceans & 10 & & 22.9 & 54.2 \\
\hline All points & 738 & 0.8 & -9.1 & 45.7 \\
\hline \multicolumn{5}{|c|}{ b) $\operatorname{AOD}(550 \mathrm{~nm})$ - dust-dominated sites } \\
\hline C. America & 2 & & -26.5 & 49.7 \\
\hline N. Africa & 18 & & 21.5 & 43.2 \\
\hline S. Africa & 1 & & -15.4 & 15.4 \\
\hline W. Asia & 12 & & -22.5 & 29.5 \\
\hline E. Asia & 5 & & -8.7 & 14.5 \\
\hline All sites & 38 & 0.76 & 2.7 & 37.2 \\
\hline \multicolumn{5}{|c|}{ c) Dust surface concentrations } \\
\hline N. America & 1 & & -74.2 & 74.2 \\
\hline C. America & 2 & & -37.5 & 38.7 \\
\hline Europe & 2 & & -90.8 & 116.6 \\
\hline N. Africa & 4 & & 21.9 & 37.7 \\
\hline E. Asia & 2 & & 71.8 & 82.2 \\
\hline Australian Ocean & 3 & & -42.0 & 81.5 \\
\hline S. Pacific Ocean & 3 & & -60.3 & 68.5 \\
\hline N. Pacific Ocean & 4 & & 89.9 & 132.7 \\
\hline Southern Ocean & 2 & & -98.5 & 112.7 \\
\hline All points & 23 & 0.99 & 19.3 & 81.2 \\
\hline \multicolumn{5}{|c|}{ d) Dust deposition rates } \\
\hline N. America & 7 & & -96.8 & 130.6 \\
\hline C. America & 3 & & -59.6 & 97.6 \\
\hline S. America & 1 & & -99.6 & 99.6 \\
\hline Europe & 14 & & -94.5 & 137.1 \\
\hline N. Africa & 23 & & -56.4 & 142.2 \\
\hline S. Africa & 4 & & -91.2 & 109.3 \\
\hline W. Asia & 5 & & -94.7 & 164.4 \\
\hline E. Asia & 14 & & -25.2 & 94 \\
\hline Australian Ocean & 9 & & -98.3 & 201.1 \\
\hline S. Pacific Ocean & 2 & & -92.0 & 93.2 \\
\hline N. Pacific Ocean & 13 & & 90.5 & 148.9 \\
\hline Southern Ocean & 15 & & -91.9 & 205.0 \\
\hline All points & 110 & 0.75 & -61.2 & 204.0 \\
\hline
\end{tabular}


https://doi.org/10.5194/gmd-2021-357

Preprint. Discussion started: 10 November 2021

(c) Author(s) 2021. CC BY 4.0 License.

(c) (i)

Table A2. Summary of statistics for the evaluation of the simulated concentrations of a) oxalate, b) sulfate, as well as for c,d,e) the dissolved and $\mathbf{f , g}, \mathrm{h}$ ) the total Fe-containing aerosols for $\mathrm{c}, \mathrm{f})$ the accumulation mode, $\mathrm{d}, \mathrm{g}$ ) the coarse mode and e,h) the total suspended particles (tsp), respectively. The number of stations $(n)$, the linear correlation coefficients $(R)$ between the simulated and the measured concentrations, the normalized mean bias (nMB) and the normalized root mean square errors (nRMSE) are indicated for the EC-Earth and ERA-Interim simulation. The results for the sensitivity simulation EC-Earth(sens) for oxalate evaluation and the EC-Earth(AerChem-AMIP) for sulfate evaluation are also shown.

\begin{tabular}{|c|c|c|c|c|}
\hline & $\mathbf{n}$ & $\mathbf{R}$ & nMB (\%) & nRSME (\%) \\
\hline \multicolumn{5}{|l|}{ a) Oxalate } \\
\hline EC-Earth & \multirow{3}{*}{143} & 0.48 & -64.18 & 116.97 \\
\hline ERA-Interim & & 0.45 & -45.96 & 110.31 \\
\hline ERA-Interim(sens) & & 0.44 & -73.66 & 124.89 \\
\hline \multicolumn{5}{|l|}{ b) Sulfate } \\
\hline EC-Earth & \multirow{3}{*}{3828} & 0.76 & 15.89 & 55.20 \\
\hline ERA-Interim & & 0.75 & 22.83 & 57.19 \\
\hline ERA-Interim(AerChem-AMIP) & & 0.70 & -4.69 & 57.05 \\
\hline \multicolumn{5}{|c|}{ c) Dissolved Fe (accumulation mode) } \\
\hline EC-Earth & \multirow{2}{*}{438} & 0.51 & 57.56 & 169.91 \\
\hline ERA-Interim & & 0.59 & 56.43 & 169.45 \\
\hline \multicolumn{5}{|l|}{ d) Dissolved Fe (coarse mode) } \\
\hline EC-Earth & \multirow{2}{*}{439} & 0.49 & 22.91 & 193.64 \\
\hline ERA-Interim & & 0.67 & 12.87 & 174.47 \\
\hline \multicolumn{5}{|l|}{ e) Dissolved Fe (tsp) } \\
\hline EC-Earth & \multirow{2}{*}{955} & 0.29 & 59.87 & 297.30 \\
\hline ERA-Interim & & 0.35 & 51.21 & 292.41 \\
\hline \multicolumn{5}{|l|}{ f) Total Fe (accumulation mode) } \\
\hline EC-Earth & \multirow{2}{*}{92} & 0.58 & 21.03 & 170.45 \\
\hline ERA-Interim & & 0.76 & -31.26 & 152.89 \\
\hline \multicolumn{5}{|l|}{ g) Total Fe (coarse mode) } \\
\hline EC-Earth & \multirow{2}{*}{83} & 0.51 & 60.83 & 206.87 \\
\hline ERA-Interim & & 0.58 & 25.35 & 178.39 \\
\hline \multicolumn{5}{|l|}{ h) Total Fe (tsp) } \\
\hline EC-Earth & \multirow{2}{*}{796} & 0.45 & 191.69 & 623.14 \\
\hline ERA-Interim & & 0.47 & 115.75 & 805.95 \\
\hline
\end{tabular}




\section{Code availability}

Access to the model code is restricted to institutes that have signed a memorandum of understanding with the EC-Earth community and a software license agreement with the ECMWF. Confidential access to the code can be granted to editors and reviewers.

\section{Data availability}

Specific fields can be made available by the authors upon request.

\section{Author contribution}

SM developed the aqueous-phase chemistry and the iron-dissolution schemes, designed the experiments, and performed the ERA-Interim simulations. EBM, MGA, and CPGP developed the mineralogy applied to dust emissions, co-designed the $\lfloor 105$ experiments, and performed the EC-Earth simulations. AI provided the Fe-containing combustion aerosol emissions. AN provided the ISORROPIA II code. Other co-authors contributed to the development of specific aspects of the model or parts of the code that are shared with EC-Earth3. SM wrote the paper with input from all co-authors.

\section{Competing interests}

The authors declare that they have no conflict of interest.

\section{$\lfloor 110$ Acknowledgments}

Stelios Myriokefalitakis, Evangelos Gerasopoulos, and Maria Kanakidou acknowledge support by the project "PANhellenic infrastructure for Atmospheric Composition and climatE change" (MIS 5021516) implemented under the Action "Reinforcement of the Research and Innovation Infrastructure", funded by the Operational Programme "Competitiveness, Entrepreneurship and Innovation" (NSRF 2014-2020) and co-financed by Greece and the European Union (European Regional

1115 Development Fund). This work was supported by computational time granted from the National Infrastructures for Research and Technology S.A. (GRNET S.A.) in the National HPC facility - ARIS - under project ID 010003 (ANION). Elisa BergasMassó, María Gonçalves-Ageitos, and Carlos Pérez García-Pando thankfully acknowledge the computer resources at Marenostrum4, granted through the PRACE project eFRAGMENT3 and the RES project AECT-2020-3-0020; as well as the technical support provided by the Barcelona Supercomputing Center (BSC) and the CES team of the Earth Sciences $\lfloor 120$ Department. Their work was supported by the ERC Consolidator Grant FRAGMENT (grant agreement No. 773051), and the AXA Chair on Sand and Dust Storms at BSC funded by the AXA Research Fund both led by Carlos Pérez García-Pando, who 
also acknowledges the Ramon y Cajal program (grant RYC-2015-18690) of the Spanish Ministry of Science, Innovation and Universities, and the ICREA program. The research leading to these results has also received funding from the Spanish Ministerio de Economía y Competitividad as part of the NUTRIENT project (CGL2017-88911-R) and the H2020 GA 821205

$\lfloor 125$ project FORCeS. Support for this research was provided to A.I. by JSPS KAKENHI Grant Number 20H04329, Integrated Research Program for Advancing Climate Models (TOUGOU) Grant Number JPMXD0717935715 from the Ministry of Education, Culture, Sports, Science and Technology (MEXT), Japan. Twan van Noije, Philippe Le Sager, and Maria Kanakidou acknowledge funding from the European Union's 2020 research and innovation programme under grant agreement No. 821205 (FORCeS)". Maria Kanakidou acknowledges support by the Deutsche Forschungsgemeinschaft (DFG, German $\lfloor 130$ Research Foundation) under Germany's Excellence Strategy (University Allowance, EXC 2077, University of Bremen). Maarten C. Krol is supported by the European Research Council (ERC) under the European Union's Horizon 2020 research and innovation program under grant agreement no. 742798 - COS-OCS. Model development was carried out on the GRNET HPC ARIS high-performance computer facility and model simulations were performed at the GRNET HPC ARIS and the BSC Marenostrum4 supercomputer. 


\section{References}

Aan de Brugh, J. M. J., Schaap, M., Vignati, E., Dentener, F., Kahnert, M., Sofiev, M., Huijnen, V. and Krol, M. C.: The European aerosol budget in 2006, Atmos. Chem. Phys., 11(3), 1117-1139, doi:10.5194/acp-11-1117-2011, 2011.

Adebiyi, A. A. and Kok, J. F.: Climate models miss most of the coarse dust in the atmosphere, Sci. Adv., 6(15), eaaz9507, doi:10.1126/sciadv.aaz9507, 2020.

Albani, S., Mahowald, N. M., Perry, A. T., Scanza, R. A., Zender, C. S., Heavens, N. G., Maggi, V., Kok, J. F. and OttoBliesner, B. L.: Improved dust representation in the Community Atmosphere Model, J. Adv. Model. Earth Syst., 6(3), 541570, doi:10.1002/2013MS000279, 2014.

Alexander, B., Park, R. J., Jacob, D. J. and Gong, S.: Transition metal-catalyzed oxidation of atmospheric sulfur: Global l145 implications for the sulfur budget, J. Geophys. Res., 114(D2), D02309, doi:10.1029/2008JD010486, 2009.

Altieri, K. E., Carlton, A. G., Lim, H.-J., Turpin, B. J. and Seitzinger, S. P.: Evidence for Oligomer Formation in Clouds: Reactions of Isoprene Oxidation Products, Environ. Sci. Technol., 40(16), 4956-4960, doi:10.1021/es052170n, 2006.

Altieri, K. E., Seitzinger, S. P., Carlton, A. G., Turpin, B. J., Klein, G. C. and Marshall, A. G.: Oligomers formed through incloud methylglyoxal reactions: Chemical composition, properties, and mechanisms investigated by ultra-high resolution FTICR mass spectrometry, Atmos. Environ., 42(7), 1476-1490, doi:10.1016/j.atmosenv.2007.11.015, 2008.

Alvarado, L. M. A., Richter, A., Vrekoussis, M., Hilboll, A., Kalisz Hedegaard, A. B., Schneising, O. and Burrows, J. P.: Unexpected long-range transport of glyoxal and formaldehyde observed from the Copernicus Sentinel-5 Precursor satellite during the 2018 Canadian wildfires, Atmos. Chem. Phys., 20(4), 2057-2072, doi:10.5194/acp-20-2057-2020, 2020.

Arimoto, R., Duce, R. A., Ray, B. J., Ellis, W. G., Cullen, J. D. and Merrill, J. T.: Trace elements in the atmosphere over the l155 North Atlantic, J. Geophys. Res. Atmos., 100(D1), 1199-1213, doi:10.1029/94JD02618, 1995.

Athanasopoulou, E., Tombrou, M., Pandis, S. N. and Russell, A. G.: The role of sea-salt emissions and heterogeneous chemistry in the air quality of polluted coastal areas, Atmos. Chem. Phys., 8(19), 5755-5769, doi:10.5194/acp-8-5755-2008, 2008.

Athanasopoulou, E., Protonotariou, A., Papangelis, G., Tombrou, M., Mihalopoulos, N. and Gerasopoulos, E.: Long-range $\lfloor 160$ transport of Saharan dust and chemical transformations over the Eastern Mediterranean, Atmos. Environ., 140, 592-604, doi:10.1016/j.atmosenv.2016.06.041, 2016.

Aumont, O., Ethé, C., Tagliabue, A., Bopp, L. and Gehlen, M.: PISCES-v2: an ocean biogeochemical model for carbon and ecosystem studies, Geosci. Model Dev., 8(8), 2465-2513, doi:10.5194/gmd-8-2465-2015, 2015.

Baboukas, E. D., Kanakidou, M. and Mihalopoulos, N.: Carboxylic acids in gas and particulate phase above the Atlantic 
Ocean, J. Geophys. Res. Atmos., 105(D11), 14459-14471, doi:10.1029/1999JD900977, 2000.

Baker, A. R. and Jickells, T. D.: Atmospheric deposition of soluble trace elements along the Atlantic Meridional Transect (AMT), Prog. Oceanogr., 158, 41-51, doi:10.1016/j.pocean.2016.10.002, 2017.

Balsamo, G., Viterbo, P., Beijaars, A., van den Hurk, B., Hirschi, M., Betts, A. K. and Scipal, K.: A revised hydrology for the ECMWF model: Verification from field site to terrestrial water storage and impact in the integrated forecast system, J. Hydrometeorol., 10(3), 623-643, doi:10.1175/2008JHM1068.1, 2009.

Barth, M. C., Sillman, S., Hudman, R., Jacobson, M. Z., Kim, C.-H., Monod, A. and Liang, J.: Summary of the cloud chemistry modeling intercomparison: Photochemical box model simulation, J. Geophys. Res., 108(D7), 4214, doi:10.1029/2002JD002673, 2003.

Bianco, A., Passananti, M., Brigante, M. and Mailhot, G.: Photochemistry of the Cloud Aqueous Phase: A Review, Molecules, 175 25(2), 423, doi:10.3390/molecules25020423, 2020.

Bibi, I., Singh, B. and Silvester, E.: Dissolution kinetics of soil clays in sulfuric acid solutions: Ionic strength and temperature effects, Appl. Geochemistry, 51, 170-183, doi:10.1016/j.apgeochem.2014.10.004, 2014.

Blando, J. D. and Turpin, B. J.: Secondary organic aerosol formation in cloud and fog droplets: a literature evaluation of plausibility, Atmos. Environ., 34(10), 1623-1632, doi:10.1016/S1352-2310(99)00392-1, 2000.

$\lfloor 180$ Bougiatioti, A., Nikolaou, P., Stavroulas, I., Kouvarakis, G., Weber, R., Nenes, A., Kanakidou, M. and Mihalopoulos, N.: Particle water and $\mathrm{pH}$ in the eastern Mediterranean: source variability and implications for nutrient availability, Atmos. Chem. Phys., 16(7), 4579-4591, doi:10.5194/acp-16-4579-2016, 2016.

Bowie, A. R., Lannuzel, D., Remenyi, T. A., Wagener, T., Lam, P. J., Boyd, P. W., Guieu, C. C., Townsend, A. T. and Trull, T. W.: Biogeochemical iron budgets of the Southern Ocean south of Australia: Decoupling of iron and nutrient cycles in the L185 subantarctic zone by the summertime supply, Global Biogeochem. Cycles, 23(4), GB4034, doi:10.1029/2009GB003500, 2009. Bräuer, P., Tilgner, A., Wolke, R. and Herrmann, H.: Mechanism development and modelling of tropospheric multiphase halogen chemistry: The CAPRAM Halogen Module 2.0 (HM2), J. Atmos. Chem., 70(1), 19-52, doi:10.1007/s10874-0139249-6, 2013.

Calvert, J. G., Lazrus, A., Kok, G. L., Heikes, B. G., Walega, J. G., Lind, J. and Cantrell, C. A.: Chemical mechanisms of acid $\lfloor 190$ generation in the troposphere, Nature, 317(6032), 27-35, doi:10.1038/317027a0, 1985.

Cao, F., Zhang, S. C., Kawamura, K., Liu, X., Yang, C., Xu, Z., Fan, M., Zhang, W., Bao, M., Chang, Y., Song, W., Liu, S., Lee, X., Li, J., Zhang, G. and Zhang, Y. L.: Chemical characteristics of dicarboxylic acids and related organic compounds in PM2.5 during biomass-burning and non-biomass-burning seasons at a rural site of Northeast China, Environ. Pollut., 231, 
654-662, doi:10.1016/j.envpol.2017.08.045, 2017.

1195 Cappiello, A., De Simoni, E., Fiorucci, C., Mangani, F., Palma, P., Trufelli, H., Decesari, S., Facchini, M. C. and Fuzzi, S.: Molecular Characterization of the Water-Soluble Organic Compounds in Fogwater by ESIMS/MS, Environ. Sci. Technol., 37(7), 1229-1240, doi:10.1021/es0259990, 2003.

Carlton, A. G., Turpin, B. J., Lim, H.-J., Altieri, K. E. and Seitzinger, S.: Link between isoprene and secondary organic aerosol (SOA): Pyruvic acid oxidation yields low volatility organic acids in clouds, Geophys. Res. Lett., 33(6), L06822, doi:10.1029/2005GL025374, 2006.

Carlton, A. G., Turpin, B. J., Altieri, K. E., Seitzinger, S., Reff, A., Lim, H.-J. and Ervens, B.: Atmospheric oxalic acid and SOA production from glyoxal: Results of aqueous photooxidation experiments, Atmos. Environ., 41(35), 7588-7602, doi:10.1016/j.atmosenv.2007.05.035, 2007.

Carlton, A. G., Wiedinmyer, C. and Kroll, J. H.: A review of Secondary Organic Aerosol (SOA) formation from isoprene, Atmos. Chem. Phys., 9(14), 4987-5005, doi:10.5194/acp-9-4987-2009, 2009.

Chameides, W. L. and Davis, D. D.: Aqueous-phase source of formic acid in clouds, Nature, 304(5925), 427-429, doi:10.1038/304427a0, 1983.

Chen, H. and Grassian, V. H.: Iron Dissolution of Dust Source Materials during Simulated Acidic Processing: The Effect of Sulfuric, Acetic, and Oxalic Acids, Environ. Sci. Technol., 130829091001000, doi:10.1021/es401285s, 2013.

1210 Chen, H., Laskin, A., Baltrusaitis, J., Gorski, C. A., Scherer, M. M. and Grassian, V. H.: Coal Fly Ash as a Source of Iron in Atmospheric Dust, Environ. Sci. Technol., 46(4), 2112-2120, doi:10.1021/es204102f, 2012.

Christian, T. J., Kleiss, B., Yokelson, R. J., Holzinger, R., Crutzen, P. J., Hao, W. M., Saharjo, B. H. and Ward, D. E.: Comprehensive laboratory measurements of biomass-burning emissions: 1. Emissions from Indonesian, African, and other fuels, J. Geophys. Res., 108(D23), 4719, doi:10.1029/2003JD003704, 2003.

1215 Claquin, T., Schulz, M. and Balkanski, Y. J.: Modeling the mineralogy of atmospheric dust sources, J. Geophys. Res. Atmos., 104(D18), 22243-22256, doi:10.1029/1999JD900416, 1999.

Collett, J. L. J., Hoag, K. J., Rao, X. and Pandis, S. N.: Internal acid buffering in San Joaquin Valley fog drops and its influence on aerosol processing, Atmos. Environ., 33(29), 4833-4847, doi:10.1016/S1352-2310(99)00221-6, 1999.

Cong, Z., Kawamura, K., Kang, S. and Fu, P.: Penetration of biomass-burning emissions from South Asia through the Himalayas: new insights from atmospheric organic acids, Sci. Rep., 5(1), 9580, doi:10.1038/srep09580, 2015.

Craig, A., Valcke, S. and Coquart, L.: Development and performance of a new version of the OASIS coupler, OASIS3MCT_3.0, Geosci. Model Dev., 10(9), 3297-3308, doi:10.5194/gmd-10-3297-2017, 2017. 
Damian, V., Sandu, A., Damian, M., Potra, F. and Carmichael, G. R.: The kinetic preprocessor KPP-a software environment for solving chemical kinetics, Comput. Chem. Eng., 26(11), 1567-1579, doi:10.1016/S0098-1354(02)00128-X, 2002.

Daskalakis, N., Tsigaridis, K., Myriokefalitakis, S., Fanourgakis, G. S. and Kanakidou, M.: Large gain in air quality compared to an alternative anthropogenic emissions scenario, Atmos. Chem. Phys., 16(15), 9771-9784, doi:10.5194/acp-16-9771-2016, 2016.

Dee, D. P., Uppala, S. M., Simmons, A. J., Berrisford, P., Poli, P., Kobayashi, S., Andrae, U., Balmaseda, M. A., Balsamo, G., Bauer, P., Bechtold, P., Beljaars, A. C. M., van de Berg, L., Bidlot, J., Bormann, N., Delsol, C., Dragani, R., Fuentes, M., Geer, A. J., Haimberger, L., Healy, S. B., Hersbach, H., Hólm, E. V, Isaksen, L., Kållberg, P., Köhler, M., Matricardi, M., McNally, A. P., Monge-Sanz, B. M., Morcrette, J.-J., Park, B.-K., Peubey, C., de Rosnay, P., Tavolato, C., Thépaut, J.-N., Vitart, F., Berg, L. Van De, Bidlot, J., Bormann, N., Delsol, C., Dragani, R., Fuentes, M., Geer, A. J. and Dee, D. P.: The ERA-Interim reanalysis: configuration and performance of the data assimilation system, Q. J. R. Meteorol. Soc., 137(656), 553-597, doi:10.1002/qj.828, 2011.

Deguillaume, L., Leriche, M., Monod, A. and Chaumerliac, N.: The role of transition metal ions on $\mathrm{HO}_{\mathrm{x}}$ radicals in clouds: a numerical evaluation of its impact on multiphase chemistry, Atmos. Chem. Phys., 4(1), 95-110, doi:10.5194/acp-4-95-2004, 2004.

Deguillaume, L., Tilgner, A., Schrödner, R., Wolke, R., Chaumerliac, N. and Herrmann, H.: Towards an operational aqueous phase chemistry mechanism for regional chemistry-transport models: CAPRAM-RED and its application to the COSMOMUSCAT model, J. Atmos. Chem., 64(1), 1-35, doi:10.1007/s10874-010-9168-8, 2009.

Deguillaume, L., Desboeufs, K. V., Leriche, M., Long, Y. and Chaumerliac, N.: Effect of iron dissolution on cloud chemistry: from laboratory measurements to model results, Atmos. Pollut. Res., 1(4), 220-228, doi:10.5094/APR.2010.029, 2010.

Donaldson, D. J. and Valsaraj, K. T.: Adsorption and Reaction of Trace Gas-Phase Organic Compounds on Atmospheric Water Film Surfaces: A Critical Review, Environ. Sci. Technol., 44(3), 865-873, doi:10.1021/es902720s, 2010.

Döscher, R., Acosta, M., Alessandri, A., Anthoni, P., Arneth, A., Arsouze, T., Bergmann, T., Bernadello, R., Bousetta, S., Caron, L.-P., Carver, G., Castrillo, M., Catalano, F., Cvijanovic, I., Davini, P., Dekker, E., Doblas-Reyes, F., Docquier, D., Echevarria, P., Fladrich, U., Fuentes-Franco, R., Gröger, M., v. Hardenberg, J., Hieronymus, J., Karami, M. P., Keskinen, J.P., Koenigk, T., Makkonen, R., Massonnet, F., Ménégoz, M., Miller, P., Moreno-Chamarro, E., Nieradzik, L., van Noije, T., Nolan, P., O’Donnell, D., Ollinaho, P., van den Oord, G., Ortega, P., Prims, O. T., Ramos, A., Reerink, T., Rousset, C., Ruprich-Robert, Y., Le Sager, P., Schmith, T., Schrödner, R., Serva, F., Sicardi, V., Sloth Madsen, M., Smith, B., Tian, T., Tourigny, E., Uotila, P., Vancoppenolle, M., Wang, S., Wårlind, D., Willén, U., Wyser, K., Yang, S., Yepes-Arbós, X. and Zhang, Q.: The EC-Earth3 Earth System Model for the Climate Model Intercomparison Project 6, Geosci. Model Dev. Discuss., in review, 1-90, doi:10.5194/gmd-2020-446, 2021. 
Eliason, T. L., Aloisio, S., Donaldson, D. J., Cziczo, D. J. and Vaida, V.: Processing of unsaturated organic acid films and aerosols by ozone, Atmos. Environ., 37(16), 2207-2219, doi:10.1016/S1352-2310(03)00149-3, 2003.

Ervens, B. and Volkamer, R.: Glyoxal processing by aerosol multiphase chemistry: towards a kinetic modeling framework of secondary organic aerosol formation in aqueous particles, Atmos. Chem. Phys., 10(17), 8219-8244, doi:10.5194/acp-10-82192010, 2010.

Ervens, B., George, C., Williams, J. E., Buxton, G. V., Salmon, G. A., Bydder, M., Wilkinson, F., Dentener, F., Mirabel, P., Wolke, R. and Herrmann, H.: CAPRAM 2.4 (MODAC mechanism): An extended and condensed tropospheric aqueous phase mechanism and its application, J. Geophys. Res., 108(D14), 4426, doi:10.1029/2002JD002202, 2003.

Ervens, B., Feingold, G., Frost, G. J. and Kreidenweis, S. M.: A modeling study of aqueous production of dicarboxylic acids: 1. Chemical pathways and speciated organic mass production, J. Geophys. Res., 109(D15), D15205, doi:10.1029/2003JD004387, 2004.

1265 Eyring, V., Bony, S., Meehl, G. A., Senior, C. A., Stevens, B., Stouffer, R. J. and Taylor, K. E.: Overview of the Coupled Model Intercomparison Project Phase 6 (CMIP6) experimental design and organization, Geosci. Model Dev., 9(5), 19371958, doi:10.5194/gmd-9-1937-2016, 2016.

Fountoukis, C. and Nenes, A.: ISORROPIA II: a computationally efficient thermodynamic equilibrium model for K+-Ca2+ $-\mathrm{Mg} 2+-\mathrm{NH} 4+-\mathrm{Na}+-\mathrm{SO} 4=-\mathrm{NO} 3--\mathrm{Cl}--\mathrm{H} 2 \mathrm{O}$ aerosols., Atmos. Chem. Phys., 7(17), 4639-4659, doi:10.5194/acp-74639-2007, 2007.

Fu, H., Lin, J., Shang, G., Dong, W., Grassian, V. H., Carmichael, G. R., Li, Y. and Chen, J.: Solubility of Iron from Combustion Source Particles in Acidic Media Linked to Iron Speciation, Environ. Sci. Technol., 46(20), 11119-11127, doi:10.1021/es302558m, 2012.

Fu, T.-M., Jacob, D. J. and Heald, C. L.: Aqueous-phase reactive uptake of dicarbonyls as a source of organic aerosol over eastern North America, Atmos. Environ., 43(10), 1814-1822, doi:10.1016/j.atmosenv.2008.12.029, 2009.

Fu, T., Jacob, D. J., Wittrock, F., Burrows, J. P., Vrekoussis, M. and Henze, D. K.: Global budgets of atmospheric glyoxal and methylglyoxal, and implications for formation of secondary organic aerosols, J. Geophys. Res., 113(D15), D15303, doi:10.1029/2007JD009505, 2008.

Furukawa, T. and Takahashi, Y.: Oxalate metal complexes in aerosol particles: implications for the hygroscopicity of oxalatecontaining particles, Atmos. Chem. Phys., 11(9), 4289-4301, doi:10.5194/acp-11-4289-2011, 2011.

Giles, D. M., Sinyuk, A., Sorokin, M. G., Schafer, J. S., Smirnov, A., Slutsker, I., Eck, T. F., Holben, B. N., Lewis, J. R., Campbell, J. R., Welton, E. J., Korkin, S. V and Lyapustin, A. I.: Advancements in the Aerosol Robotic Network (AERONET) Version 3 database - automated near-real-time quality control algorithm with improved cloud screening for Sun photometer 
aerosol optical depth (AOD) measurements, Atmos. Meas. Tech., 12(1), 169-209, doi:10.5194/amt-12-169-2019, 2019.

Gliß, J., Mortier, A., Schulz, M., Andrews, E., Balkanski, Y., Bauer, S. E., Benedictow, A. M. K., Bian, H., Checa-Garcia, R., Chin, M., Ginoux, P., Griesfeller, J. J., Heckel, A., Kipling, Z., Kirkeväg, A., Kokkola, H., Laj, P., Le Sager, P., Tronstad Lund, M., Lund Myhre, C., Matsui, H., Myhre, G., Neubauer, D., Van Noije, T., North, P., Olivié, D. J. L., Rémy, S., Sogacheva, L., Takemura, T., Tsigaridis, K. and Tsyro, S. G.: AeroCom phase III multi-model evaluation of the aerosol life cycle and optical properties using ground- And space-based remote sensing as well as surface in situ observations, Atmos. Chem. Phys., 21(1), 87-128, doi:10.5194/acp-21-87-2021, 2021.

Guieu, C., Bonnet, S., Wagener, T. and Loÿe-Pilot, M.-D.: Biomass burning as a source of dissolved iron to the open ocean?, Geophys. Res. Lett., 32(19), L19608, doi:10.1029/2005GL022962, 2005.

Hajima, T., Watanabe, M., Yamamoto, A., Tatebe, H., Noguchi, A., Abe, M., Ohgaito, R., Ito, A., Yamazaki, D., Okajima, H., Ito, A., Takata, K., Ogochi, K., Watanabe, S. and Kawamiya, M.: Description of the MIROC-ES2L Earth system model and evaluation of its climate-biogeochemical processes and feedbacks, Geosci. Model Dev. Discuss, doi:10.5194/gmd-2019-275, 2019.

Hamer, M., Graham, R. C., Amrhein, C. and Bozhilov, K. N.: Dissolution of Ripidolite (Mg, Fe-Chlorite) in Organic and Inorganic Acid Solutions, Soil Sci. Soc. Am. J., 67(2), 654, doi:10.2136/sssaj2003.6540, 2003.

Hamilton, D. S., Scanza, R. A., Feng, Y., Guinness, J., Kok, J. F., Li, L., Liu, X., Rathod, S. D., Wan, J. S., Wu, M. and

Mahowald, N. M.: Improved methodologies for Earth system modelling of atmospheric soluble iron and observation comparisons using the Mechanism of Intermediate complexity for Modelling Iron (MIMI v1.0), Geosci. Model Dev., 12(9), 3835-3862, doi:10.5194/gmd-12-3835-2019, 2019.

Hamilton, D. S., Moore, J. K., Arneth, A., Bond, T. C., Carslaw, K. S., Hantson, S., Ito, A., Kaplan, J. O., Lindsay, K., Nieradzik, L., Rathod, S. D., Scanza, R. A. and Mahowald, N. M.: Impact of Changes to the Atmospheric Soluble Iron Deposition Flux on Ocean Biogeochemical Cycles in the Anthropocene, Global Biogeochem. Cycles, 34(3), doi:10.1029/2019GB006448, 2020.

Hamilton, D. S., Perron, M. M. G., Bond, T. C., Bowie, A. R., Buchholz, R. R., Guieu, C., Ito, A., Maenhaut, W., Myriokefalitakis, S., Olgun, N., Rathod, S. D., Schepanski, K., Tagliabue, A., Wagner, R. and Mahowald, N. M.: Earth, Wind, Fire, and Pollution: Aerosol Nutrient Sources and Impacts on Ocean Biogeochemistry, Ann. Rev. Mar. Sci., 14(1), doi:10.1146/annurev-marine-031921-013612, 2022.

Harris, E., Sinha, B., Van Pinxteren, D., Tilgner, A., Fomba, K. W., Schneider, J., Roth, A., Gnauk, T., Fahlbusch, B., Mertes, S., Lee, T., Collett, J., Foley, S., Borrmann, S., Hoppe, P. and Herrmann, H.: Enhanced role of transition metal ion catalysis during in-cloud oxidation of SO2, Science (80-. )., 340(6133), 727-730, doi:10.1126/science.1230911, 2013. 
Hays, M. D., Geron, C. D., Linna, K. J., Smith, N. D. and Schauer, J. J.: Speciation of Gas-Phase and Fine Particle Emissions from Burning of Foliar Fuels, Environ. Sci. Technol., 36(11), 2281-2295, doi:10.1021/es0111683, 2002.

Herrmann, H.: Kinetics of Aqueous Phase Reactions Relevant for Atmospheric Chemistry, Chem. Rev., 103(12), 4691-4716, doi:10.1021/cr020658q, 2003.

Herrmann, H., Ervens, B., Jacobi, H. W., Wolke, R., Nowacki, P. and Zellner, R.: CAPRAM2.3: A chemical aqueous phase radical mechanism for tropospheric chemistry, J. Atmos. Chem., 36(3), 231-284, doi:10.1023/A:1006318622743, 2000.

1320 Herrmann, H., Tilgner, A., Barzaghi, P., Majdik, Z., Gligorovski, S., Poulain, L. and Monod, A.: Towards a more detailed description of tropospheric aqueous phase organic chemistry: CAPRAM 3.0, Atmos. Environ., 39(23-24), 4351-4363, doi:10.1016/j.atmosenv.2005.02.016, 2005.

Herrmann, H., Schaefer, T., Tilgner, A., Styler, S. A., Weller, C., Teich, M. and Otto, T.: Tropospheric Aqueous-Phase Chemistry: Kinetics, Mechanisms, and Its Coupling to a Changing Gas Phase, Chem. Rev., 115(10), 4259-4334, doi:10.1021/cr500447k, 2015.

Hoesly, R. M., Smith, S. J., Feng, L., Klimont, Z., Janssens-Maenhout, G., Pitkanen, T., Seibert, J. J., Vu, L., Andres, R. J., Bolt, R. M., Bond, T. C., Dawidowski, L., Kholod, N., Kurokawa, J., Li, M., Liu, L., Lu, Z., Moura, M. C. P., O Rourke, P. R. and Zhang, Q.: Historical (1750-2014) anthropogenic emissions of reactive gases and aerosols from the Community Emissions Data System (CEDS), Geosci. Model Dev., 11(1), 369-408, doi:10.5194/gmd-11-369-2018, 2018.

1330 Hoffmann, E. H., Tilgner, A., Schrödner, R., Bräuer, P., Wolke, R. and Herrmann, H.: An advanced modeling study on the impacts and atmospheric implications of multiphase dimethyl sulfide chemistry, Proc. Natl. Acad. Sci. U. S. A., 113(42), 11776-11781, doi:10.1073/pnas.1606320113, 2016.

Hoffmann, E. H., Tilgner, A., Wolke, R., Böge, O., Walter, A. and Herrmann, H.: Oxidation of substituted aromatic hydrocarbons in the tropospheric aqueous phase: Kinetic mechanism development and modelling, Phys. Chem. Chem. Phys.,

20(16), 10960-10977, doi:10.1039/c7cp08576a, 2018.

Hoyle, C. R., Fuchs, C., Järvinen, E., Saathoff, H., Dias, A., El Haddad, I., Gysel, M., Coburn, S. C., Tröstl, J., Bernhammer, A.-K., Bianchi, F., Breitenlechner, M., Corbin, J. C., Craven, J., Donahue, N. M., Duplissy, J., Ehrhart, S., Frege, C., Gordon, H., Höppel, N., Heinritzi, M., Kristensen, T. B., Molteni, U., Nichman, L., Pinterich, T., Prévôt, A. S. H., Simon, M., Slowik, J. G., Steiner, G., Tomé, A., Vogel, A. L., Volkamer, R., Wagner, A. C., Wagner, R., Wexler, A. S., Williamson, C., Winkler, 1340 P. M., Yan, C., Amorim, A., Dommen, J., Curtius, J., Gallagher, M. W., Flagan, R. C., Hansel, A., Kirkby, J., Kulmala, M., Möhler, O., Stratmann, F., Worsnop, D. R. and Baltensperger, U.: Aqueous phase oxidation of sulphur dioxide by ozone in cloud droplets, Atmos. Chem. Phys., 16(3), 1693-1712, doi:10.5194/acp-16-1693-2016, 2016.

Huang, X.-F. and Yu, J. Z.: Is vehicle exhaust a significant primary source of oxalic acid in ambient aerosols?, Geophys. Res. 
Lett., 34(2), L02808, doi:10.1029/2006GL028457, 2007.

1345 Huijnen, V., Williams, J., van Weele, M., van Noije, T., Krol, M., Dentener, F., Segers, A., Houweling, S., Peters, W., de Laat, J., Boersma, F., Bergamaschi, P., van Velthoven, P., Le Sager, P., Eskes, H., Alkemade, F., Scheele, R., Nédélec, P. and Pätz, H.-W.: The global chemistry transport model TM5: description and evaluation of the tropospheric chemistry version 3.0, Geosci. Model Dev., 3(2), 445-473, doi:10.5194/gmd-3-445-2010, 2010.

Huneeus, N., Schulz, M., Balkanski, Y., Griesfeller, J., Prospero, J., Kinne, S., Bauer, S., Boucher, O., Chin, M., Dentener, F., Diehl, T., Easter, R., Fillmore, D., Ghan, S., Ginoux, P., Grini, A., Horowitz, L., Koch, D., Krol, M. C., Landing, W., Liu, X., Mahowald, N., Miller, R., Morcrette, J.-J., Myhre, G., Penner, J., Perlwitz, J., Stier, P., Takemura, T. and Zender, C. S.: Global dust model intercomparison in AeroCom phase I, Atmos. Chem. Phys., 11(15), 7781-7816, doi:10.5194/acp-11-7781-2011, 2011.

Ito, A.: Global modeling study of potentially bioavailable iron input from shipboard aerosol sources to the ocean, Global

Biogeochem. Cycles, 27(1), 1-10, doi:10.1029/2012GB004378, 2013.

Ito, A.: Atmospheric Processing of Combustion Aerosols as a Source of Bioavailable Iron, Environ. Sci. Technol. Lett., 2(3), 70-75, doi:10.1021/acs.estlett.5b00007, 2015.

Ito, A. and Shi, Z.: Delivery of anthropogenic bioavailable iron from mineral dust and combustion aerosols to the ocean, Atmos. Chem. Phys., 16(1), 85-99, doi:10.5194/acp-16-85-2016, 2016.

1360 Ito, A., Lin, G. and Penner, J. E.: Radiative forcing by light-absorbing aerosols of pyrogenetic iron oxides, Sci. Rep., 8(1), 7347, doi:10.1038/s41598-018-25756-3, 2018.

Ito, A., Myriokefalitakis, S., Kanakidou, M., Mahowald, N. M., Scanza, R. A., Hamilton, D. S., Baker, A. R., Jickells, T., Sarin, M., Bikkina, S., Gao, Y., Shelley, R. U., Buck, C. S., Landing, W. M., Bowie, A. R., Perron, M. M. G., Guieu, C., Meskhidze, N., Johnson, M. S., Feng, Y., Kok, J. F., Nenes, A. and Duce, R. A.: Pyrogenic iron: The missing link to high iron solubility in aerosols, Sci. Adv., 5(5), eaau7671, doi:10.1126/sciadv.aau7671, 2019.

Ito, A., Ye, Y., Baldo, C. and Shi, Z.: Ocean fertilization by pyrogenic aerosol iron, npj Clim. Atmos. Sci., 4(1), 30, doi:10.1038/s41612-021-00185-8, 2021.

Jacob, D. J.: Chemistry of $\mathrm{OH}$ in remote clouds and its role in the production of formic acid and peroxymonosulfate, J. Geophys. Res., 91(D9), 9807, doi:10.1029/JD091iD09p09807, 1986.

1370 Jeuken, A., Veefkind, J. P., Dentener, F., Metzger, S. and Gonzalez, C. R.: Simulation of the aerosol optical depth over Europe for August 1997 and a comparison with observations, J. Geophys. Res. Atmos., 106(D22), 28295-28311, doi:10.1029/2001JD900063, 2001. 
https://doi.org/10.5194/gmd-2021-357

Preprint. Discussion started: 10 November 2021

(c) Author(s) 2021. CC BY 4.0 License.

(c) (i)

Johnson, M. S. and Meskhidze, N.: Atmospheric dissolved iron deposition to the global oceans: effects of oxalate-promoted Fe dissolution, photochemical redox cycling, and dust mineralogy, Geosci. Model Dev., 6(4), 1137-1155, doi:10.5194/gmd6-1137-2013, 2013.

Journet, E., Desboeufs, K. V., Caquineau, S. and Colin, J.-L.: Mineralogy as a critical factor of dust iron solubility, Geophys. Res. Lett., 35(7), L07805, doi:10.1029/2007GL031589, 2008.

Kanakidou, M., Mihalopoulos, N., Kindap, T., Im, U., Vrekoussis, M., Gerasopoulos, E., Dermitzaki, E., Unal, A., Koçak, M., Markakis, K., Melas, D., Kouvarakis, G., Youssef, A. F., Richter, A., Hatzianastassiou, N., Hilboll, A., Ebojie, F., Wittrock, 1380 F., von Savigny, C., Burrows, J. P., Ladstaetter-Weissenmayer, A. and Moubasher, H.: Megacities as hot spots of air pollution in the East Mediterranean, Atmos. Environ., 45(6), 1223-1235, doi:10.1016/j.atmosenv.2010.11.048, 2011.

Kanakidou, M., Myriokefalitakis, S. and Tsigaridis, K.: Aerosols in atmospheric chemistry and biogeochemical cycles of nutrients, Environ. Res. Lett., 13(6), 063004, doi:10.1088/1748-9326/aabcdb, 2018.

Kanakidou, M., Myriokefalitakis, S. and Tsagkaraki, M.: Atmospheric inputs of nutrients to the Mediterranean Sea, Deep Sea

Res. Part II Top. Stud. Oceanogr., 171, 104606, doi:10.1016/j.dsr2.2019.06.014, 2020.

Karydis, V. A., Tsimpidi, A. P., Pozzer, A., Astitha, M. and Lelieveld, J.: Effects of mineral dust on global atmospheric nitrate concentrations, Atmos. Chem. Phys., 16(3), 1491-1509, doi:10.5194/acp-16-1491-2016, 2016.

Karydis, V. A., Tsimpidi, A. P., Pozzer, A. and Lelieveld, J.: How alkaline compounds control atmospheric aerosol acidity, Atmos. Chem. Phys., preprint, doi:10.5194/acp-2020-1222, 2020.

1390 Kawamura, K. and Ikushima, K.: Seasonal changes in the distribution of dicarboxylic acids in the urban atmosphere, Environ. Sci. Technol., 27(10), 2227-2235, doi:10.1021/es00047a033, 1993.

Kawamura, K. and Kaplan, I. R.: Motor exhaust emissions as a primary source for dicarboxylic acids in Los Angeles ambient air, Environ. Sci. Technol., 21(1), 105-110, doi:10.1021/es00155a014, 1987.

Kawamura, K. and Sakaguchi, F.: Molecular distributions of water soluble dicarboxylic acids in marine aerosols over the

Pacific Ocean including tropics, J. Geophys. Res. Atmos., 104(D3), 3501-3509, doi:10.1029/1998JD100041, 1999.

Knote, C., Hodzic, A., Jimenez, J. L., Volkamer, R., Orlando, J. J., Baidar, S., Brioude, J., Fast, J., Gentner, D. R., Goldstein, A. H., Hayes, P. L., Knighton, W. B., Oetjen, H., Setyan, A., Stark, H., Thalman, R., Tyndall, G., Washenfelder, R., Waxman, E. and Zhang, Q.: Simulation of semi-explicit mechanisms of SOA formation from glyoxal in aerosol in a 3-D model, Atmos. Chem. Phys., 14(12), 6213-6239, doi:10.5194/acp-14-6213-2014, 2014.

1400 Kok, J. F.: A scaling theory for the size distribution of emitted dust aerosols suggests climate models underestimate the size of the global dust cycle, Proc. Natl. Acad. Sci., 108(3), 1016-1021, doi:10.1073/pnas.1014798108, 2011. 
Koulouri, E., Saarikoski, S., Theodosi, C., Markaki, Z., Gerasopoulos, E., Kouvarakis, G., M??kel??, T., Hillamo, R. and Mihalopoulos, N.: Chemical composition and sources of fine and coarse aerosol particles in the Eastern Mediterranean, Atmos. Environ., 42(26), 6542-6550, doi:10.1016/j.atmosenv.2008.04.010, 2008.

1405 Krishnamurthy, A., Moore, J. K., Mahowald, N., Luo, C., Doney, S. C., Lindsay, K. and Zender, C. S.: Impacts of increasing anthropogenic soluble iron and nitrogen deposition on ocean biogeochemistry, Global Biogeochem. Cycles, 23(3), GB3016, doi:10.1029/2008GB003440, 2009.

Krishnamurthy, A., Moore, J. K., Mahowald, N., Luo, C. and Zender, C. S.: Impacts of atmospheric nutrient inputs on marine biogeochemistry, J. Geophys. Res., 115(G1), G01006, doi:10.1029/2009JG001115, 2010.

1410 Krol, M., Houweling, S., Bregman, B., van den Broek, M., Segers, A., van Velthoven, P., Peters, W., Dentener, F. and Bergamaschi, P.: The two-way nested global chemistry-transport zoom model TM5: algorithm and applications, Atmos. Chem. Phys., 5(2), 417-432, doi:10.5194/acp-5-417-2005, 2005.

Kundu, S., Kawamura, K., Lee, M., Andreae, T. W. ., Hoffer, A. and Andreae, M. O.: Comparison of Amazonian biomass burning and East Asian marine aerosols : Bulk organics, diacids and related compounds, water-soluble inorganic ions, stable 1415 carbon and nitrogen isotope ratios, Low Temp. Sci., 68(68), 89-100 [online] Available from: http://hdl.handle.net/2115/45168 (Accessed 31 May 2016), 2010.

Lanzl, C. A., Baltrusaitis, J. and Cwiertny, D. M.: Dissolution of Hematite Nanoparticle Aggregates: Influence of Primary Particle Size, Dissolution Mechanism, and Solution pH, Langmuir, 28(45), 15797-15808, doi:10.1021/la3022497, 2012.

Lasaga, A. C., Soler, J. M., Ganor, J., Burch, T. E. and Nagy, K. L.: Chemical weathering rate laws and global geochemical cycles, Geochim. Cosmochim. Acta, 58(10), 2361-2386, doi:10.1016/0016-7037(94)90016-7, 1994.

Legrand, M., Preunkert, S., Oliveira, T., Pio, C. A., Hammer, S., Gelencsér, A., Kasper-Giebl, A. and Laj, P.: Origin of C 2 C 5 dicarboxylic acids in the European atmosphere inferred from year-round aerosol study conducted at a west-east transect, J. Geophys. Res., 112(D23), D23S07, doi:10.1029/2006JD008019, 2007.

Lelieveld, J. and Crutzen, P. J.: The role of clouds in tropospheric photochemistry, J. Atmos. Chem., 12(3), 229-267, doi:10.1007/BF00048075, 1991.

Liao, H., Adams, P. J., Chung, S. H., Seinfeld, J. H., Mickley, L. J. and Jacob, D. J.: Interactions between tropospheric chemistry and aerosols in a unified general circulation model, J. Geophys. Res., 108(D1), 4001, doi:10.1029/2001JD001260, 2003.

Lim, H.-J., Carlton, A. G. and Turpin, B. J.: Isoprene Forms Secondary Organic Aerosol through Cloud Processing: Model 1430 Simulations, Environ. Sci. Technol., 39(12), 4441-4446, doi:10.1021/es048039h, 2005. 
Lim, Y. B., Tan, Y., Perri, M. J., Seitzinger, S. P. and Turpin, B. J.: Aqueous chemistry and its role in secondary organic aerosol (SOA) formation, Atmos. Chem. Phys., 10(21), 10521-10539, doi:10.5194/acp-10-10521-2010, 2010.

Lim, Y. B., Tan, Y. and Turpin, B. J.: Chemical insights, explicit chemistry, and yields of secondary organic aerosol from $\mathrm{OH}$ radical oxidation of methylglyoxal and glyoxal in the aqueous phase, Atmos. Chem. Phys., 13(17), 8651-8667, doi:10.5194/acp-13-8651-2013, 2013.

Lin, G., Penner, J. E., Sillman, S., Taraborrelli, D. and Lelieveld, J.: Global modeling of SOA formation from dicarbonyls, epoxides, organic nitrates and peroxides, Atmos. Chem. Phys., 12(10), 4743-4774, doi:10.5194/acp-12-4743-2012, 2012.

Lin, G., Sillman, S., Penner, J. E. and Ito, A.: Global modeling of SOA: the use of different mechanisms for aqueous-phase formation, Atmos. Chem. Phys., 14(11), 5451-5475, doi:10.5194/acp-14-5451-2014, 2014.

Liu, J., Horowitz, L. W., Fan, S., Carlton, A. G. and Levy, H.: Global in-cloud production of secondary organic aerosols: Implementation of a detailed chemical mechanism in the GFDL atmospheric model AM3, J. Geophys. Res. Atmos., 117(D15), 1-15, doi:10.1029/2012JD017838, 2012.

Mahowald, N. M., Baker, A. R., Bergametti, G., Brooks, N., Duce, R. A., Jickells, T. D., Kubilay, N. N., Prospero, J. M. and Tegen, I.: Atmospheric global dust cycle and iron inputs to the ocean, Global Biogeochem. Cycles, 19(4), GB4025, doi:10.1029/2004GB002402, 2005.

Mahowald, N. M., Engelstaedter, S., Luo, C., Sealy, A., Artaxo, P., Benitez-Nelson, C., Bonnet, S., Chen, Y., Chuang, P. Y., Cohen, D. D., Dulac, F., Herut, B., Johansen, A. M., Kubilay, N., Losno, R., Maenhaut, W., Paytan, A., Prospero, J. M., Shank, L. M. and Siefert, R. L.: Atmospheric iron deposition: global distribution, variability, and human perturbations., Ann. Rev. Mar. Sci., 1, 245-278, doi:10.1146/annurev.marine.010908.163727, 2009.

Mahowald, N. M., Scanza, R., Brahney, J., Goodale, C. L., Hess, P. G., Moore, J. K. and Neff, J.: Aerosol Deposition Impacts on Land and Ocean Carbon Cycles, Curr. Clim. Chang. Reports, 1-16, doi:10.1007/s40641-017-0056-z, 2017.

Mahowald, N. M., Hamilton, D. S., Mackey, K. R. M., Moore, J. K., Baker, A. R., Scanza, R. A. and Zhang, Y.: Aerosol trace metal leaching and impacts on marine microorganisms, Nat. Commun., 9(1), 2614, doi:10.1038/s41467-018-04970-7, 2018.

van Marle, M. J. E., Kloster, S., Magi, B. I., Marlon, J. R., Daniau, A.-L., Field, R. D., Arneth, A., Forrest, M., Hantson, S., 1455 Kehrwald, N. M., Knorr, W., Lasslop, G., Li, F., Mangeon, S., Yue, C., Kaiser, J. W. and van der Werf, G. R.: Historic global biomass burning emissions for CMIP6 (BB4CMIP) based on merging satellite observations with proxies and fire models (1750-2015), Geosci. Model Dev., 10(9), 3329-3357, doi:10.5194/gmd-10-3329-2017, 2017.

Marticorena, B., Chatenet, B., Rajot, J. L., Traoré, S., Coulibaly, M., Diallo, A., Koné, I., Maman, A., NDiaye, T. and Zakou, A.: Temporal variability of mineral dust concentrations over West Africa: analyses of a pluriannual monitoring from the 1460 AMMA Sahelian Dust Transect, Atmos. Chem. Phys., 10(18), 8899-8915, doi:10.5194/acp-10-8899-2010, 2010. 
https://doi.org/10.5194/gmd-2021-357

Preprint. Discussion started: 10 November 2021

(c) Author(s) 2021. CC BY 4.0 License.

(c) (i)

Martinelango, P. K., Dasgupta, P. K. and Al-Horr, R. S.: Atmospheric production of oxalic acid/oxalate and nitric acid/nitrate in the Tampa Bay airshed: Parallel pathways, Atmos. Environ., 41(20), 4258-4269, doi:10.1016/j.atmosenv.2006.05.085, 2007.

Meskhidze, N., Völker, C., Al-Abadleh, H. A., Barbeau, K., Bressac, M., Buck, C., Bundy, R. M., Croot, P., Feng, Y., Ito, A., Johansen, A. M., Landing, W. M., Mao, J., Myriokefalitakis, S., Ohnemus, D., Pasquier, B. and Ye, Y.: Perspective on identifying and characterizing the processes controlling iron speciation and residence time at the atmosphere-ocean interface, Mar. Chem., 217, 103704, doi:10.1016/j.marchem.2019.103704, 2019.

Metzger, S., Dentener, F., Pandis, S. and Lelieveld, J.: Gas/aerosol partitioning: 1. A computationally efficient model, J. Geophys. Res., 107(D16), 4312, doi:10.1029/2001JD001102, 2002.

1470 Myriokefalitakis, S., Vrekoussis, M., Tsigaridis, K., Wittrock, F., Richter, A., Brühl, C., Volkamer, R., Burrows, J. P. and Kanakidou, M.: The influence of natural and anthropogenic secondary sources on the glyoxal global distribution, Atmos. Chem. Phys., 8(16), 4965-4981, doi:10.5194/acp-8-4965-2008, 2008.

Myriokefalitakis, S., Tsigaridis, K., Mihalopoulos, N., Sciare, J., Nenes, A., Kawamura, K., Segers, A. and Kanakidou, M.: In-cloud oxalate formation in the global troposphere: a 3-D modeling study, Atmos. Chem. Phys., 11(12), 5761-5782, doi:10.5194/acp-11-5761-2011, 2011.

Myriokefalitakis, S., Daskalakis, N., Mihalopoulos, N., Baker, A. R., Nenes, A. and Kanakidou, M.: Changes in dissolved iron deposition to the oceans driven by human activity: a 3-D global modelling study, Biogeosciences, 12(13), 3973-3992, doi:10.5194/bg-12-3973-2015, 2015.

Myriokefalitakis, S., Ito, A., Kanakidou, M., Nenes, A., Krol, M. C., Mahowald, N. M., Scanza, R. A., Hamilton, D. S., Johnson, M. S., Meskhidze, N., Kok, J. F., Guieu, C., Baker, A. R., Jickells, T. D., Sarin, M. M., Bikkina, S., Shelley, R., Bowie, A., Perron, M. M. G. and Duce, R. A.: Reviews and syntheses: the GESAMP atmospheric iron deposition model intercomparison study, Biogeosciences, 15(21), 6659-6684, doi:10.5194/bg-15-6659-2018, 2018.

Myriokefalitakis, S., Gröger, M., Hieronymus, J. and Döscher, R.: An explicit estimate of the atmospheric nutrient impact on global oceanic productivity, Ocean Sci., 16(5), 1183-1205, doi:10.5194/os-16-1183-2020, 2020a.

1485 Myriokefalitakis, S., Daskalakis, N., Gkouvousis, A., Hilboll, A., van Noije, T., Williams, J. E., Le Sager, P., Huijnen, V., Houweling, S., Bergman, T., Nüß, J. R., Vrekoussis, M., Kanakidou, M. and Krol, M. C.: Description and evaluation of a detailed gas-phase chemistry scheme in the TM5-MP global chemistry transport model (r112), Geosci. Model Dev., 13(11), 5507-5548, doi:10.5194/gmd-13-5507-2020, 2020 b.

Nickovic, S., Vukovic, A., Vujadinovic, M., Djurdjevic, V. and Pejanovic, G.: Technical Note: High-resolution mineralogical 1490 database of dust-productive soils for atmospheric dust modeling, Atmos. Chem. Phys., 12(2), 845-855, doi:10.5194/acp-12- 
845-2012, 2012.

Nickovic, S., Vukovic, A. and Vujadinovic, M.: Atmospheric processing of iron carried by mineral dust, Atmos. Chem. Phys., 13(18), 9169-9181, doi:10.5194/acp-13-9169-2013, 2013.

van Noije, T. P. C., Le Sager, P., Segers, A. J., van Velthoven, P. F. J., Krol, M. C., Hazeleger, W., Williams, A. G. and Chambers, S. D.: Simulation of tropospheric chemistry and aerosols with the climate model EC-Earth, Geosci. Model Dev., 7(5), 2435-2475, doi:10.5194/gmd-7-2435-2014, 2014.

van Noije, T., Bergman, T., Le Sager, P., O’Donnell, D., Makkonen, R., Gonçalves-Ageitos, M., Döscher, R., Fladrich, U., von Hardenberg, J., Keskinen, J.-P., Korhonen, H., Laakso, A., Myriokefalitakis, S., Ollinaho, P., Pérez García-Pando, C., Reerink, T., Schrödner, R., Wyser, K. and Yang, S.: EC-Earth3-AerChem: a global climate model with interactive aerosols 1500 and atmospheric chemistry participating in CMIP6, Geosci. Model Dev., 14(9), 5637-5668, doi:10.5194/gmd-14-5637-2021, 2021.

Norton, R. B., Roberts, J. M. and Huebert, B. J.: Tropospheric oxalate, Geophys. Res. Lett., 10(7), 517-520, doi:10.1029/GL010i007p00517, 1983.

Oakes, M., Ingall, E. D., Lai, B., Shafer, M. M., Hays, M. D., Liu, Z. G., Russell, A. G. and Weber, R. J.: Iron Solubility 1505 Related to Particle Sulfur Content in Source Emission and Ambient Fine Particles, Environ. Sci. Technol., 46(12), 6637-6644, doi:10.1021/es300701c, 2012.

Ortiz-Montalvo, D. L., Häkkinen, S. A. K., Schwier, A. N., Lim, Y. B., McNeill, V. F. and Turpin, B. J.: Ammonium Addition (and Aerosol pH) Has a Dramatic Impact on the Volatility and Yield of Glyoxal Secondary Organic Aerosol, Environ. Sci. Technol., 48(1), 255-262, doi:10.1021/es4035667, 2014.

1510 Paciga, A. L., Riipinen, I. and Pandis, S. N.: Effect of ammonia on the volatility of organic diacids., Environ. Sci. Technol., 48(23), 13769-75, doi:10.1021/es5037805, 2014.

Paris, R. and Desboeufs, K. V.: Effect of atmospheric organic complexation on iron-bearing dust solubility, Atmos. Chem. Phys., 13(9), 4895-4905, doi:10.5194/acp-13-4895-2013, 2013.

Paris, R., Desboeufs, K. V., Formenti, P., Nava, S. and Chou, C.: Chemical characterisation of iron in dust and biomass burning 1515 aerosols during AMMA-SOP0/DABEX: implication for iron solubility, Atmos. Chem. Phys., 10(9), 4273-4282, doi:10.5194/acp-10-4273-2010, 2010.

Paris, R., Desboeufs, K. V. and Journet, E.: Variability of dust iron solubility in atmospheric waters: Investigation of the role of oxalate organic complexation, Atmos. Environ., 45(36), 6510-6517, doi:10.1016/j.atmosenv.2011.08.068, 2011.

Pérez García-Pando, C., Miller, R. L., Perlwitz, J. P., Rodríguez, S. and Prospero, J. M.: Predicting the mineral composition 
of dust aerosols: Insights from elemental composition measured at the Izaña Observatory, Geophys. Res. Lett., 43(19), 10,52010,529, doi:10.1002/2016GL069873, 2016.

Perlwitz, J. P., Pérez García-Pando, C. and Miller, R. L.: Predicting the mineral composition of dust aerosols - Part 1: Representing key processes, Atmos. Chem. Phys., 15(20), 11593-11627, doi:10.5194/acp-15-11593-2015, 2015 a.

Perlwitz, J. P., Pérez García-Pando, C. and Miller, R. L.: Predicting the mineral composition of dust aerosols - Part 2: Model evaluation and identification of key processes with observations, Atmos. Chem. Phys., 15(20), 11629-11652, doi:10.5194/acp15-11629-2015, 2015b.

Perri, M. J., Seitzinger, S. and Turpin, B. J.: Secondary organic aerosol production from aqueous photooxidation of glycolaldehyde: Laboratory experiments, Atmos. Environ., 43(8), 1487-1497, doi:10.1016/j.atmosenv.2008.11.037, 2009.

Perri, M. J., Lim, Y. B., Seitzinger, S. P. and Turpin, B. J.: Organosulfates from glycolaldehyde in aqueous aerosols and clouds: Laboratory studies, Atmos. Environ., 44(21-22), 2658-2664, doi:10.1016/j.atmosenv.2010.03.031, 2010.

Pringle, K. J., Tost, H., Metzger, S., Steil, B., Giannadaki, D., Nenes, A., Fountoukis, C., Stier, P., Vignati, E. and Lelieveld, J.: Description and evaluation of GMXe: a new aerosol submodel for global simulations (v1), Geosci. Model Dev., 3(2), 413413, doi:10.5194/gmd-3-413-2010, 2010.

Prospero, J. M.: The Atmospheric Transport of Particles to the Ocean, in Particle Flux in the Ocean, edited by V. Ittekkot, P. Schafer, S. Honjo, and P. J. Depetris, John Wiley \& Sons Ltd, Chichester, United Kingdom., 1996.

Prospero, J. M.: Long-term measurements of the transport of African mineral dust to the southeastern United States: Implications for regional air quality, J. Geophys. Res. Atmos., 104(D13), 15917-15927, doi:10.1029/1999JD900072, 1999.

Prospero, J. M., Uematsu, M. and Savoie, D. L.: Mineral aerosol transport to the Pacific Ocean, edited by J. P. Riley, Academic Press, New York., 1989.

1540 Pye, H. O. T., Nenes, A., Alexander, B., Ault, A. P., Barth, M. C., Clegg, S. L., Collett, J. L., Fahey, K. M., Hennigan, C. J., Herrmann, H., Kanakidou, M., Kelly, J. T., Ku, I. T., Faye McNeill, V., Riemer, N., Schaefer, T., Shi, G., Tilgner, A., Walker, J. T., Wang, T., Weber, R., Xing, J., Zaveri, R. A. and Zuend, A.: The acidity of atmospheric particles and clouds, Atmos. Chem. Phys., 20(8), 4809-4888, doi:10.5194/acp-20-4809-2020, 2020.

Le Quéré, C., Rodenbeck, C., Buitenhuis, E. T., Conway, T. J., Langenfelds, R., Gomez, A., Labuschagne, C., Ramonet, M., 1545 Nakazawa, T., Metzl, N., Gillett, N. and Heimann, M.: Saturation of the Southern Ocean CO2 Sink Due to Recent Climate Change, Science (80-. )., 316(5832), 1735-1738, doi:10.1126/science.1136188, 2007.

Le Quéré, C., Andres, R. J., Boden, T., Conway, T., Houghton, R. A., House, J. I., Marland, G., Peters, G. P., van der Werf, G. R., Ahlström, A., Andrew, R. M., Bopp, L., Canadell, J. G., Ciais, P., Doney, S. C., Enright, C., Friedlingstein, P., 
Huntingford, C., Jain, A. K., Jourdain, C., Kato, E., Keeling, R. F., Klein Goldewijk, K., Levis, S., Levy, P., Lomas, M., budget 1959-2011, Earth Syst. Sci. Data, 5(1), 165-185, doi:10.5194/essd-5-165-2013, 2013.

Rousset, C., Vancoppenolle, M., Madec, G., Fichefet, T., Flavoni, S., Barthélemy, A., Benshila, R., Chanut, J., Levy, C., Masson, S. and Vivier, F.: The Louvain-La-Neuve sea ice model LIM3.6: global and regional capabilities, Geosci. Model Dev., 8(10), 2991-3005, doi:10.5194/gmd-8-2991-2015, 2015.

Sander, R.: Compilation of Henry's law constants (version 4.0) for water as solvent, Atmos. Chem. Phys., 15(8), 4399-4981, doi:10.5194/acp-15-4399-2015, 2015.

Sander, R., Baumgaertner, A., Cabrera-Perez, D., Frank, F., Gromov, S., Grooß, J.-U., Harder, H., Huijnen, V., Jöckel, P., Karydis, V. A., Niemeyer, K. E., Pozzer, A., Riede, H., Schultz, M. G., Taraborrelli, D. and Tauer, S.: The community atmospheric chemistry box model CAABA/MECCA-4.0, Geosci. Model Dev., 12(4), 1365-1385, doi:10.5194/gmd-12-13652019, 2019.

Sandu, A. and Sander, R.: Technical note: Simulating chemical systems in Fortran90 and Matlab with the Kinetic PreProcessor KPP-2.1, Atmos. Chem. Phys., 6(1), 187-195, doi:10.5194/acp-6-187-2006, 2006.

Scanza, R. A., Hamilton, D. S., Perez Garcia-Pando, C., Buck, C., Baker, A. and Mahowald, N. M.: Atmospheric processing of iron in mineral and combustion aerosols: development of an intermediate-complexity mechanism suitable for Earth system models, Atmos. Chem. Phys., 18(19), 14175-14196, doi:10.5194/acp-18-14175-2018, 2018.

Schmidl, C., Marr, I. L., Caseiro, A., Kotianová, P., Berner, A., Bauer, H., Kasper-Giebl, A. and Puxbaum, H.: Chemical characterisation of fine particle emissions from wood stove combustion of common woods growing in mid-European Alpine regions, Atmos. Environ., 42(1), 126-141, doi:10.1016/j.atmosenv.2007.09.028, 2008.

Schroth, A. W., Crusius, J., Sholkovitz, E. R. and Bostick, B. C.: Iron solubility driven by speciation in dust sources to the ocean, Nat. Geosci., 2(5), 337-340, doi:10.1038/ngeo501, 2009.

Schwartz, S. E.: Mass-Transport Considerations Pertinent to Aqueous Phase Reactions of Gases in Liquid-Water Clouds, in Chemistry of Multiphase Atmospheric Systems, pp. 415-471, Springer Berlin Heidelberg, Berlin, Heidelberg., 1986.

Sedlak, D. L. and Hoigné, J.: The role of copper and oxalate in the redox cycling of iron in atmospheric waters, Atmos. Environ. Part A, Gen. Top., 27(14), 2173-2185, doi:10.1016/0960-1686(93)90047-3, 1993.

1575 Seinfeld, J. H. and Pandis, S. N.: Atmospheric Chemistry and Physics: From Air Pollution to Climate Change., 2006.

Sempére, R. and Kawamura, K.: Comparative distributions of dicarboxylic acids and related polar compounds in snow, rain and aerosols from urban atmosphere, Atmos. Environ., 28(3), 449-459, doi:10.1016/1352-2310(94)90123-6, 1994. 
Shi, Z., Bonneville, S., Krom, M. D., Carslaw, K. S., Jickells, T. D., Baker, A. R. and Benning, L. G.: Iron dissolution kinetics of mineral dust at low pH during simulated atmospheric processing, Atmos. Chem. Phys., 11(3), 995-1007, doi:10.5194/acp11-995-2011, 2011.

Sholkovitz, E. R., Sedwick, P. N., Church, T. M., Baker, A. R. and Powell, C. F.: Fractional solubility of aerosol iron: Synthesis of a global-scale data set, Geochim. Cosmochim. Acta, 89, 173-189, doi:10.1016/j.gca.2012.04.022, 2012.

Sinreich, R., Coburn, S., Dix, B. and Volkamer, R.: Ship-based detection of glyoxal over the remote tropical Pacific Ocean, Atmos. Chem. Phys., 10(23), 11359-11371, doi:10.5194/acp-10-11359-2010, 2010.

Smith, B., Prentice, I. C. and Sykes, M. T.: Representation of vegetation dynamics in the modelling of terrestrial ecosystems: comparing two contrasting approaches within European climate space, Glob. Ecol. Biogeogr., 10(6), 621-637, doi:10.1046/j.1466-822X.2001.t01-1-00256.x, 2001.

Smith, B., Wårlind, D., Arneth, A., Hickler, T., Leadley, P., Siltberg, J. and Zaehle, S.: Implications of incorporating N cycling and $\mathrm{N}$ limitations on primary production in an individual-based dynamic vegetation model, Biogeosciences, 11(7), 2027-2054, doi:10.5194/bg-11-2027-2014, 2014.

Smith, H. J.: The state of ocean $\mathrm{CO}_{2}$ uptake, edited by S. Hurtley, Science (80-. )., 363(6432), 1187.2-1187, doi:10.1126/science.363.6432.1187-b, 2019.

Sorooshian, A., Varutbangkul, V., Brechtel, F. J., Ervens, B., Feingold, G., Bahreini, R., Murphy, S. M., Holloway, J. S., Atlas, E. L., Buzorius, G., Jonsson, H., Flagan, R. C. and Seinfeld, J. H.: Oxalic acid in clear and cloudy atmospheres: Analysis of data from International Consortium for Atmospheric Research on Transport and Transformation 2004, J. Geophys. Res. Atmos., 111(D23S45), 1-17, doi:10.1029/2005JD006880, 2006.

Sposito, G.: The Chemistry of Soils, Oxford University Press, Oxford., 1989.

Stocker, T. F., Dahe, Q., Plattner, G.-K., Alexander, L. V., Allen, S. K., Bindoff, N. L., Bréon, F.-M., Church, J. A., Cubash, U., Emori, S., Forster, P., Friedlingstein, P., Talley, L. D., Vaughan, D. G. and Xie, S.-P.: Technical Summary, in Climate Change 2013 - The Physical Science Basis, edited by Intergovernmental Panel on Climate Change, pp. 31-116, Cambridge University Press, Cambridge., 2013.

Tagliabue, A., Aumont, O., Death, R., Dunne, J. P., Dutkiewicz, S., Galbraith, E., Misumi, K., Moore, J. K., Ridgwell, A., Sherman, E., Stock, C., Vichi, M., Völker, C. and Yool, A.: How well do global ocean biogeochemistry models simulate dissolved iron distributions?, Global Biogeochem. Cycles, 30(2), 149-174, doi:10.1002/2015GB005289, 2016.

1605 Tan, Y., Lim, Y. B., Altieri, K. E., Seitzinger, S. P. and Turpin, B. J.: Mechanisms leading to oligomers and SOA through aqueous photooxidation: insights from $\mathrm{OH}$ radical oxidation of acetic acid and methylglyoxal, Atmos. Chem. Phys., 12(2), 801-813, doi:10.5194/acp-12-801-2012, 2012. 
https://doi.org/10.5194/gmd-2021-357

Preprint. Discussion started: 10 November 2021

(c) Author(s) 2021. CC BY 4.0 License.

(c) (i)

Taylor, K. E., Williamson, D. and Zwiers, F.: The sea surface temperature and sea ice concentration boundary conditions for AMIP II simulations, Progr. Clim. Model Diagnosis Intercomp., 60(PCMDI Report), 25 [online] Available from: https://pcmdi.llnl.gov/report/pdf/60.pdf?id=42 (Accessed 25 May 2021), 2000.

Tegen, I., Harrison, S. P., Kohfeld, K., Prentice, I. C., Coe, M. and Heimann, M.: Impact of vegetation and preferential source areas on global dust aerosol: Results from a model study, J. Geophys. Res. Atmos., 107(D21), AAC 14-1-AAC 14-27, doi:10.1029/2001JD000963, 2002.

Tilgner, A. and Herrmann, H.: Tropospheric Aqueous-Phase OH Oxidation Chemistry: Current Understanding, Uptake of 1615 Highly Oxidized Organics and Its Effects, pp. 49-85., 2018.

Tilgner, A., Bräuer, P., Wolke, R. and Herrmann, H.: Modelling multiphase chemistry in deliquescent aerosols and clouds using CAPRAM3.0i, J. Atmos. Chem., 70(3), 221-256, doi:10.1007/s10874-013-9267-4, 2013.

Tsai, I.-C., Chen, J.-P., Lin, P.-Y., Wang, W.-C. and Isaksen, I. S. A.: Sulfur cycle and sulfate radiative forcing simulated from a coupled global climate-chemistry model, Atmos. Chem. Phys., 10(8), 3693-3709, doi:10.5194/acp-10-3693-2010, 2010.

1620 Vancoppenolle, M., Fichefet, T., Goosse, H., Bouillon, S., Madec, G. and Maqueda, M. A. M.: Simulating the mass balance and salinity of Arctic and Antarctic sea ice. 1. Model description and validation, Ocean Model., 27(1-2), 33-53, doi:10.1016/j.ocemod.2008.10.005, 2009.

Vignati, E., Wilson, J. and Stier, P.: M7: An efficient size-resolved aerosol microphysics module for large-scale aerosol transport models, J. Geophys. Res. Atmos., 109(D22), D22202, doi:10.1029/2003JD004485, 2004.

1625 Warneck, P.: In-cloud chemistry opens pathway to the formation of oxalic acid in the marine atmosphere, Atmos. Environ., 37(17), 2423-2427, doi:10.1016/S1352-2310(03)00136-5, 2003.

Wittrock, F., Richter, A., Oetjen, H., Burrows, J. P., Kanakidou, M., Myriokefalitakis, S., Volkamer, R., Beirle, S., Platt, U. and Wagner, T.: Simultaneous global observations of glyoxal and formaldehyde from space, Geophys. Res. Lett., 33(16), L16804, doi:10.1029/2006GL026310, 2006.

1630 Yamasoe, M. A., Artaxo, P., Miguel, A. H. and Allen, A. G.: Chemical composition of aerosol particles from direct emissions of vegetation fires in the Amazon Basin: water-soluble species and trace elements, Atmos. Environ., 34(10), 1641-1653, doi:10.1016/S1352-2310(99)00329-5, 2000.

Yang, F., Chen, H., Wang, X., Yang, X., Du, J. and Chen, J.: Single particle mass spectrometry of oxalic acid in ambient aerosols in Shanghai: Mixing state and formation mechanism, Atmos. Environ., 43(25), 3876-3882, doi:10.1016/j.atmosenv.2009.05.002, 2009.

Yang, L. and Yu, L. E.: Measurements of oxalic acid, oxalates, malonic acid, and malonates in atmospheric particulates., 
https://doi.org/10.5194/gmd-2021-357

Preprint. Discussion started: 10 November 2021

(c) Author(s) 2021. CC BY 4.0 License.

(c) (1)

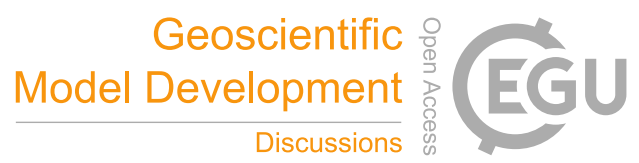

Environ. Sci. Technol., 42(24), 9268-75, doi:10.1021/es801820z, 2008.

Yao, X., Fang, M. and Chan, C. K.: Size distributions and formation of dicarboxylic acids in atmospheric particles, Atmos. Environ., 36(13), 2099-2107, doi:10.1016/S1352-2310(02)00230-3, 2002.

1640 Yoon, T. H., Johnson, S. B., Musgrave, C. B. and Brown, G. E.: Adsorption of organic matter at mineral/water interfaces: I. ATR-FTIR spectroscopic and quantum chemical study of oxalate adsorbed at boehmite/water and corundum/water interfaces, Geochim. Cosmochim. Acta, 68(22), 4505-4518, doi:10.1016/j.gca.2004.04.025, 2004.

Yu, J. Z., Huang, X., Xu, J. and Hu, M.: When Aerosol Sulfate Goes Up, So Does Oxalate: Implication for the Formation Mechanisms of Oxalate, Environ. Sci. Technol., 39(1), 128-133, doi:10.1021/es049559f, 2005.

1645 Zhu, X., Prospero, J. M., Savoie, D. L., Millero, F. J., Zika, R. G. and Saltzman, E. S.: Photoreduction of iron(III) in marine mineral aerosol solutions, J. Geophys. Res. Atmos., 98(D5), 9039-9046, doi:10.1029/93JD00202, 1993.

Zuo, Y. and Deng, Y.: Iron(II)-catalyzed photochemical decomposition of oxalic acid and generation of $\mathrm{H} 2 \mathrm{O} 2$ in atmospheric liquid phases, Chemosphere, 35(9), 2051-2058, doi:10.1016/S0045-6535(97)00228-2, 1997. 
https://doi.org/10.5194/gmd-2021-357

Preprint. Discussion started: 10 November 2021

(C) Author(s) 2021. CC BY 4.0 License.

(c) (1)

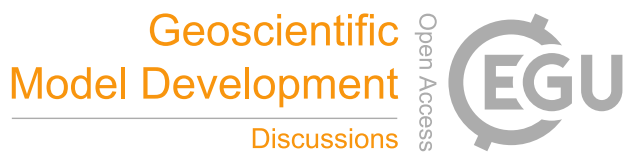

\section{Table and Figures}

Table 1. Overview of the simulations performed for this study.

\begin{tabular}{ll}
\hline Simulation & Description \\
\hline & $\begin{array}{l}\text { Aqueous-phase chemistry scheme for simulating OXL production and Fe dissolution, coupled to the MOGUNTIA gas-phase } \\
\text { chemistry scheme. Meteorology calculated online by IFS and observed sea surface temperature and sea ice concentration } \\
\text { Ed-Earth }\end{array}$ \\
$\begin{array}{l}\text { boundary conditions (AMIP-CMIP6) are applied. } \\
\text { As for EC-Earth simulation but driven by meteorological data from the ECMWF reanalysis ERA-Interim. } \\
\text { ERA-Interim(sens) }\end{array}$ & $\begin{array}{l}\text { As for ERA-Interim simulation but neglecting the contribution of glyoxal high molecular weight species on GLX and OXL } \\
\text { formation. }\end{array}$ \\
\hline
\end{tabular}


https://doi.org/10.5194/gmd-2021-357

Preprint. Discussion started: 10 November 2021

(c) Author(s) 2021. CC BY 4.0 License.

1655 Table 2. Global budgets, atmospheric burdens, and lifetimes, averaged for the period 2000-2014, of a) oxalate (OXL), b) sulfate as well as, for the dissolved Fe-containing aerosols from c) combustion processes (FeC) and d) mineral dust (FeD) for the EC-Earth, ERA-Interim, and ERA-Interim(sens) simulations.

\begin{tabular}{|c|c|c|c|}
\hline & EC-Earth & Era-Interim & Era-Interim(sens) \\
\hline \multicolumn{4}{|l|}{ a) Oxalate } \\
\hline Emissions $\left(\mathrm{Tg} \mathrm{yr}^{-1}\right)$ & \multirow{2}{*}{\multicolumn{3}{|c|}{0.373}} \\
\hline Chemistry Production $\left(\mathrm{Tg} \mathrm{yr}^{-1}\right)$ & & & \\
\hline - $\quad \mathrm{GLYOLI}+\mathrm{OH}$ & 10.597 & 14.764 & - \\
\hline - $\quad M G L Y+O H$ & 1.079 & 1.415 & 1.552 \\
\hline - $\quad \mathrm{GLX}+\mathrm{OH} / \mathrm{NO}_{3}$ & 3.369 & 4.618 & 9.962 \\
\hline \multicolumn{4}{|l|}{ Chemistry Loss $\left(\mathrm{Tg} \mathrm{yr}^{-1}\right)$} \\
\hline - $\quad \mathrm{OXL}+\mathrm{OH} / \mathrm{NO}_{3}$ & 1.019 & 1.189 & 0.822 \\
\hline - $\left[\mathrm{Fe}(\mathrm{OXL})_{2}\right]^{-}+h v$ & 1.412 & 1.475 & 0.680 \\
\hline \multicolumn{4}{|l|}{ Deposition $\left({\left.\operatorname{Tg~} \mathrm{yr}^{-1}\right)}^{-1}\right.$} \\
\hline - Dry Deposition & 0.134 & 0.176 & 0.097 \\
\hline - Wet Scavenging & 12.850 & 18.313 & 10.286 \\
\hline Atmospheric Burden (Tg) & 0.219 & 0.330 & 0.189 \\
\hline Lifetime (days) & 5.175 & 5.691 & 5.810 \\
\hline \multicolumn{4}{|l|}{ b) Sulfate } \\
\hline $\begin{array}{l}\text { Emissions }\left(\mathrm{Tg} \mathrm{S} \mathrm{yr}^{-1}\right) \\
\mathrm{H}_{2} \mathrm{SO}_{4} \text { Chemistry Production }\left(\mathrm{Tg} \mathrm{S} \mathrm{yr}^{-1}\right)\end{array}$ & \multicolumn{3}{|c|}{1.593} \\
\hline $\begin{array}{l}\quad \mathrm{SO}_{2}+\mathrm{OH} \\
\mathrm{S}(\mathrm{VI}) \mathrm{Chemistry} \text { Production }\left(\mathrm{Tg} \mathrm{S} \mathrm{yr}^{-1}\right)\end{array}$ & 11.976 & 11.088 & \\
\hline - $\mathrm{S}(\mathrm{IV})+\mathrm{H}_{2} \mathrm{O}_{2}$ & 32.902 & 35.812 & \\
\hline - $\quad \mathrm{S}(\mathrm{IV})+\mathrm{O}_{3}$ & 5.927 & 4.760 & \\
\hline - $\quad \mathrm{S}(\mathrm{IV})+\mathrm{HO}_{2}$ & 0.004 & 0.004 & \\
\hline - $\mathrm{S}(\mathrm{IV})+\mathrm{CH}_{3} \mathrm{O}_{2} \mathrm{H}$ & 0.051 & 0.049 & \\
\hline \multicolumn{4}{|l|}{ Deposition $\left(\mathrm{Tg} \mathrm{S} \mathrm{yr}^{-1}\right)$} \\
\hline - Dry Deposition & 3.079 & 2.912 & \\
\hline - Wet Scavenging & 49.368 & 50.394 & \\
\hline Atmospheric Burden (Tg S) & 0.692 & 0.961 & \\
\hline Lifetime (days) & 4.816 & 6.579 & \\
\hline \multicolumn{4}{|l|}{ c) Dissolved FeC } \\
\hline Emissions $\left({\left.\mathrm{Tg} \mathrm{yr}^{-1}\right)}^{-1}\right.$ & \multirow{2}{*}{\multicolumn{3}{|c|}{0.012}} \\
\hline Dissolution $\left(\mathrm{Tg} \mathrm{yr}^{-1}\right)$ & & & \\
\hline - $\mathrm{FeC}+\mathrm{H}^{+}$ & 0.047 & 0.049 & 0.049 \\
\hline - $\mathrm{FeC}+\mathrm{OXL}$ & 0.182 & 0.188 & 0.183 \\
\hline - $\quad F e C+h v$ & 0.045 & 0.047 & 0.046 \\
\hline \multicolumn{4}{|l|}{ Deposition $\left({\left.\operatorname{Tg~} \mathrm{yr}^{-1}\right)}^{-1}\right.$} \\
\hline - Dry Deposition & 0.081 & 0.080 & 0.077 \\
\hline - Wet Scavenging & 0.206 & 0.217 & 0.212 \\
\hline Atmospheric Burden (Tg) & 0.002 & 0.003 & 0.003 \\
\hline Lifetime (days) & 2.970 & 4.163 & 4.203 \\
\hline \multicolumn{4}{|l|}{ d) Dissolved FeD } \\
\hline Emissions $\left(\mathrm{Tg} \mathrm{yr}^{-1}\right)$ & 0.059 & 0.049 & 0.049 \\
\hline \multicolumn{4}{|l|}{ Dissolution $\left(\mathrm{Tg} \mathrm{yr}^{-1}\right)$} \\
\hline - $\mathrm{FeD}+H^{+}$ & 0.315 & 0.311 & 0.311 \\
\hline - $F e D+O X L$ & 0.170 & 0.168 & 0.164 \\
\hline - $F e D+h v$ & 0.047 & 0.049 & 0.048 \\
\hline \multicolumn{4}{|l|}{ Deposition $\left(\mathrm{Tg} \mathrm{yr}^{-1}\right)$} \\
\hline - Dry Deposition & 0.140 & 0.132 & 0.130 \\
\hline - Wet Scavenging & 0.452 & 0.446 & 0.441 \\
\hline Atmospheric Burden (Tg) & 0.006 & 0.010 & 0.010 \\
\hline Lifetime (days) & 3.837 & 6.236 & 6.264 \\
\hline
\end{tabular}


a)

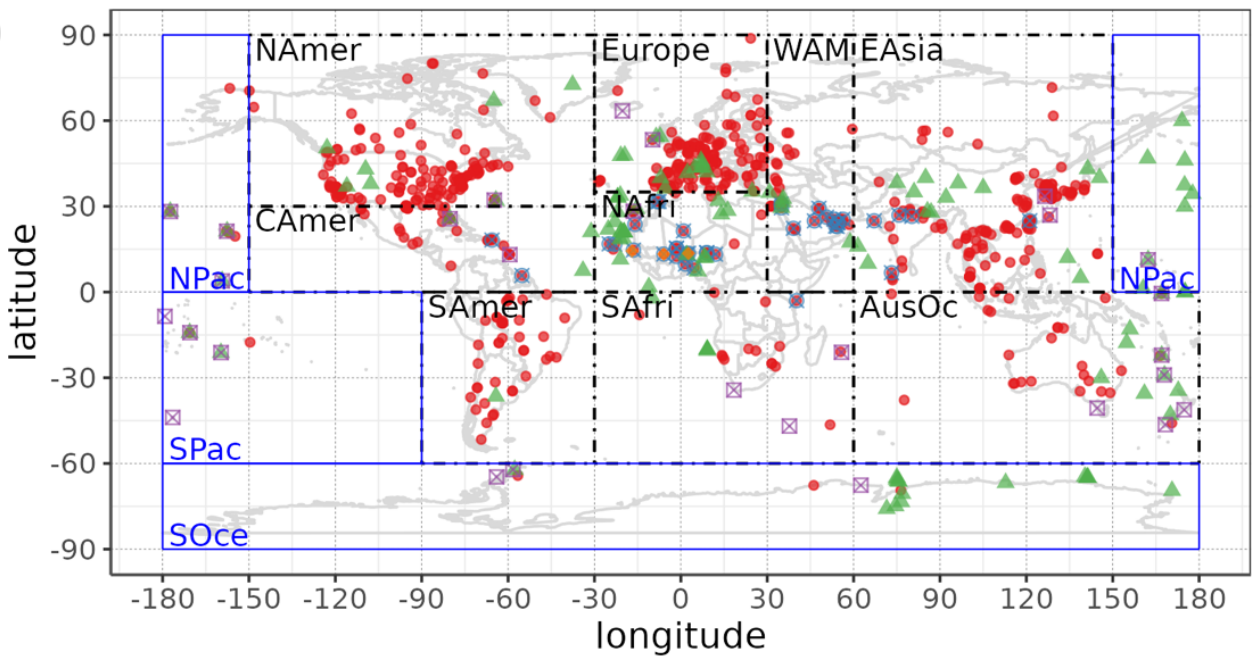

- AERONET $\otimes$ AERONET DUST $\triangle$ DEPO. $\otimes$ RSMA $*$ AMMA

b)

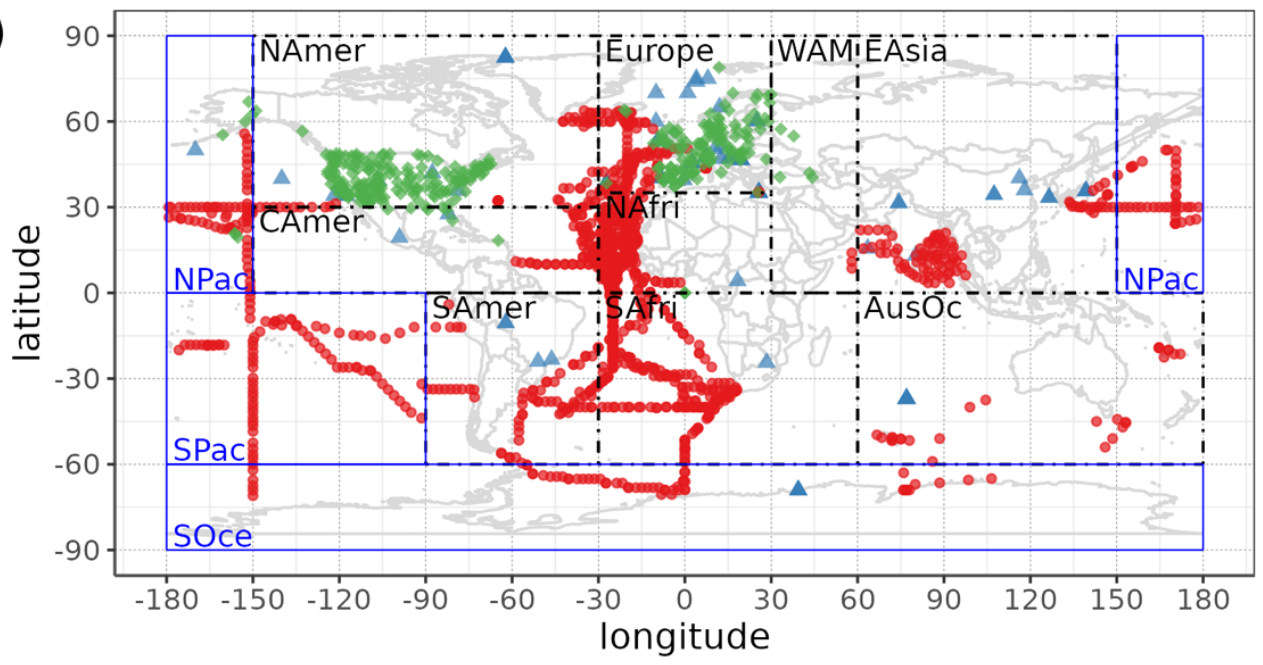

$\triangle \mathrm{OXL} \cdot \mathrm{IRON} \cdot \mathrm{SO} 4$

Figure 1: Site location map of observations a) for AOD (AERONET; red dots, AERONET-DUST; blue squares), dust surface concentration (RSMA; purple squares, and AMMA; orange diamonds) and dust deposition rates (several sources compiled in Albani et al. (2014); green triangles) and b) for surface oxalate (OXL; blue triangles), cruise aerosol Fe concentrations (red circles), and sulfate (green diamonds). 
(c) (i)

a)

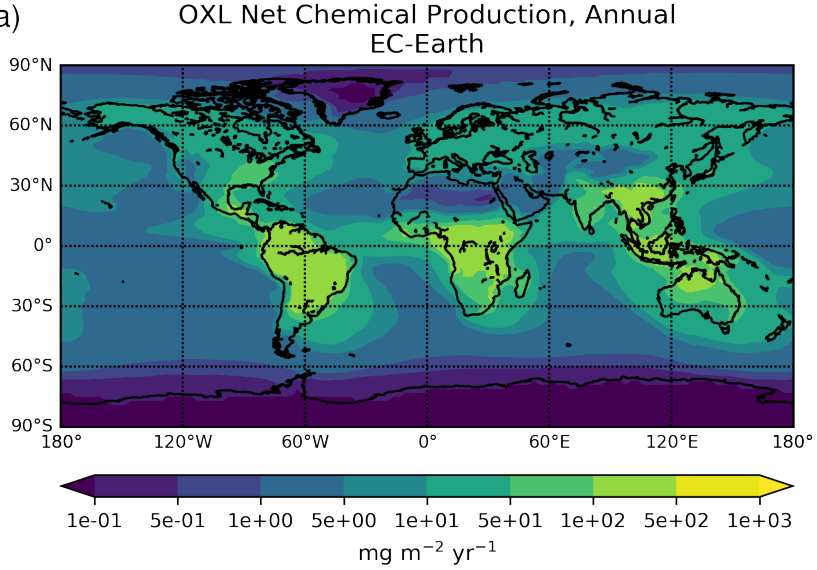

c)

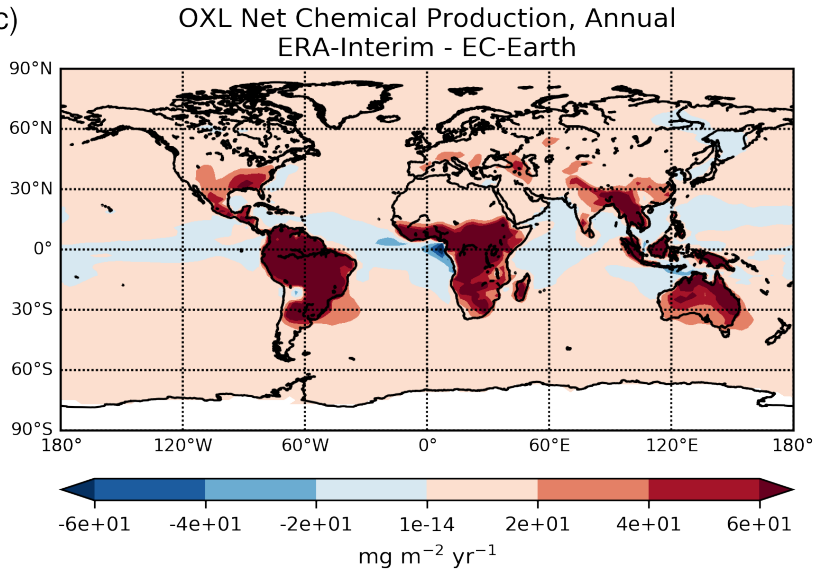

b) SO4 Net Chemical Production, Annual

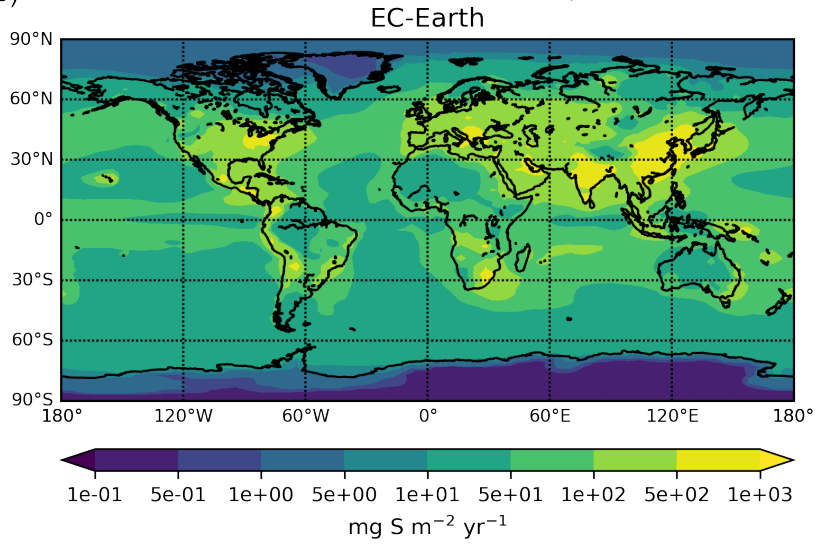

d)

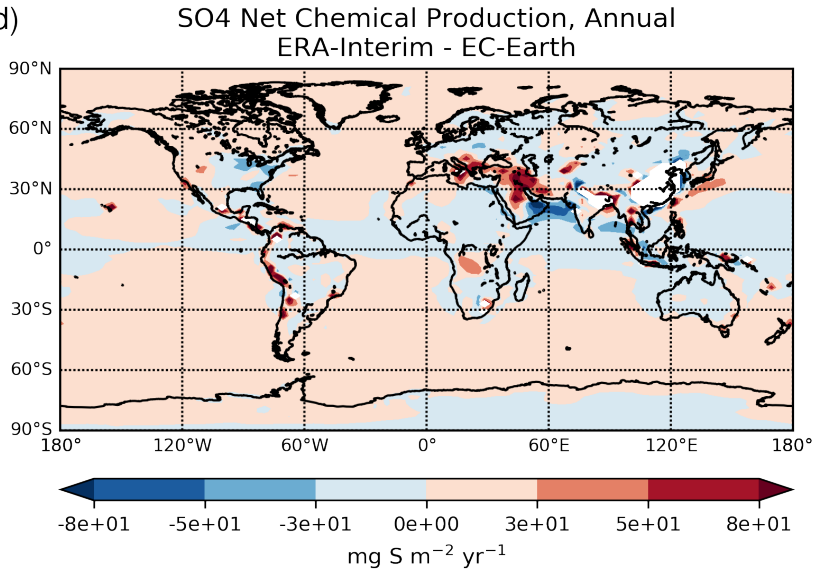

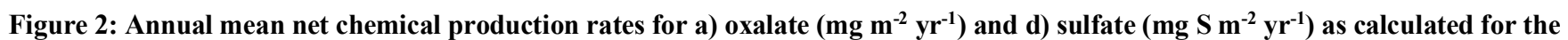
EC-Earth simulation averaged for the period 2000-2014, and the respective absolute differences to the ERA-Interim simulation (c,d). 
a)

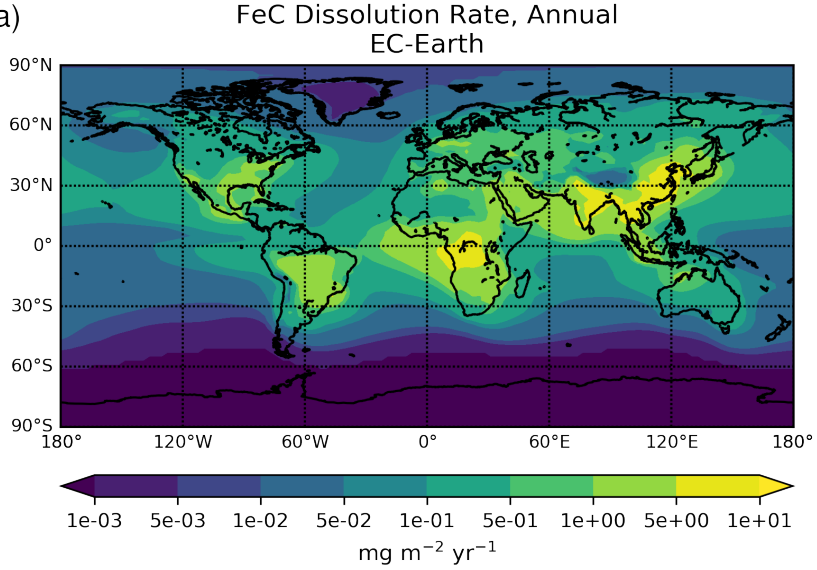

c)

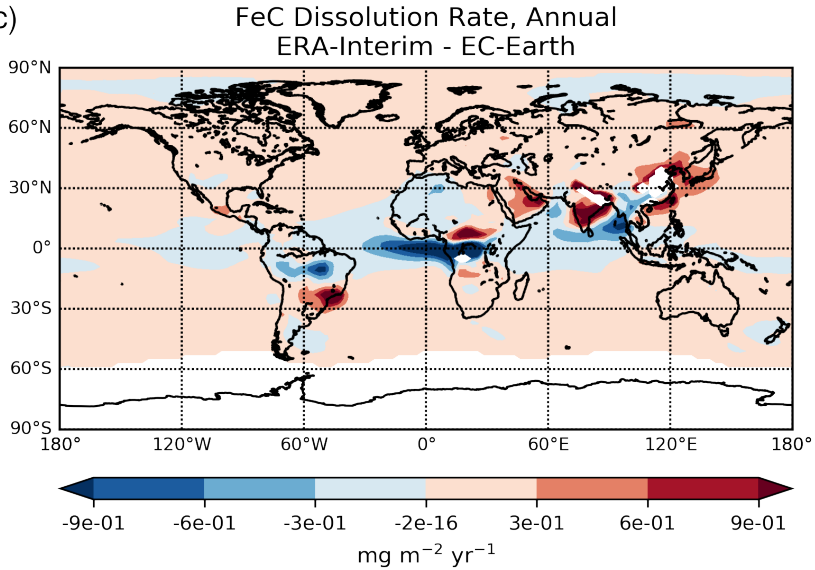

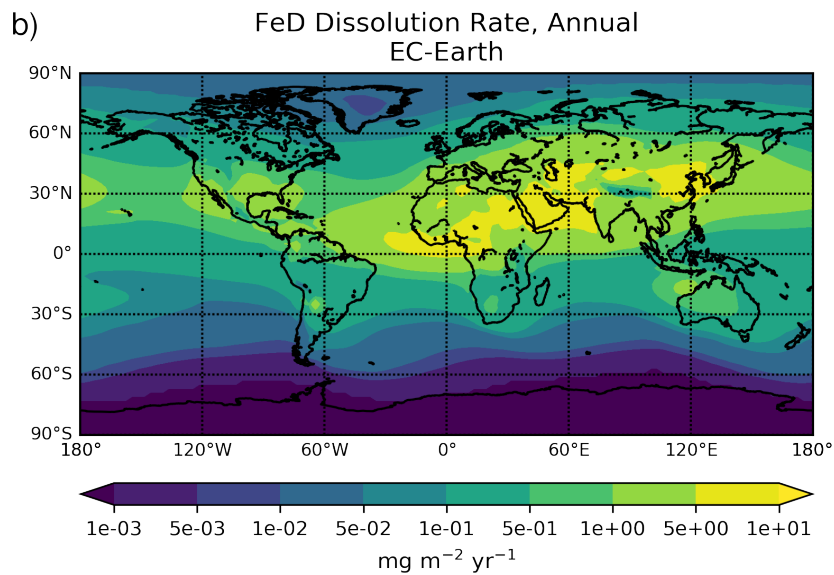

d)

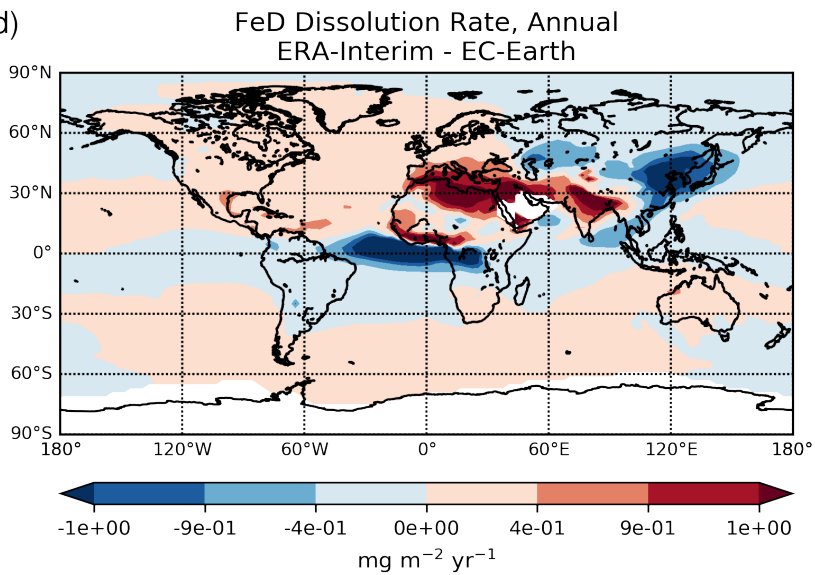

Figure 3: Annual mean dissolution rates $\left(\mathrm{mg} \mathrm{m}^{-2} \mathrm{yr}^{-1}\right)$ of combustion (a) and mineral dust (b) aerosols as calculated for the EC-Earth simulation averaged for the period 2000-2014, and the respective absolute differences to the ERA-Interim simulation (c,d). 
https://doi.org/10.5194/gmd-2021-357

Preprint. Discussion started: 10 November 2021

(c) Author(s) 2021. CC BY 4.0 License.

(c) (i)
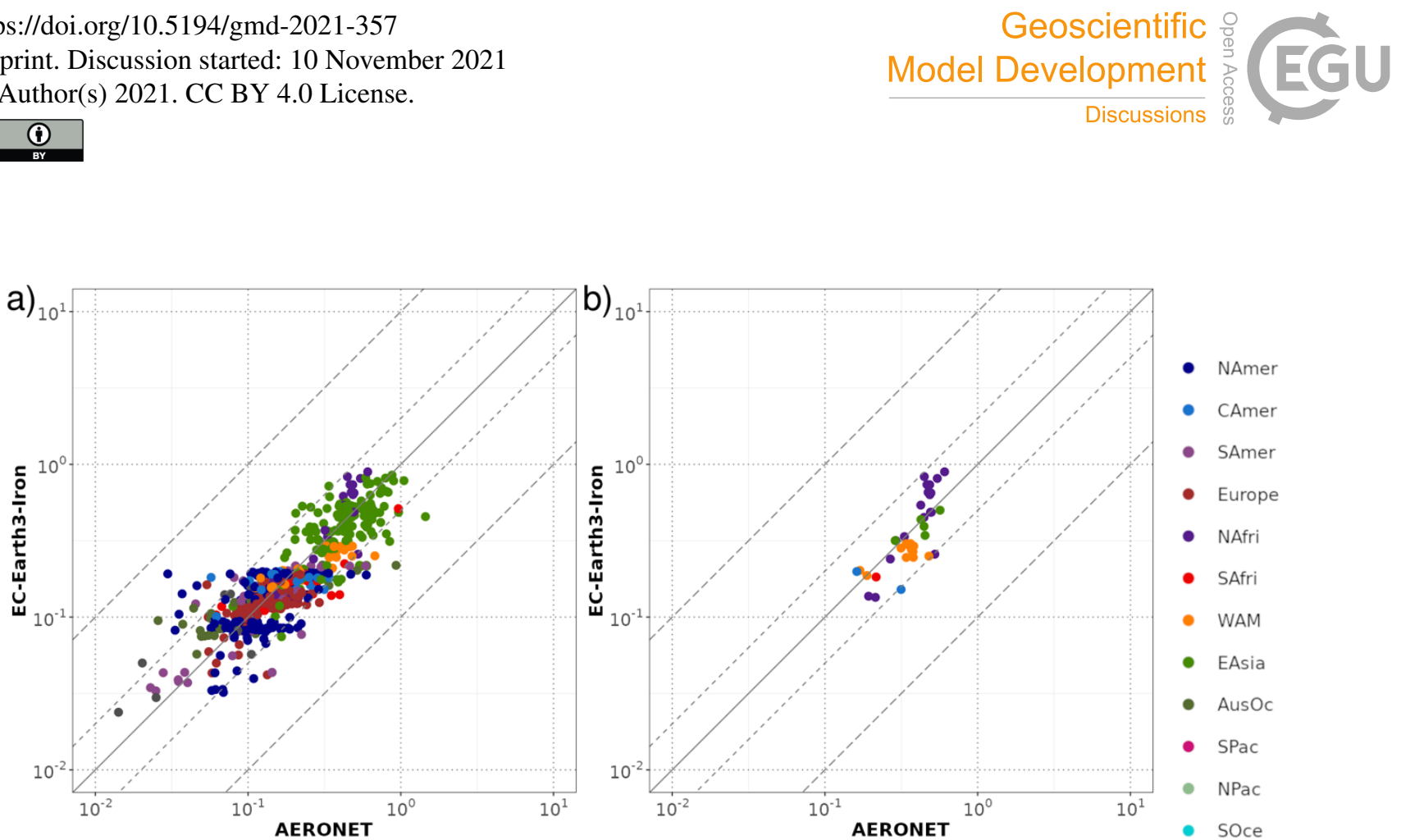

- NAmer

- CAmer

- SAmer

- Europe

- NAfri

- SAfri

- WAM

- EAsia

- AusOc

- SPac

- NPac
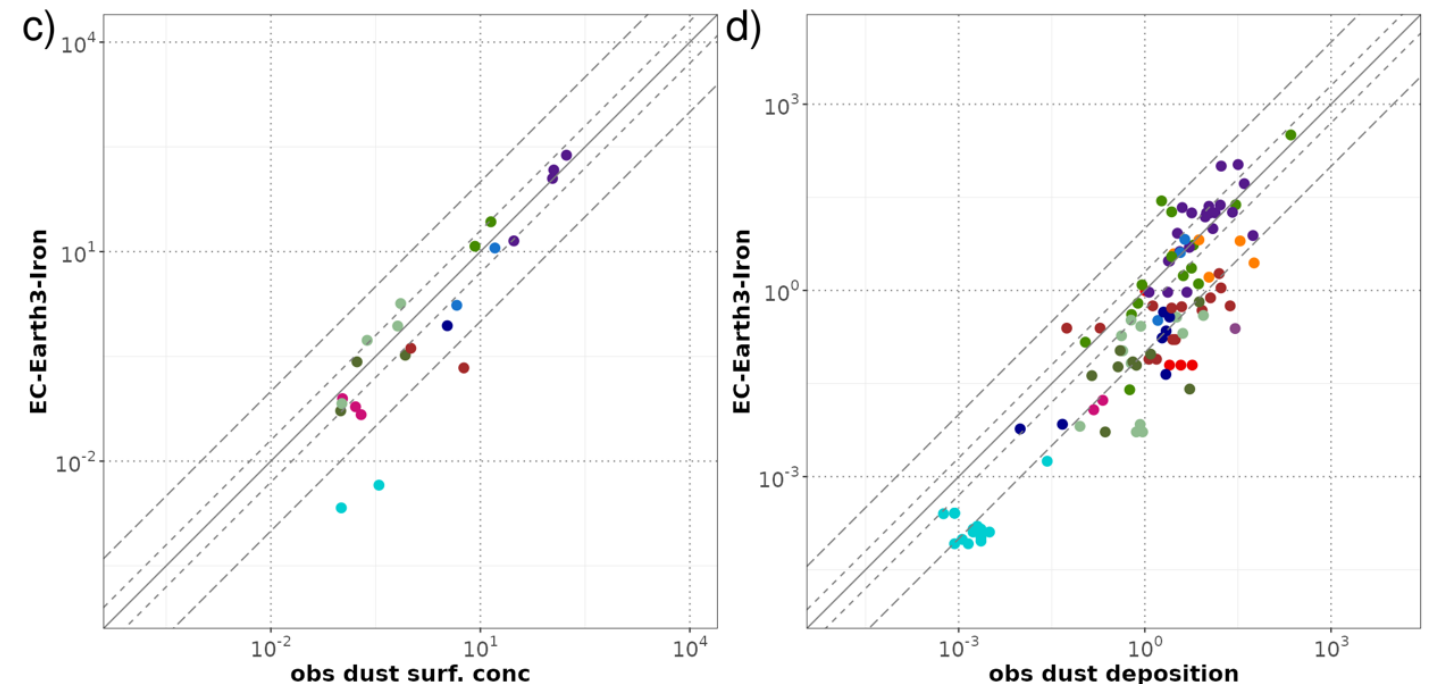

- SOce

- Remote

1675 Figure 4: Comparison of a) the modeled annual mean AOD at $550 \mathrm{~nm}$ against AERONET retrievals for all available stations covering the 2000-2014 period, b) same but for selected dusty AERONET sites, c) the modeled annual mean dust surface concentration for 2000-2014 compared to climatological mean values from RSMA sites and AMMA campaign, and d) modeled annual dust deposition flux averaged for the period 2000-2014 against observations compiled in Albani et al. (2014) from several sources. 
a)

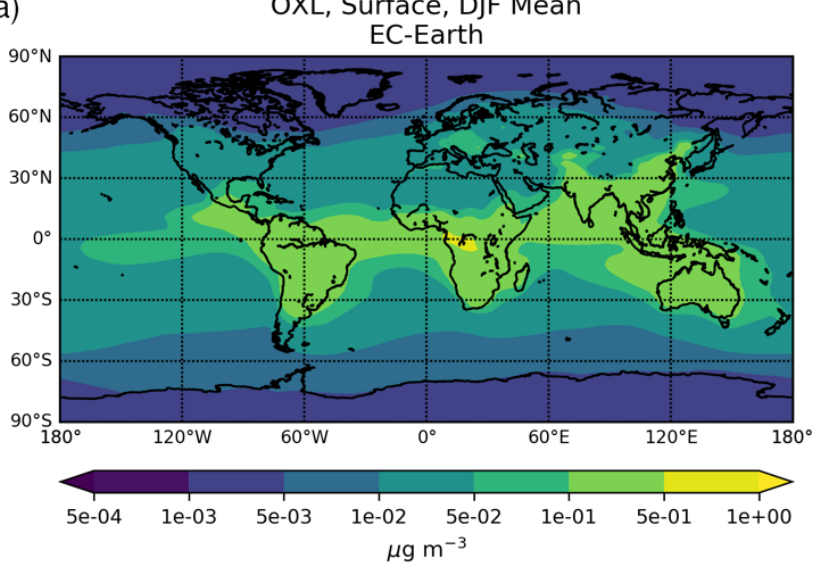

c)

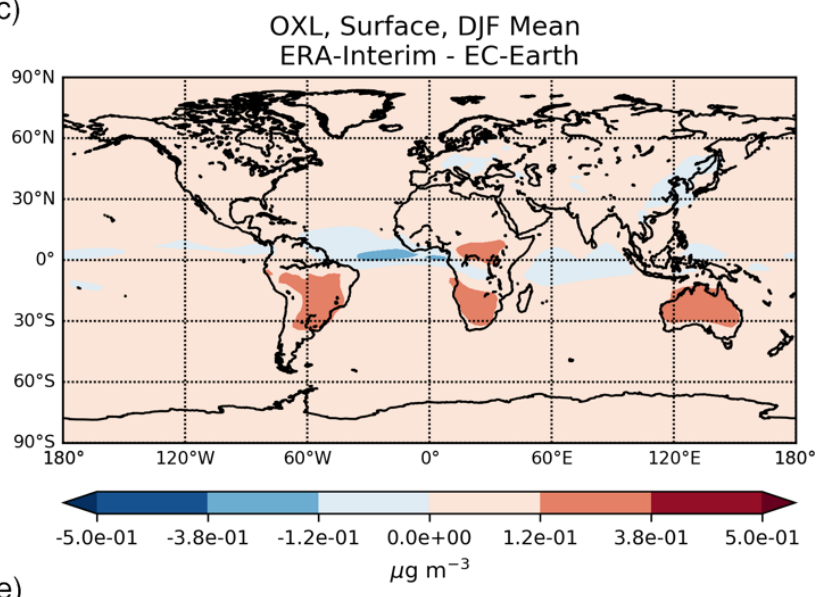

e)

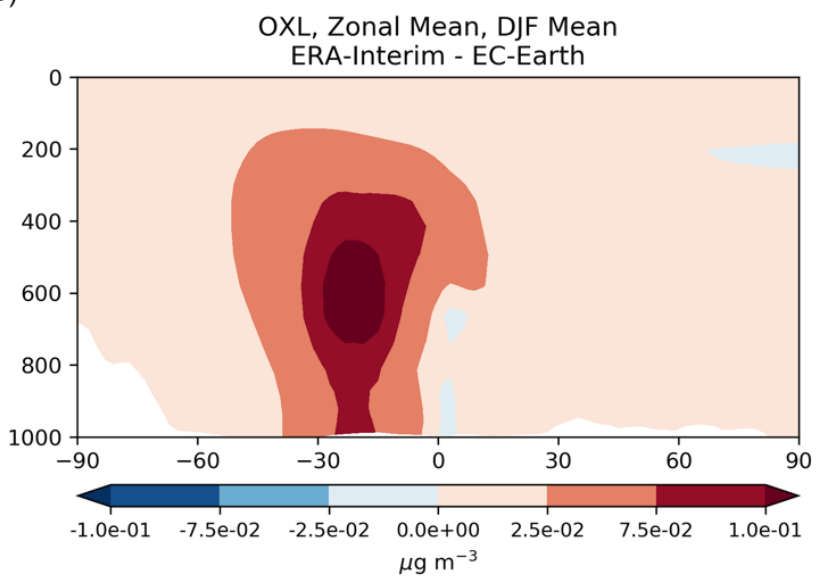

b)

OXL, Surface, JJA Mean EC-Earth

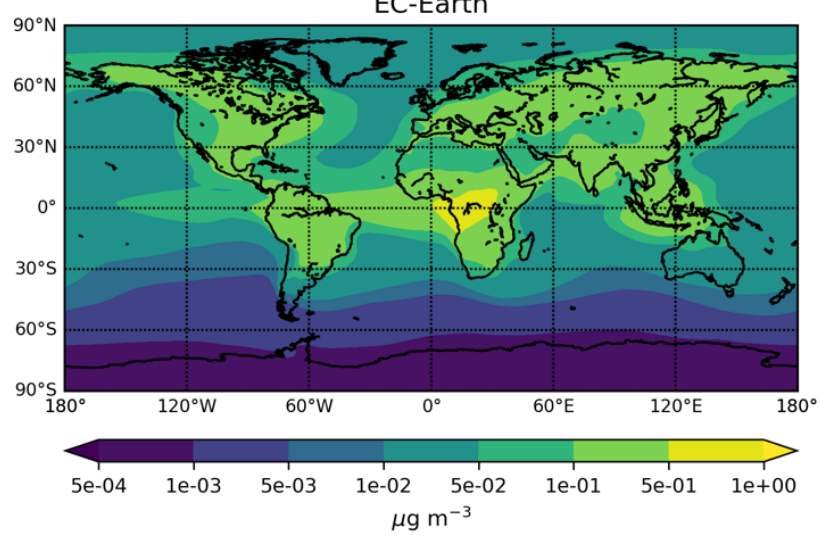

d)
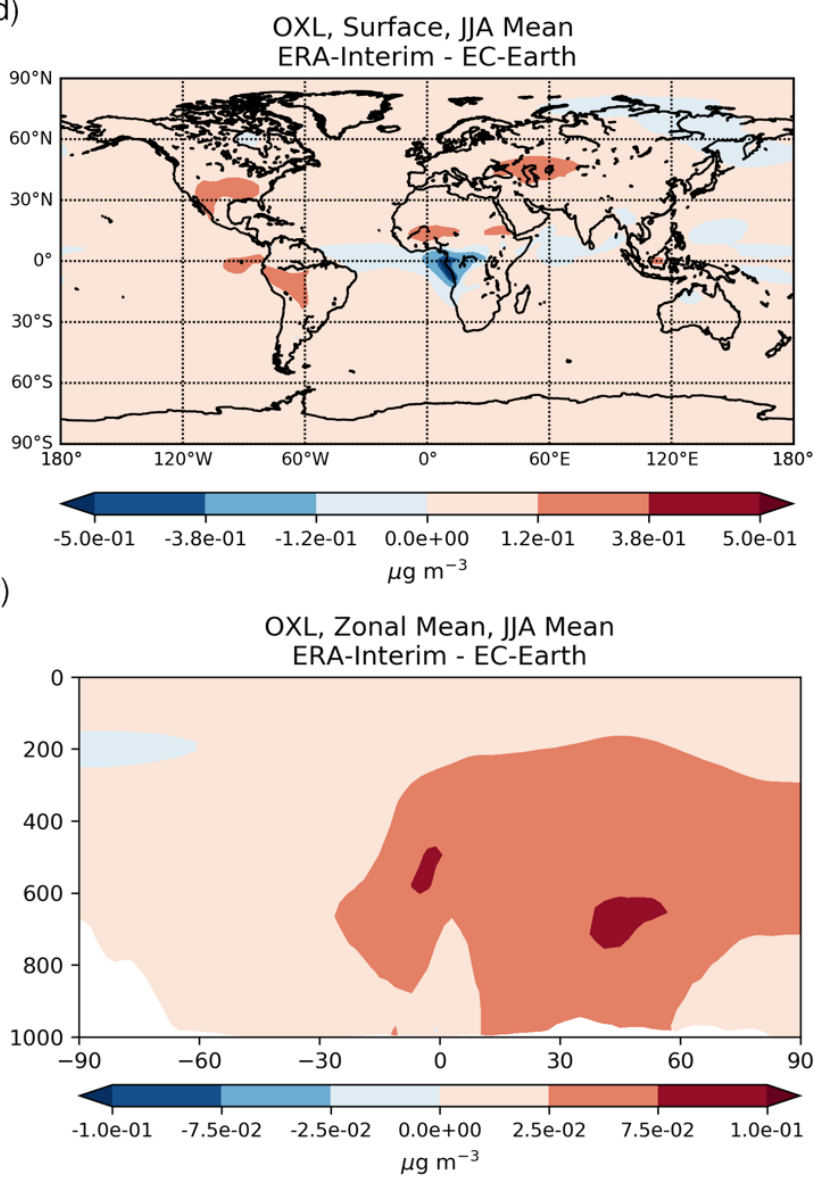

1680 Figure 5: Oxalate (OXL) surface concentrations $\left(\mu \mathrm{g} \mathrm{m}^{-3}\right)$ for the boreal winter (DJF; a) and boreal summer (JJA; b) as simulated for the EC-Earth simulation averaged for the period 2000-2014, and the respective absolute differences to the ERA-Interim simulation for surface (c,d) and zonal mean $(e, f)$. 
a)

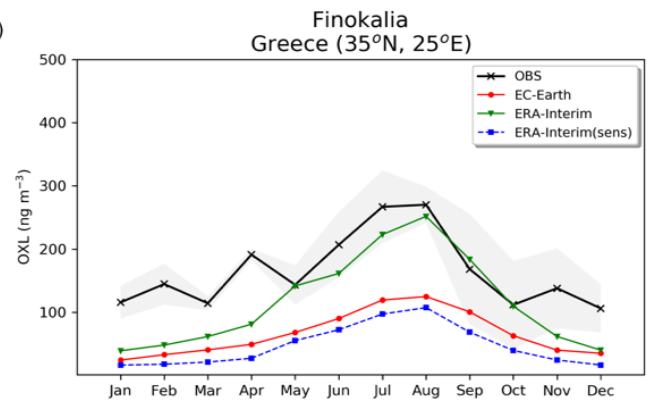

c)

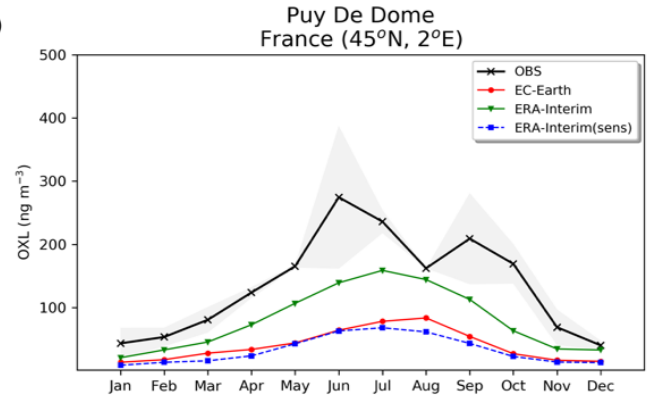

e)

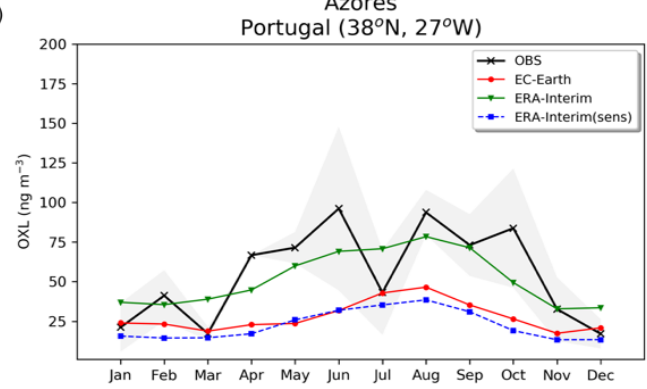

g)

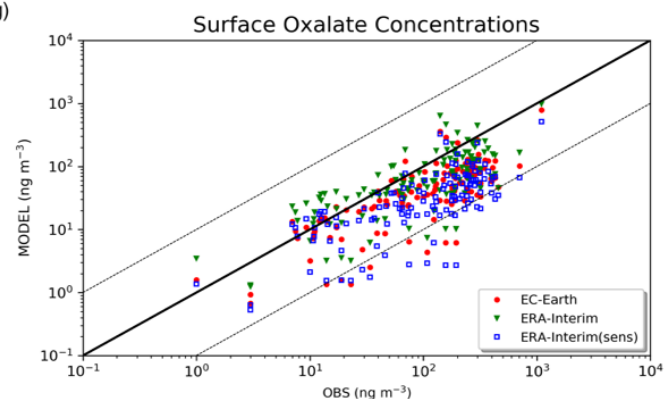

b)

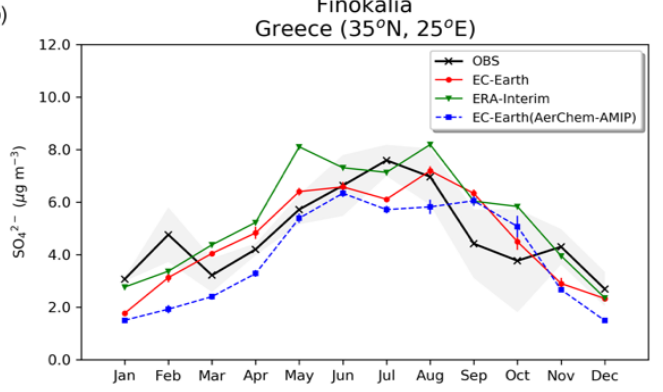

d)

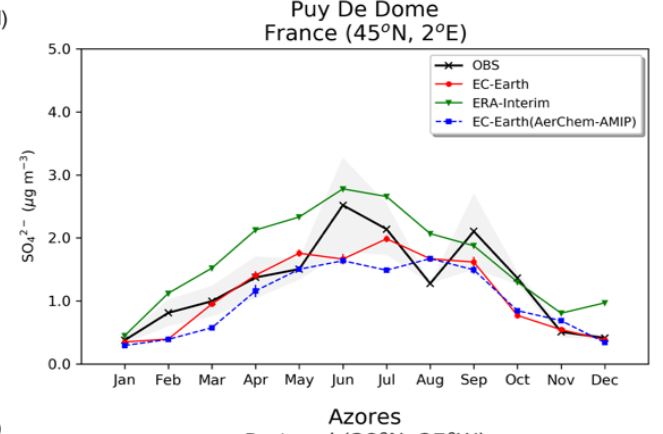

f)

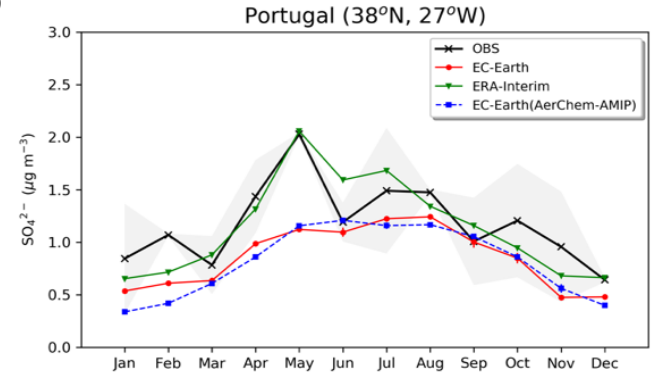

h)

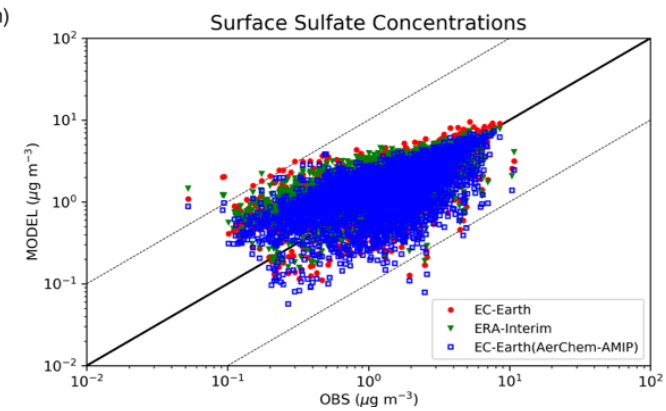

Figure 6: Comparison of daily mean observations (black line) of OXL $\left(\mathrm{ng} \mathrm{m}^{-3} ;\right.$ left) and $\mathrm{nss}_{-} \mathrm{SO}_{4}{ }^{2-}\left(\mathrm{gg} \mathrm{m}^{-3}\right.$; right) with the EC-Earth (red line) and the ERA-Interim (green line) simulations for a,b) Finokalia (Greece) for the period July 2004 - July 2006 (Koulouri et al., 2008), for c,d) Puy de Dome (France) and e,f) Azores (Portugal), for the period September 2002 - September 2004 (Legrand et al., 2007), along with $d, f)$ scatterplot comparisons for observations around the globe; the solid line represents the $1: 1$ correspondence and the dashed lines show the $10: 1$ and $1: 10$ relationships, respectively. For completeness, the comparisons for the sensitivity simulation ERA-Interim(sens) (blue line/squares) for OXL and the EC-Earth(AerChem-AMIP) (blue line/squares) for sulfate are also presented. Gray shaded areas represent the standard deviation of the observations and for the EC-Earth simulations the error bars represent the standard error of the multi-annual mean for the individual observational period. 
a)

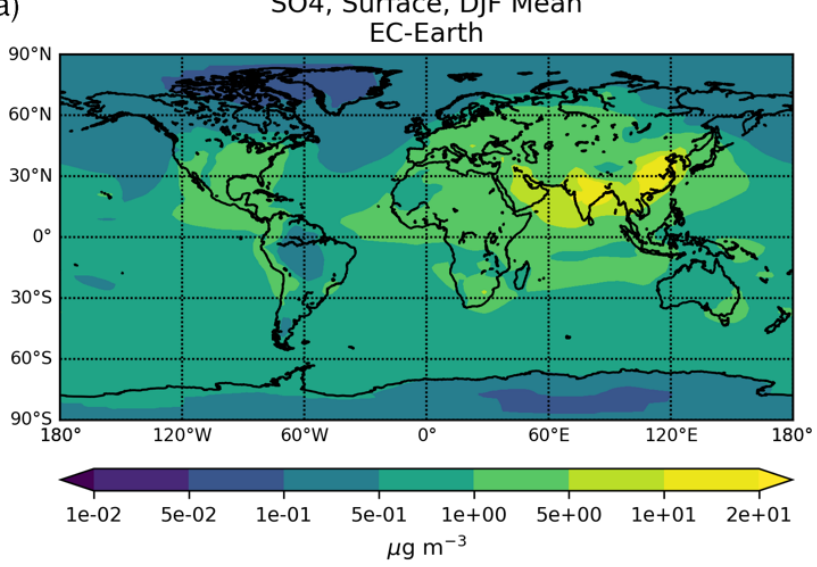

c)

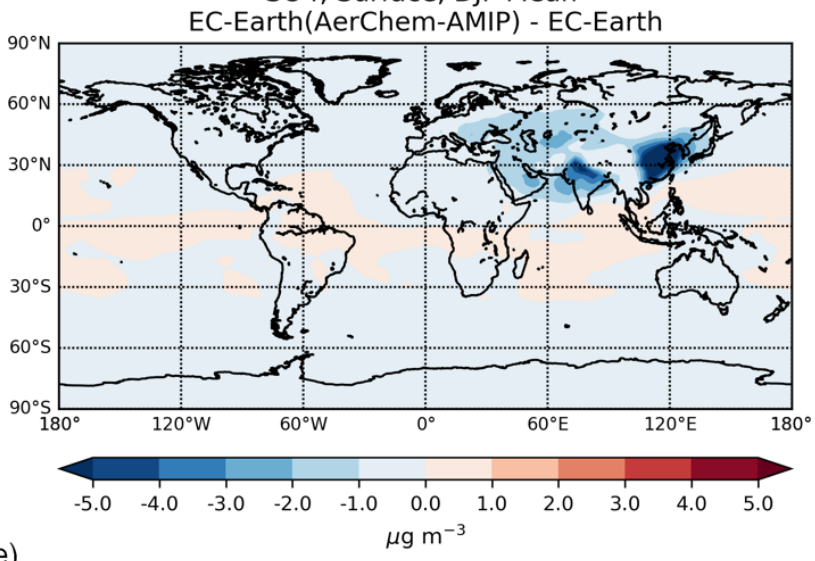

e)

SO4, Zonal Mean, DJF Mean

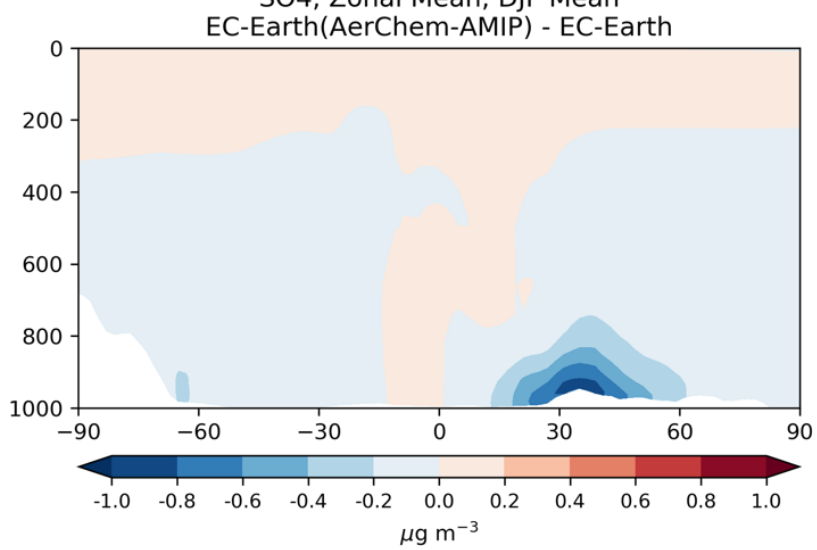

b)

SO4, Surface, JJA Mean EC-Earth

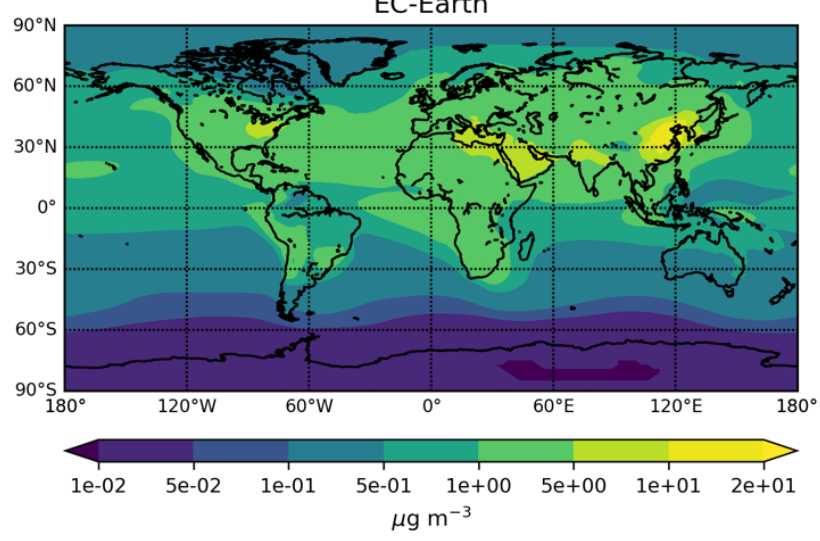

SO4, Surface, JJA Mean

EC-Earth(AerChem-AMIP) - EC-Earth

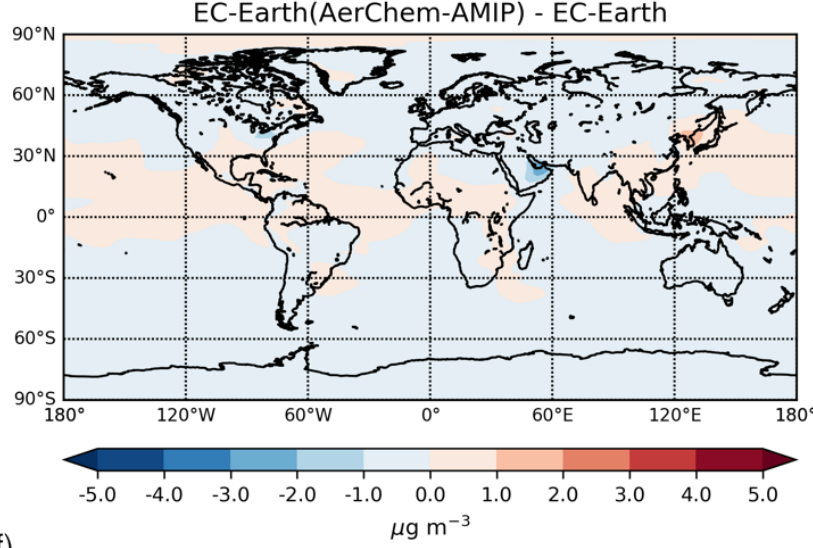

SO4, Zonal Mean, JJA Mean EC-Earth(AerChem-AMIP) - EC-Earth

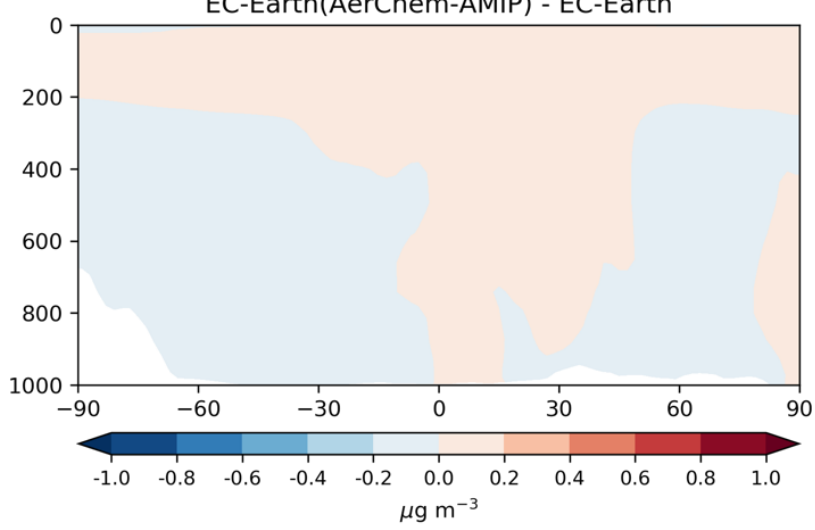

Figure 7: Sulfate (SO4) surface concentrations $\left(\mu \mathrm{g} \mathrm{m}^{-3}\right)$ for the boreal winter (DJF; a) and boreal summer (JJA; b) as simulated for the EC-Earth simulation averaged for the period 2000-2014, and the respective absolute differences to the EC-Earth(AerChemAMIP) simulation for surface (c,d) and zonal mean $(e, f)$. 
a)

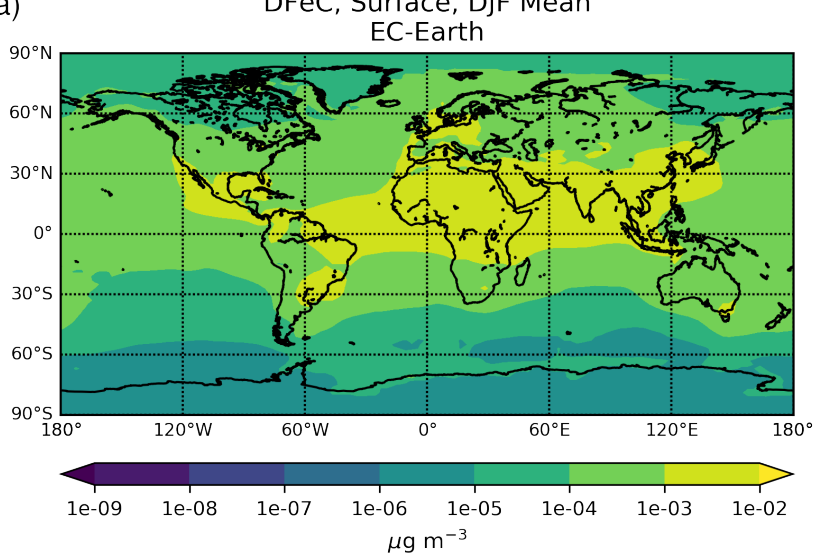

c)

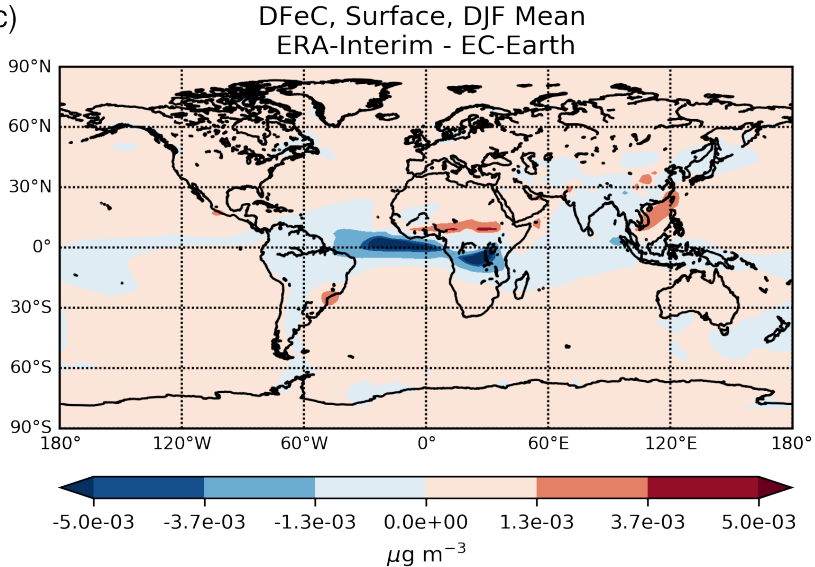

b) DFeC, Surface, JJA Mean

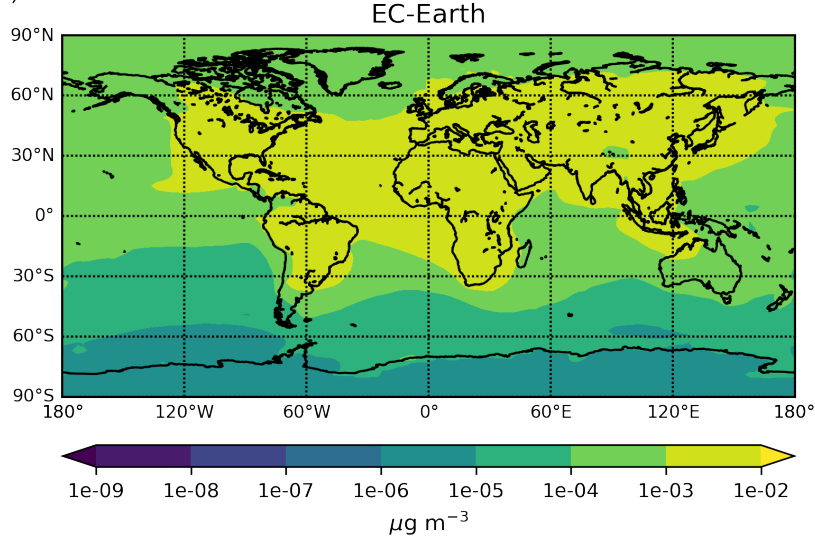

d)

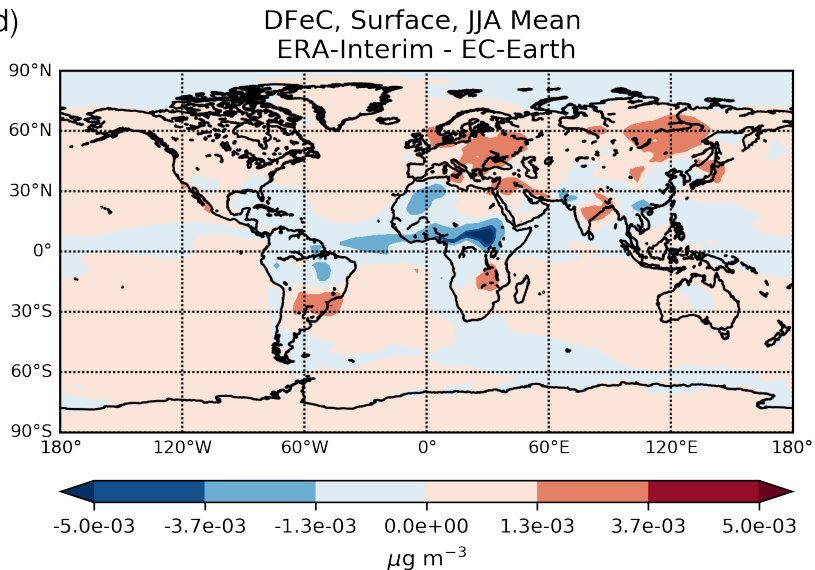

Figure 8: Dissolved iron surface concentrations $\left(\mu \mathrm{g} \mathrm{m}^{-3}\right)$ from combustion aerosols (DFeC) for the boreal winter (DJF; a) and summer (JJA; b) seasons for the EC-Earth simulation averaged for the period 2000-2014, and the respective absolute differences to the ERA-Interim simulation (c,d). 
a)

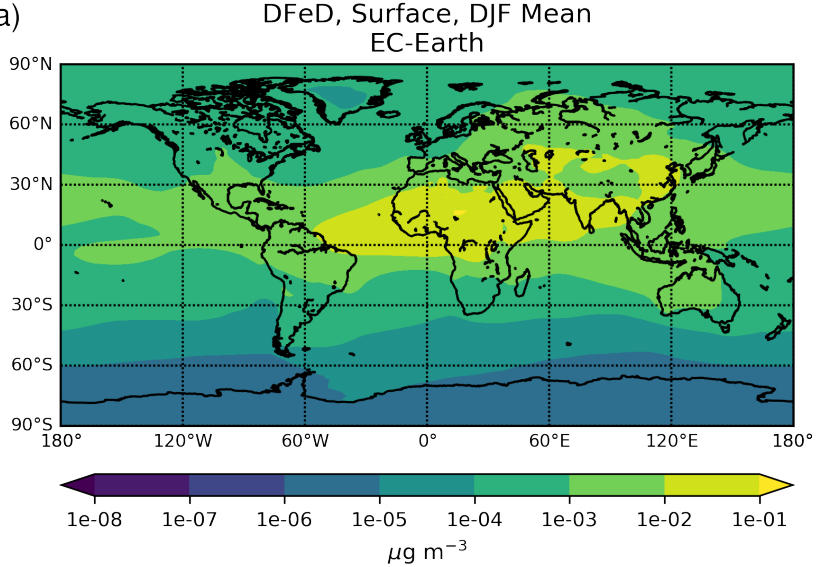

c)

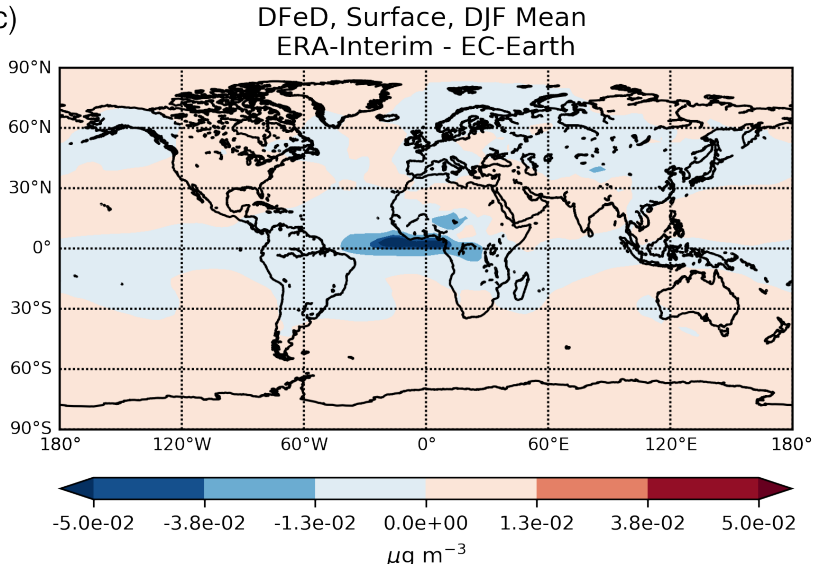

b) DFeD, Surface, JJA Mean

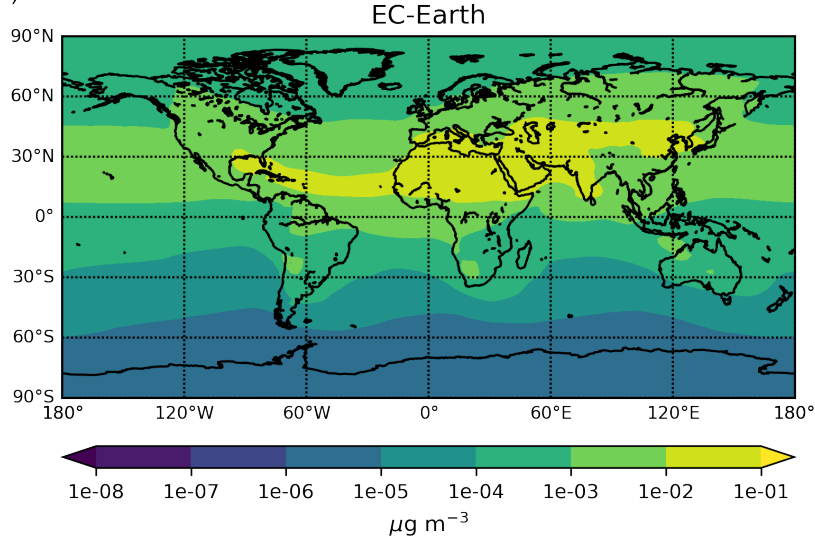

d)

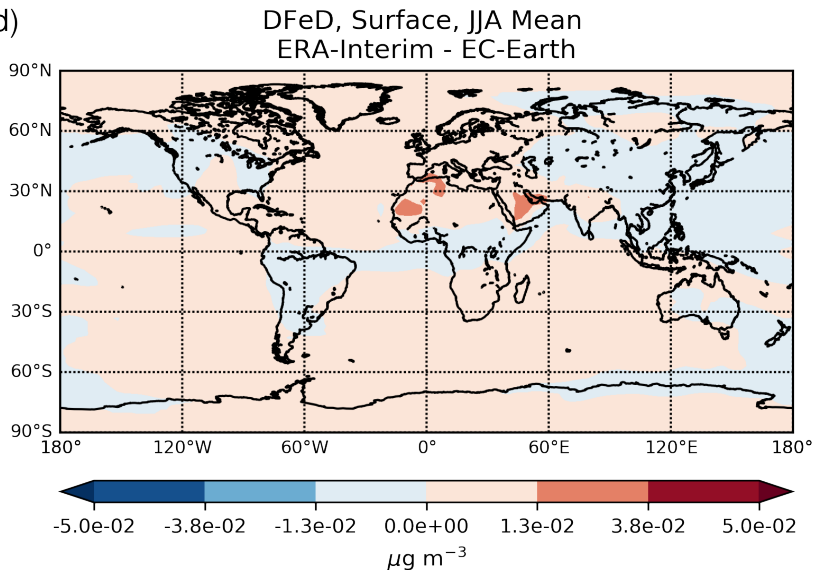

Figure 9: Dissolved iron surface concentrations $\left(\mu \mathrm{g} \mathrm{m}^{-3}\right)$ from mineral dust (DFeD) for the boreal winter (DJF; a) and summer (JJA; b) seasons for the EC-Earth simulation averaged for the period 2000-2014, and the respective absolute differences to the ERAInterim simulation (c,d). 

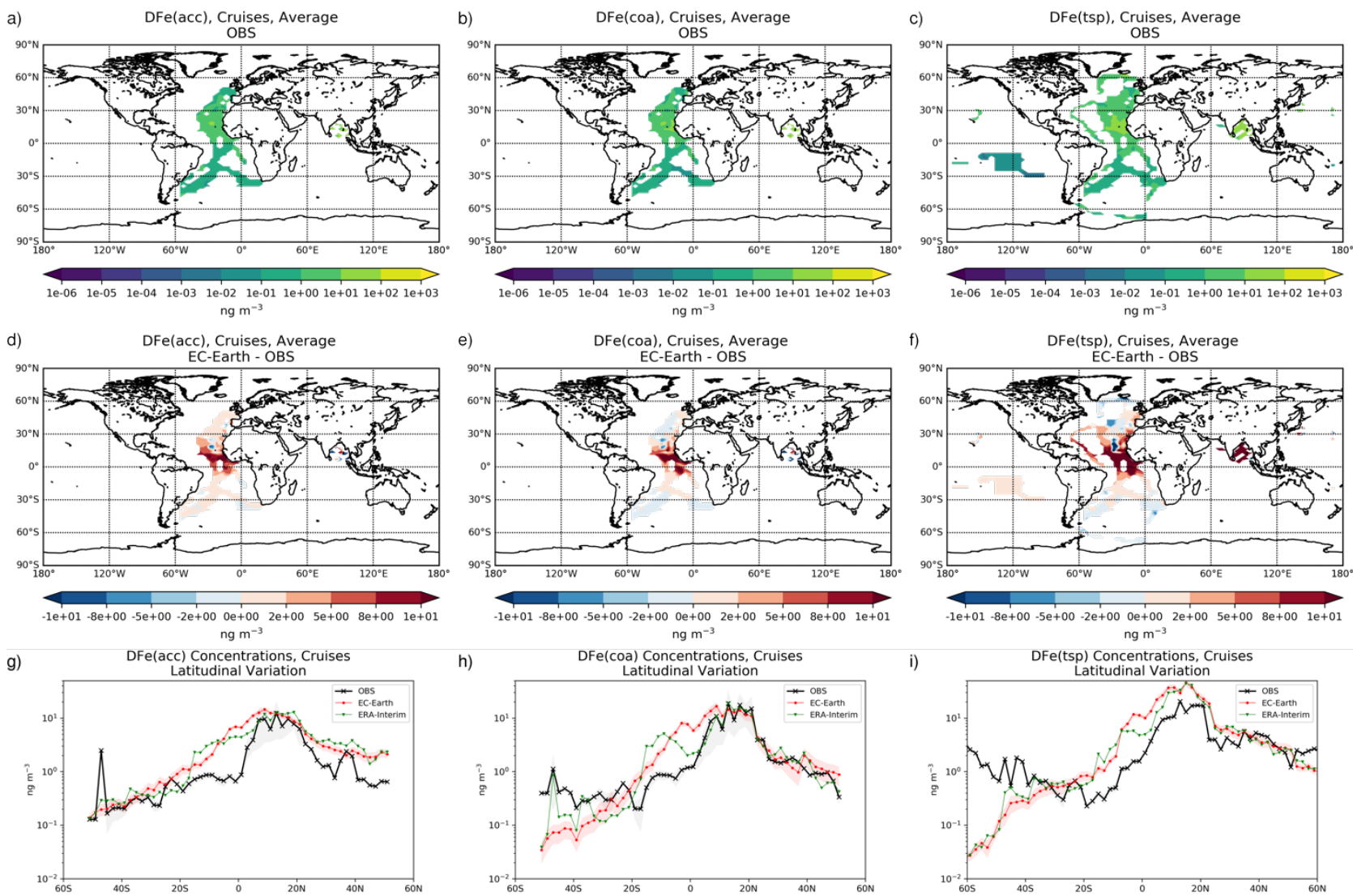

Figure 10: Observed dissolved iron (DFe) concentrations $\left(\mathrm{ng} \mathrm{m}^{-3}\right)$ of a) accumulation aerosols, b) coarse aerosols, and c) total suspended particles (tsp), the respective absolute differences to the ERA-Interim simulation (d, e, f), and the comparison to observations (black $x$-line) in latitudinal order (g,e,f) with the EC-Earth (red circle-line) and ERA-Interim(green triangle-line) simulations; the grey shaded areas correspond to the standard deviation of the observations and the red shaded areas correspond to the standard error of the multi-annual mean for the individual observational period for the EC-Earth simulations. 

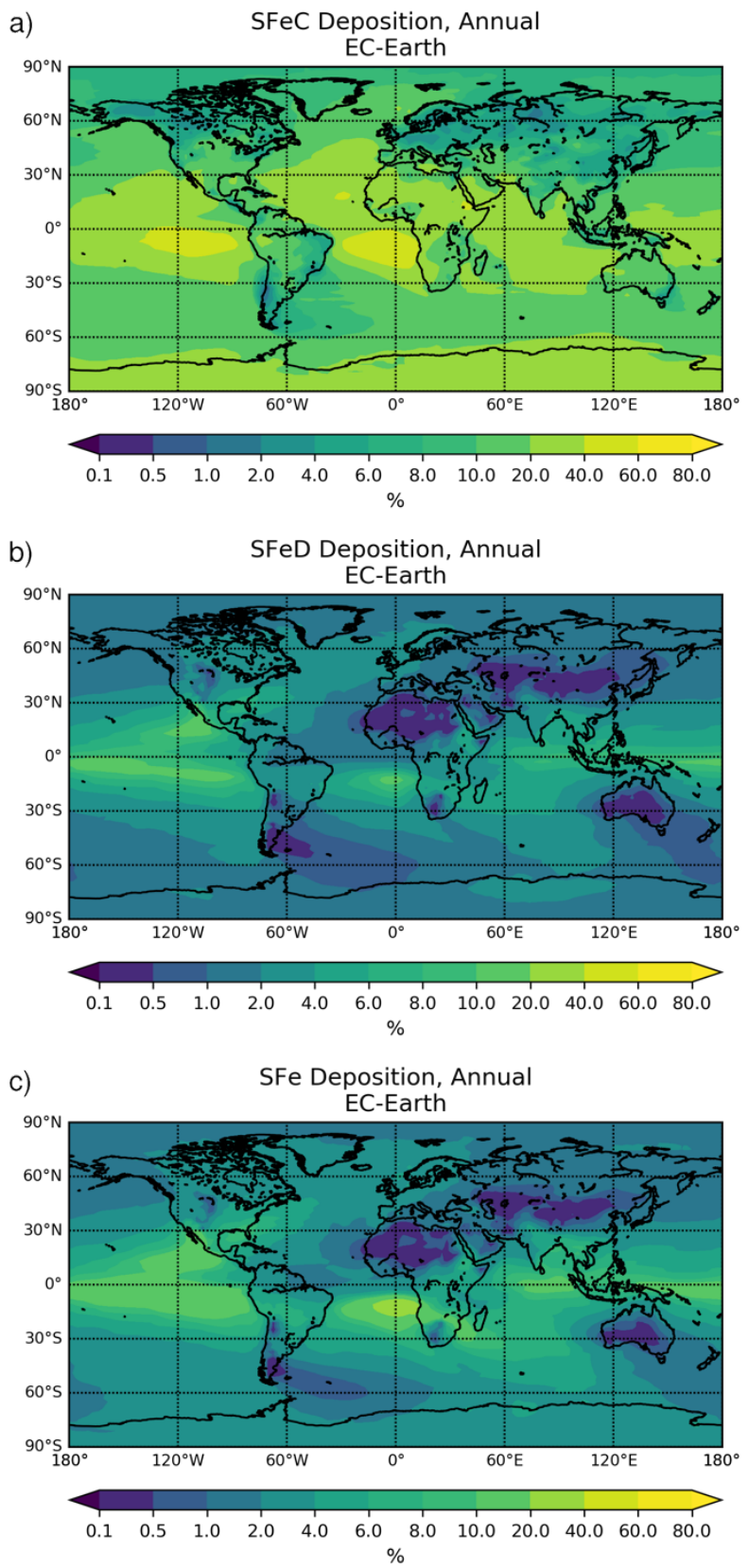

Figure 11: Annual mean Fe-containing aerosol solubility at deposition fluxes (\%) as simulated for the EC-Earth simulation averaged for the period 2000-2014, for a) mineral dust aerosols, b) sum of solid fuel combustion, liquid fuel combustion and open biomass burning aerosols, and c) sum of all aerosol sources. 